\title{
Des Gaulois sur l'île Guennoc (Landéda, Finistère)
}

Gaulish people on Guennoc Island (Landéda, Finistère)

Marie-Yvane Daire et Laurent Quesnel

\section{CpenEdition}

\section{Journals}

Édition électronique

URL : http://journals.openedition.org/rao/577

DOI : $10.4000 /$ rao. 577

ISBN : 978-2-7535-1608-3

ISSN : $1775-3732$

Éditeur

Presses universitaires de Rennes

Édition imprimée

Date de publication : 20 décembre 2008

Pagination : 93-137

ISBN : 978-2-7535-0789-0

ISSN : 0767-709X

\section{Référence électronique}

Marie-Yvane Daire et Laurent Quesnel, « Des Gaulois sur l'île Guennoc (Landéda, Finistère) », Revue archéologique de l'Ouest [En ligne], 25 | 2008, mis en ligne le 20 décembre 2010, consulté le 06

décembre 2020. URL : http://journals.openedition.org/rao/577 ; DOI : https://doi.org/10.4000/rao.577 


\title{
Des Gaulois sur l'île Guennoc (Landéda, Finistère)
}

\author{
Gaulish people on Guennoc Island (Landéda, Finistère)
}

\author{
Marie-Yvane DAIRE* \\ avec la collaboration de Laurent QUESNEL*
}

Ces pages sont dédiées à l'éternel " aîné d'entre nous " (Pierre-Roland Gıт), au nom d'une nissophilie partagée.

Résumé : Au cours des fouilles menées sur l'île Guennoc à Landéda dans les années 1960, P.-R. Giot s’intéressa principalement à une série de cairns mégalithiques, mais reconnut plusieurs autres phases d'occupation humaine. Le réexamen systématique des collections, des publications, ainsi que l'exploitation d'un mémoire universitaire demeuré inédit, montrent aujourd'hui la richesse des données de terrain et du mobilier du second Âge du Fer. La présentation des contextes naturels et historiographiques de l'étude sera suivie par l'exposé de la démarche d'enquête débouchant sur une analyse des vestiges laténiens; la structuration de l'espace, les constructions et l'ensemble mobilier (céramique en particulier) alimenteront une réflexion synthétique sur l'occupation gauloise de l'île qui, projetée dans une perspective plus large, montre des points de comparaison avec d'autres sites insulaires finistériens et contribue à caractériser les populations côtières de l'ouest de la Gaule.

\begin{abstract}
During his excavations on Guennoc island (Landéda, Finistère) in the 1960's, P.-R. Giot was mainly concerned with the series of megalithic monuments, but he identified remains belonging to other periods. The systematic re-examination of collections and publications, plus the use of a still unpublished thesis now reveal the richness of the second Iron Age field data and assemblage. The presentation of natural and historiographical contexts in the study will be followed by a presentation of the current investigation, leading to the analysis of the Second Iron Age remains: spatial organisation, buildings and assemblages (especially ceramics) allow synthesis of the Gaulish occupation of this island. Enlarged to a wider view, it shows comparisons with other insular sites of Finistere, furthering the characterization of the coastal populations of Western Gaul.
\end{abstract}

Mots clés : Île, Âge du Fer, Céramiques, Bâtiment, Enclos, mégalithisme.

Key words: Island, Iron Age, Ceramics, Building, Enclosure, Megalithism.

\section{Préambule}

\section{Une île de la côte léonarde dans son environnement}

L'île Guennoc (ou Geignog, ou Gaignoc... selon les sources) fait partie de la cinquantaine d'îles et îlots qui foisonnent le long de la côte léonarde, entre les pointes de
Corsen (Plouarzel) et de Porz Grae (Plouguerneau), dont l'abondance s'explique à la fois par la présence des abers, d'un estran assez développé et d'une côte rocheuse (Brigand, 2002, p. 72) (fig. 1). Guennoc occupe une place privilégiée parmi ceux qui se concentrent plus particulièrement entre les chenaux prolongeant l'Aber Wrac'h et l'Aber Benoît (Landéda) en formant une sorte de couronne qui déborde jusqu'à 1,5 mille au large, car c'est aujourd'hui une véritable

* UMR 6566-CReAAH (Centre de Recherche en Archéologie, Archéosciences et Histoire) : CNRS; universités de Rennes 1, Rennes 2 et Nantes; Ministère de la Culture - Campus de Beaulieu, CS 74205, 35042 Rennes cedex. 


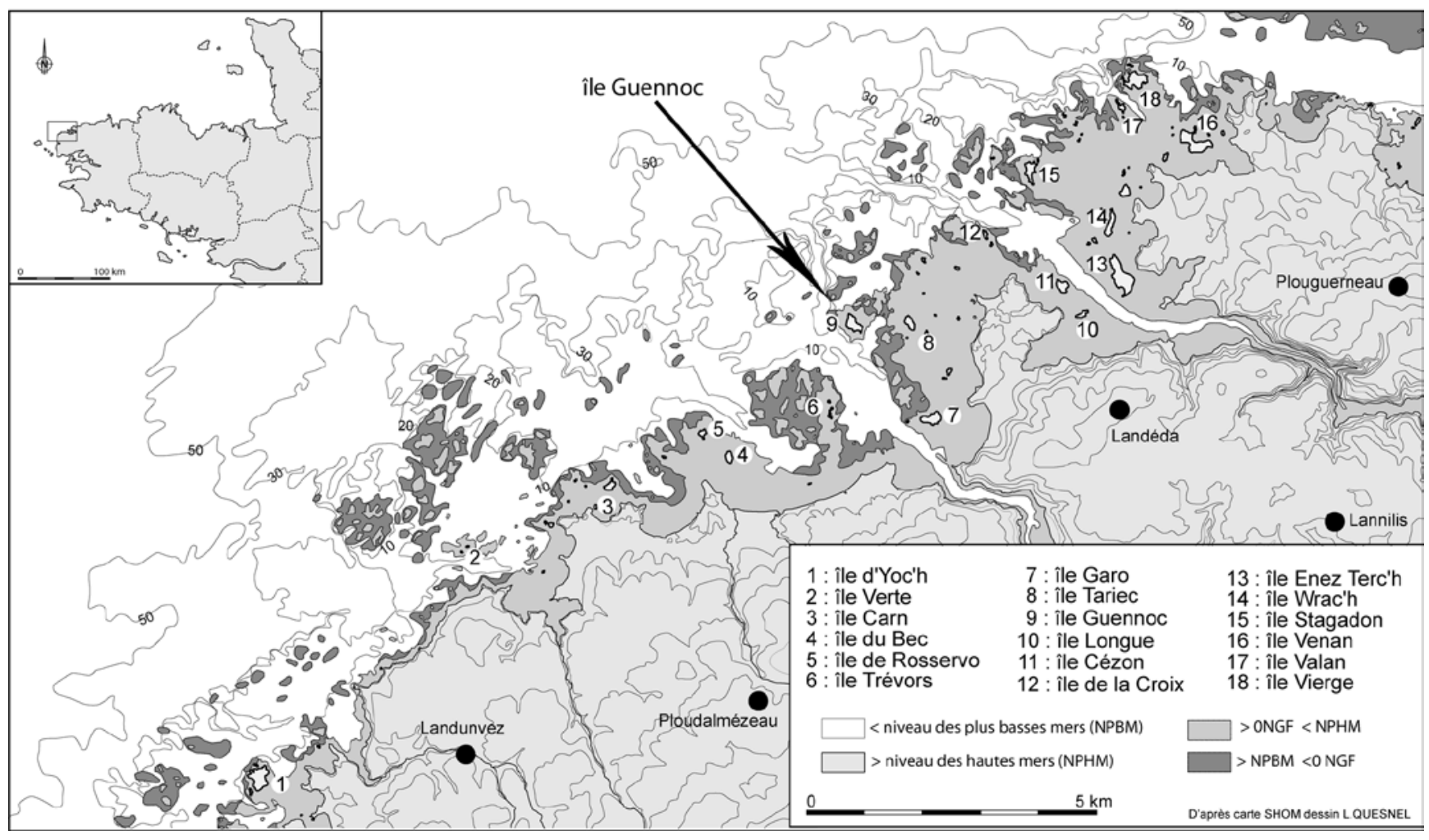

Figure 1: Carte de localisation de l'île Guennoc sur fond de carte du SHOM pour les niveaux marins (DAO L. Quesnel).

Figure 1: Location map of Guennoc Island (map base from the French Navy's hydrographic Service for bathymetric contours).

île inaccessible à pied sec. Comme les autres îles de cette couronne, Guennoc émerge d'une plate-forme littorale à demi immergée qui se prolonge sous la mer sur quelques kilomètres (ibid., p. 72). Avant la fin de la remontée des eaux au Postglaciaire, cet ensemble formait un bas pays devant une falaise morte délimitant le plateau léonard. Ce dernier fut très fréquenté pendant la Préhistoire et, au cours du Néolithique, des monuments mégalithiques furent installés sur les sommets devenus ensuite les îles d'Yoc'h, Carn et Guennoc, (fig. 1, nº 1, 3 et 9)...

Guennoc n'est aujourd'hui qu'un grand "rocher " de 5,6 ha, mesurant un peu moins de $400 \mathrm{~m}$ de long, du nordnord-ouest au sud-sud-est, et $160 \mathrm{~m}$ au plus large, avec une côte rocheuse, d'accès difficile, ceinturant un grand dôme surbaissé couvert de pelouse littorale luxuriante. Une crête axiale, soulignée par un talus ancien, se déploie sur $300 \mathrm{~m}$ de long du nord au sud et atteint 15 à 16 m d'altitude NGF. Le paysage actuel de l'île, sauvage, austère et déserté, contraste avec la richesse et la diversité d'un complexe archéologique témoignant d'occupations humaines successives, apparemment discontinues mais parfois intenses, auxquelles quelques chercheurs se sont intéressés par le passé.

Malgré la découverte, en 1890, d'un dépôt de l'Âge du Bronze, précédée par celle de "bracelets d'or ", P. Du
Chatellier (1881) ne visita jamais l'île. Plus tard, le Commandant A. Devoir (1913) y signale un "tumulus " qu'il ne va pourtant reconnaître qu'en 1919, ainsi qu'un "vaste retranchement elliptique, avec entrée parée de deux mégalithes et trois autres à l'intérieur. Les murets ont de trois à cinq mètres de large et plus d'un mètre en saillie... "; il signale en outre une "pierre percée " ou " pierre trouée ", sans doute le socle rudimentaire d'une croix disparue (notes transcrites par E. Morel).

En 1953, un incendie avait lentement ravagé la végétation de pelouse rase, dégageant une partie des structures archéologiques jusque-là peu connues et mal documentées, mais aussitôt signalées à P.-R. Giot qui visita le site en novembre 1955, puis en 1958. Les premières observations révélèrent l'existence de trois cairns principaux, les restes d'un ou de deux autres, d'un enclos au centre de l'île et des vestiges de «fortifications » sur l'une des faces exposées au continent.

Ce n'est qu'à partir de 1960 que P.-R. Giot s'engagea dans un long programme de fouilles, dont les douze campagnes s'étalèrent jusqu'en 1972 (Giot, 1987). À cette époque, les vestiges visibles (fig. 2) étaient quatre cairns mégalithiques répartis sur la crête centrale de l'île selon un axe globalement orienté nord-sud, et distribués deux par deux de part 
Figure 2 : Répartition des principaux vestiges « visibles » sur l'île Guennoc, aménagements modernes exclus (Landéda, Finistère) (DAO L. Quesnel, d'après Giot, 1987).

Figure 2: Location of the main "visible" remains on Guennoc Island (modern elements excluded).

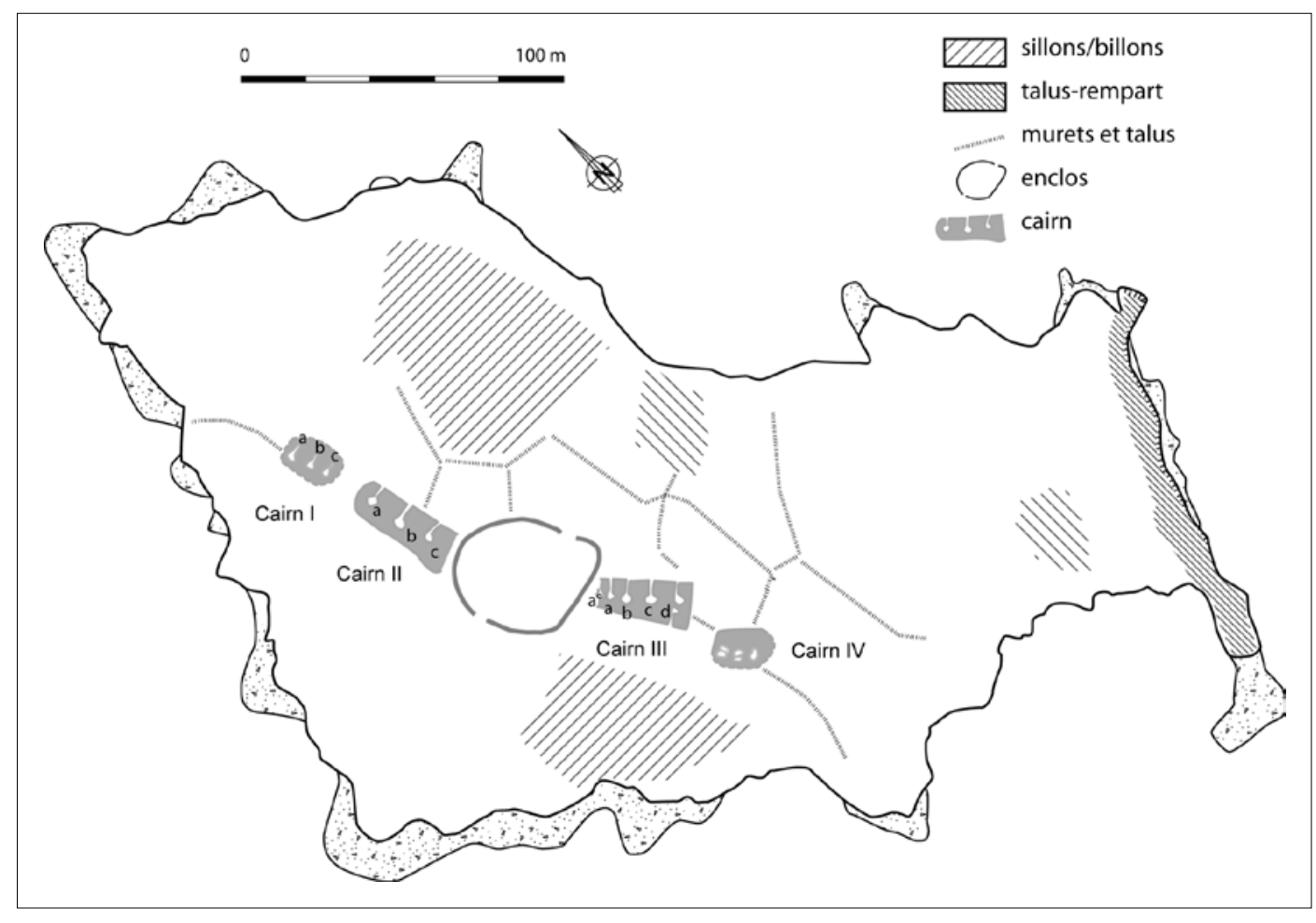

et d'autre d'un enclos délimité par un talus, un talus-rempart bordant la falaise sud-est de l'île et, en divers points, des talus-murets associés à des traces de pratiques culturales anciennes (billons/sillons). L'objectif du programme de fouille était l'étude des quatre cairns mégalithiques dont les chambres et couloirs furent systématiquement explorés, de même que les abords immédiats des cairns dont les parements firent l'objet de quelques restaurations de fortune. Quelques sondages et vérifications ponctuelles furent menés parallèlement, au cour de l'enclos central et sur des traces de substructions et des vestiges de bâtiments, qui seront analysés par la suite.

\section{Des occupations humaines successives}

La plus ancienne trace d'occupation humaine de l'île remonte à l'Azilien et au Mésolithique, avec en particulier un gisement reconnu lors de l'exploration de l'enclos central au sommet de l'île. Par la suite, sur $180 \mathrm{~m}$ de la crête axiale, une douzaine de dolmens à couloir, groupés au sein de cairns mégalithiques complexes, furent implantés au Néolithique moyen, époque à laquelle l'île était encore rattachée au Continent.

La Protohistoire est tout d'abord représentée par un dépôt de l'Âge du Bronze final III, du faciès atlantique à épée en langue de carpe. Il fut découvert en février 1890 en un lieu du littoral non précisé à l'époque (Du Chatellier, 1891), mais qui peut être situé dans le secteur sud-ouest de l'île (Briard et Onnée, 1996), des tessons de céramiques rouges grossières à décors digités et un bracelet en bronze ayant été collectés dans ce secteur à l'époque des fouilles. D'autres éléments de cette même période ont été recueillis vers le centre de l'île, dans le secteur des cairns (expertise Muriel Fily, com. pers.). D'autre part, des dates radiocarbone de l'Âge du Bronze ont été obtenues pour des foyers localisés dans la sépulture A du cairn I, les sépultures B des cairns II et III et le dolmen $\mathrm{C}$ du cairn III, ce qui confirme largement la fréquentation de l'île durant cette période. Pendant l'Âge $\mathrm{du}$ Fer, tout comme pendant l'Âge du Bronze, ces chambres dolméniques furent visitées, occupées voire démantelées, ce qui a souvent dépité les membres de l'équipe de P.-R. Giot qui se seraient satisfaits de stratigraphies et dépôts moins perturbés.

Les traces des occupations humaines à l'Âge du Fer apparaissent aujourd'hui comme nombreuses et variées sur ce territoire actuellement insulaire et elles seront détaillées infra. Par rapport aux premières réflexions et publications (Giot, 1987), nous proposons ici une relecture de certaines structures - en particulier l'enclos localisé au centre de l'île et les bâtiments qu'il recèle - à la lumière de l'abondante série céramique mise au jour sur le site et datée de La Tène. Une datation au sein du Moyen Âge avait été un temps proposée par P.-R. Giot pour cette enceinte et ces bâtiments, probablement parce que certaines zones de l'intérieur de l'enclos 
(mais aussi de l'extérieur) avaient livré de la céramique médiévale, sans doute un peu antérieure aux $\mathrm{X}^{\mathrm{e}}-\mathrm{XI}^{\mathrm{e}}$ siècles (Giot, 1982).

Un foyer a été allumé dans le couloir du dolmen $A^{\circ}$ du cairn III pendant le Moyen Âge. Le dolmen B du cairn I livra également un niveau de foyers avec de gros fragments de céramiques médiévales tardives (voire postmédiévales), indiquant une seconde réutilisation du monument (après celle de l'Âge du Fer), comme abri ou bivouac. "C'est, parmi le matériel récent découvert sur l'âle Guennoc, celui qui fait le plus penser aux contrebandiers du XVIII siècle " (Giot, 1987, p. 141). En effet, pendant longtemps, l'île ne fut plus guère fréquentée que par des pêcheurs et des goémoniers, mais aussi peut-être par des contrebandiers qui furent nombreux sur cette côte sous l'Ancien régime. Des baux du XIx e siècle mentionneraient encore l'existence d'une fermette ou habitation. Les fours à brûler le goémon du sud-est de l'île et quelques fers à cheval témoignent probablement de ces fréquentations. Vers le début du $\mathrm{Xx}^{\mathrm{e}}$ siècle, un boucher de Lannilis installa ses moutons sur l'île; on lui doit le creusement, de part et d'autre de la crête, de deux trous d'eau remplis en hiver, le plus oriental étant alimenté par deux rigoles à fond cimenté. En outre, des abris à moutons en pierres sèches furent installés au contact de l'enclos central et du cairn III ainsi qu'au sud du cairn IV.

\section{Une enquête délicate}

Dans l'ensemble, les recherches menées par P.-R. Giot sur l'île Guennoc livrèrent un abondant mobilier de l'Âge du Fer qui, dans l'esprit de la fouille, fut largement considéré comme intrusif et, de ce fait, assez mal publié dans une foule de notes et notices; l'objectif de P.-R. Giot n'était pas l'étude de l'occupation protohistorique de l'île, et c'est sans doute aussi pourquoi il n'a que très peu exploité ce potentiel dans sa publication finale : "Barnenez, Carn, Guennoc " (Giot, 1987). Regrettant l'absence d'une publication collective scientifique qui aurait relaté les diverses étapes du peuplement de l'île Guennoc, J. Briard synthétisa, voici quelques années, les données concernant l'Âge du Bronze et publia notamment le dépôt à épée en langue de carpe, tout en livrant un certain nombre de détails sur la fouille et son " témoignage " en tant que membre de l'équipe de terrain (Briard et Onnée, 1996).

Conscient malgré tout de l'intérêt de la collection de céramiques de l'Âge du Fer collectée à Guennoc, P.-R. Giot m'avait confié en 1983 l'étude de ces quelques milliers de tessons de poteries gauloises, ce qui déboucha sur un mémoire de DEA (Daire, 1983), lequel demeura confidentiel et ne donna lieu qu'à une publication limitée (Daire, 1985). C'est donc vingt-cinq ans plus tard que, relisant le « $B C G$ » de
P.-R. Giot, je fus frappée par la richesse de cette occupation à l'Âge du Fer, richesse trop discrètement égrenée au fil des paragraphes d'un texte très analytique décrivant davantage les dolmens et cairns. D'où la décision de publier le contenu de l'étude céramologique initiale (Daire, 1983) qui ne prendrait son sens que dans une synthèse sur les formes et traces de l'occupation humaine de l'île Guennoc à l'Âge du Fer.

De là, il fallut aller "à la pêche " aux documents et aux sources, avec un handicap : la "disparition» de la quasitotalité de la documentation de fouille (rapports, carnets et plans originaux), seule une partie de la documentation photographique et la majeure partie du mobilier étant encore accessibles dans des collections publiques (archives du labo. Archéosciences, UMR 6566, à Rennes et collections du Musée de Préhistoire finistérienne à Saint-Guénolé Penmarc'h). Relisant tout ce qui a été publié sur Guennoc, de la simple notice dans une "Chronique " à l'article plus développé, des éléments sont apparus, parfois solides, souvent confus et même contradictoires et mentionnés là où on ne les attendait pas : ainsi, des plans de bâtiments de l'Âge du Fer furent publiés par P.-R. Giot dans un article consacré aux occupations médiévales de l'île, un autre dans les pages de l'Anthropologie sur l'épisode « mésolithique " de son peuplement, etc.

Il s'agissait donc, à la base, d'engager une démarche documentaire, afin de rassembler toutes les pièces du puzzle et de les inscrire dans l'évolution de la pensée de P.-R. Giot qui fut souvent amené à réviser ses interprétations et conclusions antérieures sur ce site. Dans les "chroniques" annuelles parues à l'époque des fouilles (dans les Annales de Bretagne et dans le Bulletin de la Société archéologique du Finistère) entre 1960 et 1974, ainsi que dans les "informations " de Gallia-Préhistoire (1962-1971), P.-R. Giot attribue à plusieurs reprises les murets de maisons et l'enclos à l'époque gauloise, en liaison avec l'abondant mobilier de La Tène qu'il recueille un peu partout sur l'île. Puis, dans son article de 1982 (dans les Mélanges d'Archéologie et d'Histoire médiévales en l'honneur du doyen Michel de Boüard), probablement influencé par la fouille qu'il mène alors (depuis 1977) sur les installations monacales de l'île Lavret, P.-R. Giot revient sur la plupart de ses attributions en rajeunissant les bâtiments empierrés et l'enclos central : "C'est pourquoi, n'ayant trouvé dans son sol que quelques tessons de poteries de l'Âge du Fer, et aucun attribuable plus clairement à une époque plus récente, nous nous y sommes laissés prendre et l'avons-nous attribuée à l'époque de La Tène finale... Depuis, nous nous sommes persuadés que les fonds de cabane armoricaines de l'Âge du Fer sont beaucoup plus frustes et que ce type de constructions avec des petites murettes basses ne commence réellement qu'au très haut Moyen Âge " (Giot, 1982, p. 182). Enfin, dans son ouvrage de synthèse de 1987, il reviendra à ses premières conclusions, 
ayant entre-temps visité la fouille alors en cours du hameau gaulois de l'île d'Yoc'h (Daire, 2001), dont les bâtiments de La Tène finale ressemblent énormément aux constructions de Guennoc.

C'est donc à la fois à une enquête "policière " et à une analyse de texte éclairée par la chronologie relative des publications qu'il a fallu se livrer, pour démêler un imbroglio de données. P.-R. Giot ne nous en tiendrait pas rigueur puisqu'il insistait lui-même sur la liberté d'autocritique dont doit jouir le véritable chercheur, liberté de revenir sur une interprétation, une conclusion, de se contredire, liberté qu'il a mise en pratique à plusieurs reprises dans une véritable démarche scientifique. L'exercice présenté ici ne lui aurait donc sans doute pas déplu et il aurait probablement adhéré à l'idée de faire le point sur l'épisode gaulois du peuplement de Guennoc.

À partir de ces données contradictoires, et à la lueur de l'avancée des recherches plus récentes, nous proposons donc aujourd'hui un assemblage des éléments de ce puzzle, afin de présenter une synthèse inédite des occupations de l'île Guennoc à l'Âge du Fer, dont les conclusions et hypothèses seront raisonnablement limitée.

\section{Les occupations de l’ÂGe du Fer}

Au cours de l'Âge du Fer, et particulièrement à la fin de la période, la réutilisation de plusieurs chambres dolméniques, comme " habitats» ou comme dépotoirs, voire également

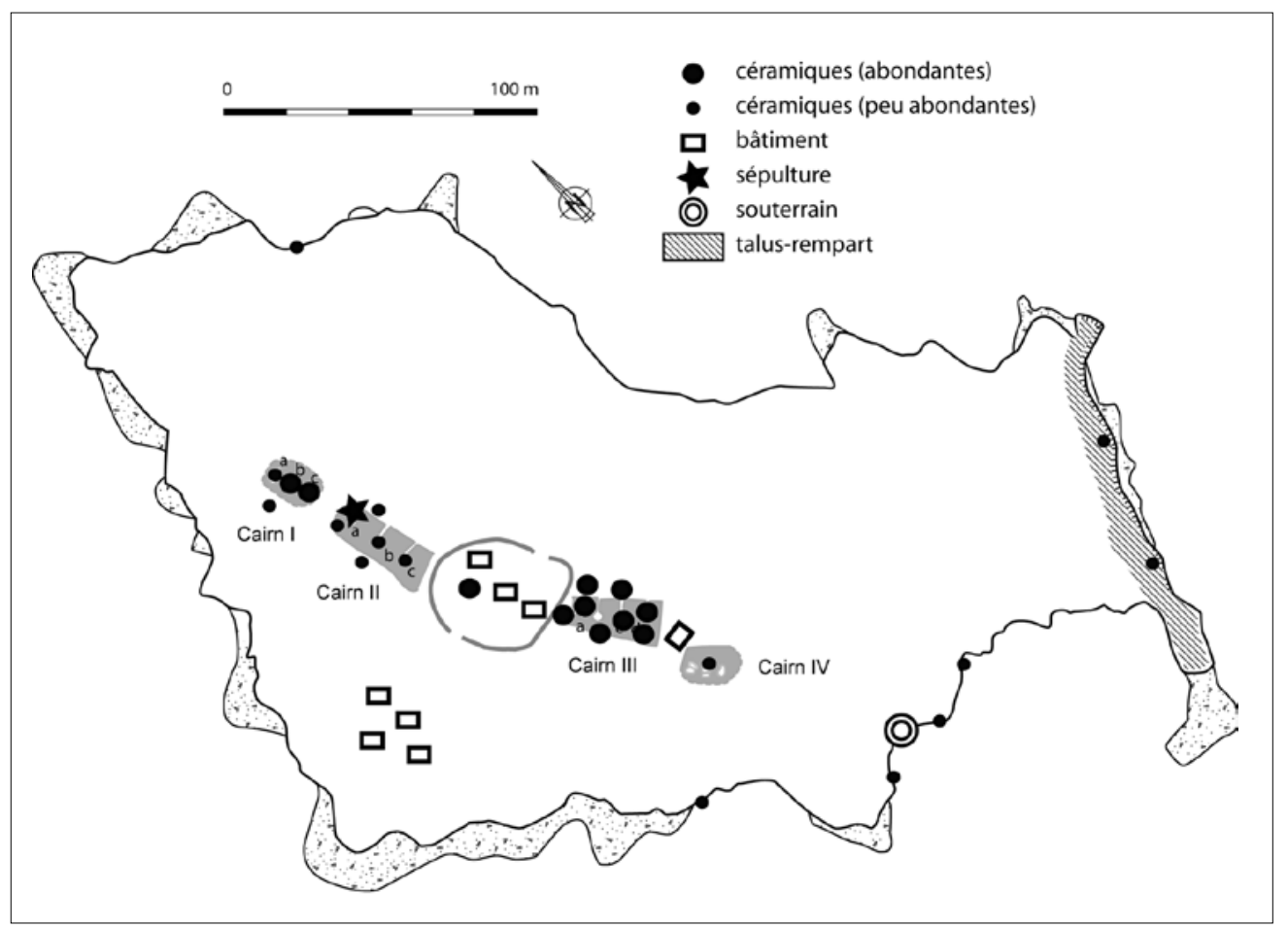

comme sépulture (tombe du couloir IIA : Giot, 1987, p. 146) atteste une occupation assez intense. Ce sont notamment des débris de céramiques qui abondent dans ces dolmens ainsi qu'au pied des murs de parements des cairns, en grande partie écroulés depuis. Mais ces sépultures mégalithiques ont également servi de carrière pour la construction de bâtiments et de structures propres, que nous analyserons infra. Les éléments bibliographiques et iconographiques disponibles montrent en fait une occupation de l'Âge du Fer touchant divers secteurs de ce territoire aujourd'hui insulaire et, probablement à l'origine, sa totalité, mais avec des variations sensibles dans la nature de ces traces d'occupation (fig. 3).

\section{Une structuration de l'espace}

Notre relecture des descriptions et notes sur les structures de l'île Guennoc se fait aujourd'hui à la lueur des recherches menées sur d'autres sites littoraux et insulaires de Bretagne (Daire, 1990 ; 2004). L'île Guennoc devait encore être attachée à la terre ferme, au moins à marée basse, pendant l'Âge du Fer car, tout comme la proche île d'Yoc'h, sa face orientale (tournée vers le continent) conserve les traces d'un talusrempart daté de cette période et constitué de galets d'origine marine, en partie mangé par l'érosion et le recul de la falaise (fig. 4) (Giot, 1962). Une section pratiquée à travers ce talus a montré deux phases d'édification remontant toutes deux à l'Âge du Fer (Giot, 1967a et b); la partie tournante ébréchée d'une meule figurait parmi les pierres entassées dans le corps
Figure 3 : Répartition des vestiges de l'Âge du Fer sur l'île Guennoc (interprétation M.-Y. Daire, DAO L. Quesnel).

Figure 3: Interpretative distribution of Iron Age remains on Guennoc Island. 


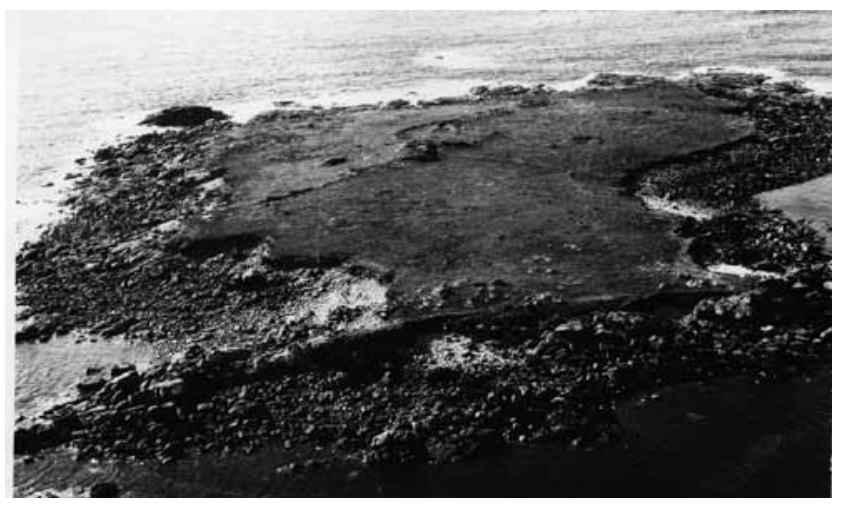

Figure 4 : Lîle Guennoc en 1962 : au premier plan, le talus-rempart (cl. P.-R. Giot, archives de l'UMR 6566).

Figure 4: Guennoc Island in 1962, with bank in foreground.

du rempart, à côté de blocs équarris et de galets marins de tailles variées.

Les cairns II et III sont séparés par un enclos subcirculaire, installé en position centrale de l'île; il s'étend sur une quarantaine de mètres de grand axe à la faveur d'un léger ensellement de la crête (fig. 5). Seules des zones limitées en ont été fouillées, au nord et au sud, à l'intérieur et à l'extérieur de l'enclos, tandis qu'un sondage a donné l'occasion d'effectuer une coupe dans le talus (Giot, 1987).

L'enclos est délimité par un muret curviligne (de 1 à $1,2 \mathrm{~m}$ de large dans sa partie nord-ouest, la mieux conservée), installé sur les restes discontinus d'un talus plus ancien, affaissé; cette construction en deux phases successives, avec une recharge $\mathrm{du}$ talus initial sur son pourtour externe est particulièrement nette sur les clichés de l'époque (fig. 6). On ne peut ici parler de retranchement, aucune trace de fossé extérieur n'ayant été décelée. Nous proposons de voir dans la première phase d'édification de l'enclos une structuration de l'espace à La Tène finale, deux des constructions protohistoriques (cf. infra) s'étant simultanément appuyées sur le talus. En tant que " protection " (contre les intempéries notamment), cette structure sera renforcée ultérieurement, probablement au Moyen Âge si l'on en croit la datation d'une partie des céramiques de ce secteur. Dans ces circonstances, il est difficile de savoir si les deux entrées de l'enceinte, au nord-ouest et au sud-est, existaient déjà dans la première phase. Une partition interne de l'enclos (les deux parties étant d'ailleurs de superficies inégales) sous la forme d'un petit talus empierré (prenant d'avantage l'aspect d'un muret dans la partie nord-ouest) s'appuie sur les angles ouest et est de la «maison centrale » (fig. 7); la branche orientale de cette partition montre une " porte » de communication, matérialisée par deux petites dalles verticales. Le compartiment nord, qui a livré d'abondants vestiges gaulois (os, coquilles de patelles et tessons de poteries), révèle l'existence d'autres constructions et d'empierrements, de même que le compartiment sud.

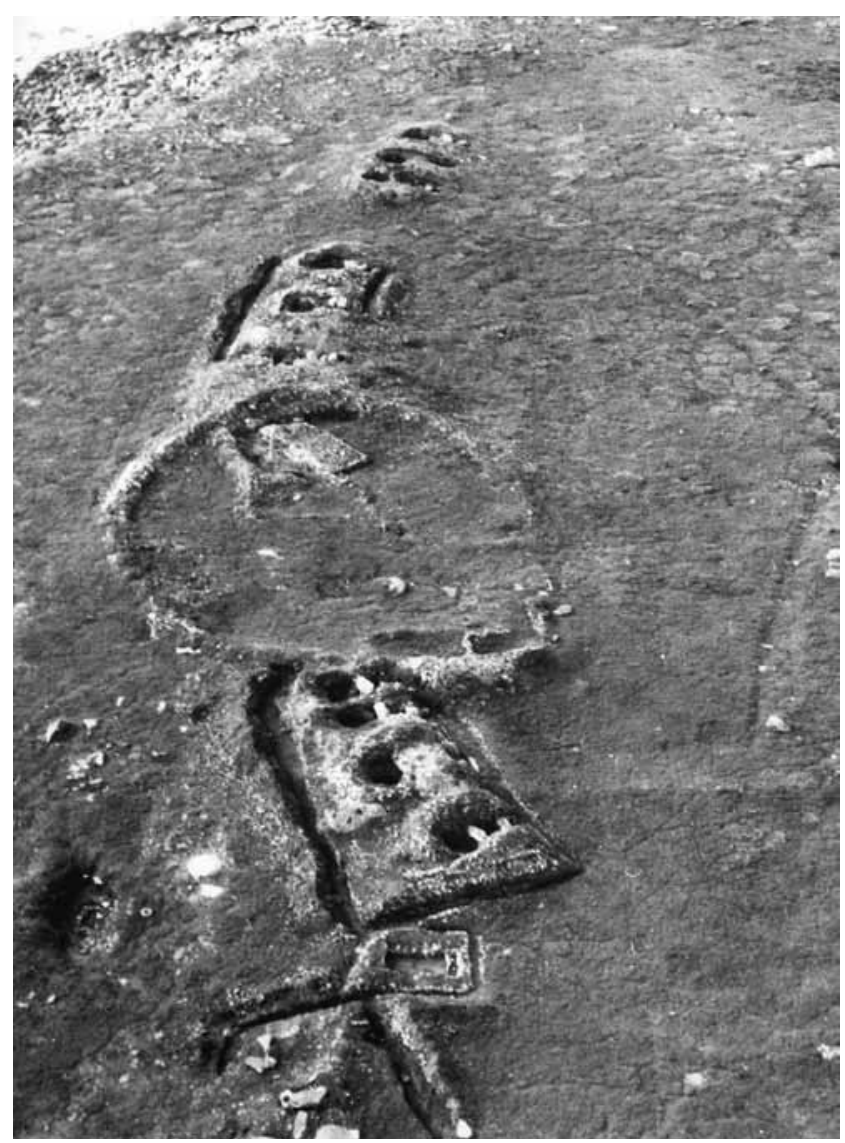

Figure 5 : La partie centrale de l'île Guennoc en 1963, avec ses divers monuments mégalithiques en cours de fouille et l'enclos; en bas, la maison $\mathrm{n}^{\circ} 4$ (cl. Aéronavale, archives de l'UMR 6566).

Figure 5: Central part of Guennoc Island in 1963: megalith in course of excavation, central enclosure and House $n^{\circ} 4$ at bottom (from French Fleet Air photography).

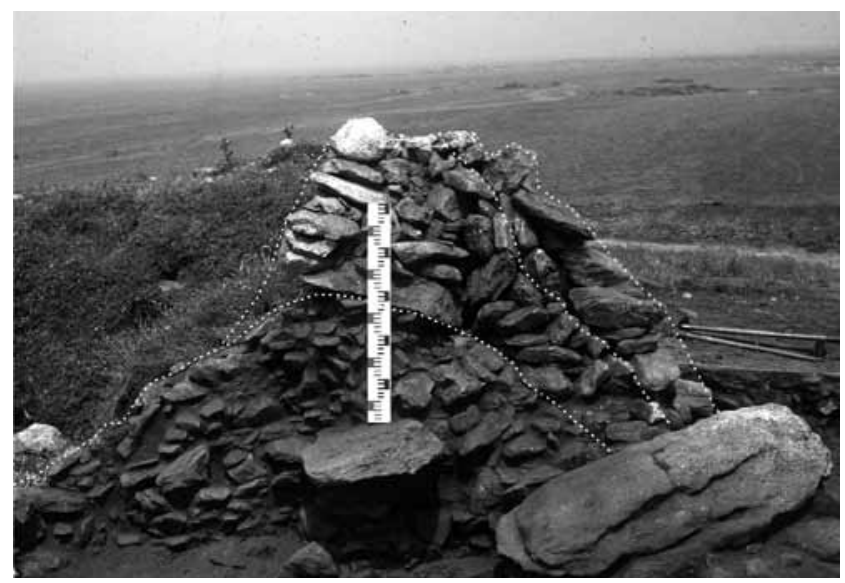

Figure 6 : Coupe dans le talus de l'enclos central de l'île Guennoc (les phases de construction du talus sont suggérées par le pointillé) (cl. P.-R. Giot, archives de l'UMR 6566).

Figure 6: Section through the bank of the central enclosure (building phases are suggested by dotted lines). 


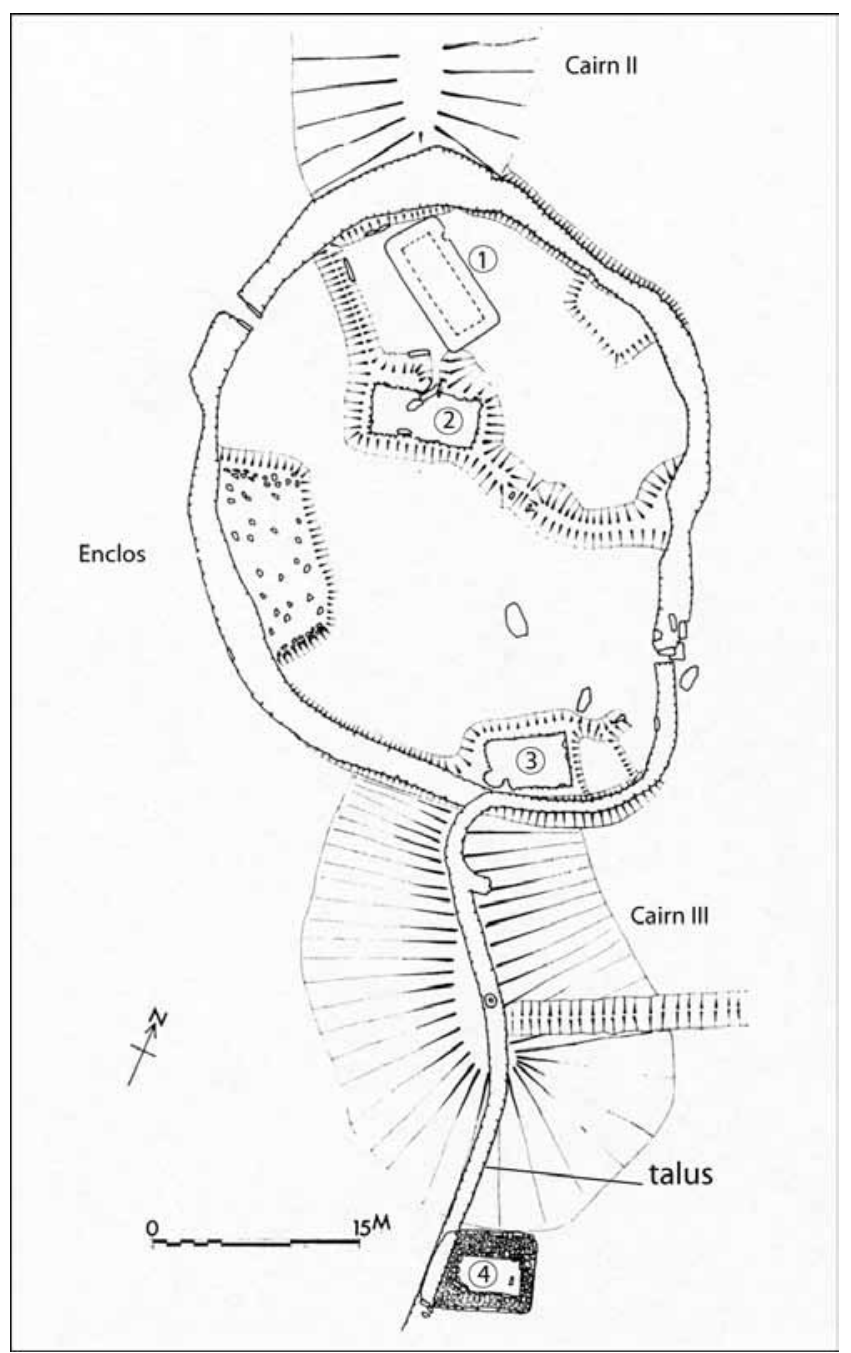

Figure 7 : Plan de l'enclos central, de ses structures internes (dont les maisons $n^{\circ} 1,2$ et 3 ) et du bâtiment 4 , au sud du cairn III (d'après Giot, 1982).

Figure 7: Plan of central enclosure with its internal structures (including houses 1 to 3), plus building 4 south of cairn III.

C'est sans doute à propos de cet enclos qu'on relève le plus d'attributions chronologiques divergentes de la part de P.-R. Giot, qui hésite à plusieurs reprises, au fil des publications, entre la Protohistoire (Bronze final? Âge du Fer) et le Moyen Âge pour son édification (1962; 1964, p. 135-136; 1982, p. 183). Il est vrai que cet enclos révèle des occupations successives à partir de l'Âge du Fer, au haut Moyen Âge, au bas Moyen Âge et à l'époque postmédiévale, avec cependant une omniprésence de céramiques de l'Âge du Fer un peu partout. Nous sommes tentés de retenir l'Âge du Fer comme période d'édification du talus initial et d'y voir une enceinte périphérique contemporaine de certains bâtiments (qui seront détaillés plus loin). Si les enclos de l'Âge du Fer sont plus généralement fossoyés et délimités par un réseau de talus et fossés, on retiendra au titre des comparaisons l'enceinte empierrée de Kersigneau/Saint-Jean à Plouhinec (Finistère), dont l'organisation est assez proche de celle de Guennoc avec des constructions adossées au talus-muret périphérique (Giot et Morzadec, 1989; Giot et al., 1991). Une nouvelle occupation des lieux au Moyen Âge, avec réfection du talus et aménagement de nouvelles structures internes, semble également probable, tandis que les occupations postérieures n'ont pas forcément entraîné de remaniements architecturaux.

\section{La question des structures agraires}

Sur le versant oriental de l'île, relativement protégé des vents dominants par la topographie ainsi que par l'enclos central et les monuments mégalithiques, une zone déclive va du milieu du cairn II à l'extrémité méridionale du cairn III, délimitée par des talus très amortis rejoignant le bord de mer (fig. 2); cette zone porte des traces de cultures en petites parcelles, courtils ou jardinets; des restes de clôtures plus ou moins effacées ont été un moment décelées un peu plus au sud (Giot, 1982; Batt et Giot, 1980); en outre, des traces de cultures en billons ont été décelées en lumière rasante ou grâce à l'examen des photos prises par l'Aéronavale en 1960 (fig. 8). Ces billons correspondent à des rehaussements du sol résultant d'anciennes techniques de labours consistant à appuyer les unes contre les autres une série de bandes de terre retournées.

Les traces de cultures en petites parcelles répondent à un système nettement apparenté aux " champs celtiques », mais

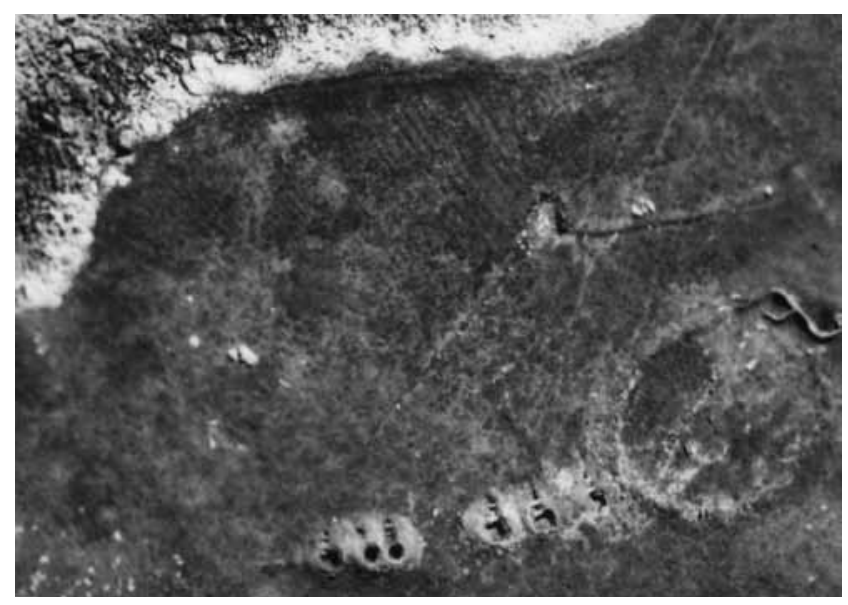

Figure 8 : Traces de cultures en billons et sillons sur le flanc est de l'île Guennoc (recoupées par les rigoles d'alimentation du puisard-abreuvoir est) (d'après un cliché de l'Aéronavale, archives de l'UMR 6566).

Figure 8: Cultivation traces on East side of Guennoc island: ridges and furrows cut by the drainage ditches feeding the eastern source (from French Fleet Air photography). 
qui ont pu aussi bien être en usage pendant la Protohistoire qu'au haut Moyen Âge. Ces traces de billons et sillons, dont certaines sont orientées selon la pente et d'autres perpendiculairement à celle-ci, révèlent une exploitation effectuée avec des outils manuels, à la bêche ou à la houe (Giot $e t$ al., 1982). La partie la plus abritée conservait en outre les reliques d'une flore rappelant une pâture continentale, plus drue, avec trèfle et plantain.

Bien entendu, l'attribution chronologique de ces traces de pratiques agricoles, de toute manière fort anciennes, reste conjecturale. Mais nous les considérons aujourd'hui à la lueur de observations inédites faites sur l'île d'Yoc'h postérieurement aux fouilles et publications de P.-R. Giot sur l'île Guennoc. En effet, des photographies aériennes de cette autre île léonarde (là encore prises par l'Aéronavale dans les années 1980) révèlent des traces de billons identiques à celles de Guennoc, réparties par plages (fig. 9). À l'île d'Yoc'h, le parcellaire "moderne " a recoupé ces traces de billons, révélant ainsi une chronologie relative des structures agraires et une antériorité des sillons; or, en dehors de l'importante occupation humaine de l'île à La Tène finale (matérialisée elle aussi par un talus rempart, et un hameau ou village comportant plusieurs bâtiments surimposés à une sépulture mégalithique : Daire, 2001), aucune occupation médiévale n’a été mise en évidence, ce qui nous incite à attribuer ces traces de cultures à l'époque gauloise, de manière quasi-certaine pour Yoc'h et, par voie de conséquence, avec de fortes présomptions pour Guennoc.

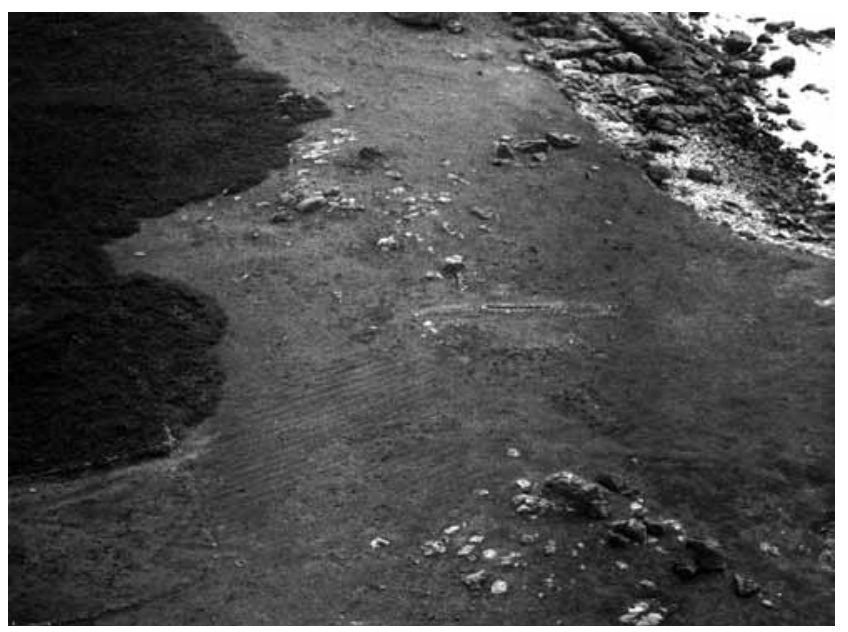

Figure 9 : Traces de cultures en billons et sillons sur le flanc sud-est de l'île d'Yoc'h à Landunvez, à proximité immédiate des installations de goémoniers (d'après un cliché de l'Aéronavale).

Figure 9: Cultivation traces (ridges and furrows) on S-E side of Yoc'h island (Landunvez), close to modern seaweed collection installations.

\section{Des constructions et des bâtiments}

À l'intérieur de l'enclos central de Guennoc apparaissent les fondations de plusieurs constructions (fig. 7).

Dans le compartiment nord de l'enclos, figure un bâtiment $\left(\mathrm{n}^{\circ} 1\right)$, décrit comme possédant des angles extérieurs arrondis et deux portes centrales au milieu des grands côtés; l'emprise totale de cette construction nous est inconnue car aucun plan n'en a apparemment été publié. En outre, ce compartiment de l'enclos montre une zone empierrée adossée au talus, plus probablement une aire isolée de stockage (bois? fourrage?) qu'un bâtiment ruiné.

En position stratégique puisque servant d'appui au talus de compartimentage de l'enclos, le bâtiment $\mathrm{n}^{\circ} 2$, dénommé " maison centrale » par P.-R. Giot, a un plan rectangulaire assez régulier et une emprise totale d'une cinquantaine de mètres carrés pour une surface intérieure utile d'environ $25 \mathrm{~m}^{2}$. Il présente une entrée orientée au nord, marquée à l'origine par des piliers dressés de part et d'autre et un foyer central (fig. 10). Ses murets en pierre sèche à double parement atteignaient encore $1 \mathrm{~m}$ de haut dans les années 1960; le parement intérieur était principalement constitué de dalles verticales au-dessus desquelles subsistaient une ou deux rangées de pierres horizontales. Le fond de la construction était garni d'un pavage irrégulier de pierres de petites dimensions, disposées à plat afin de régulariser le fond rocheux. Dans la partie occidentale, deux pierres plantées constituent peut-être les restes d'un calage de poteau (fig. 11), tandis que quelques dalles verticales correspondaient peut-être à un aménagement ruiné le long de la paroi sud. À proximité se trouvait un gros fragment d'une meule rotative.

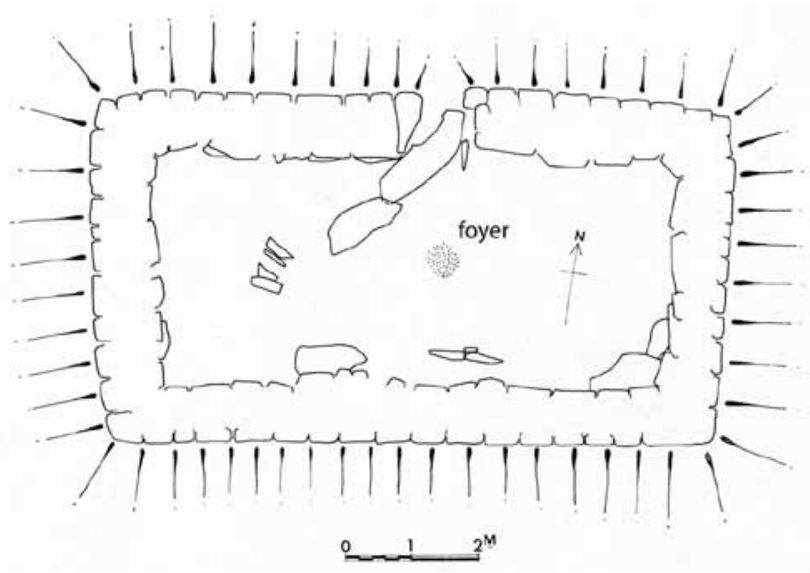

Figure 10 : Plan de la maison $\mathrm{n}^{\circ} 2$ au centre de l'enclos, avec son foyer central (d'après Giot, 1982).

Figure 10: Plan of House $n^{\circ} 2$, in the middle of the enclosure, with its central hearth. 


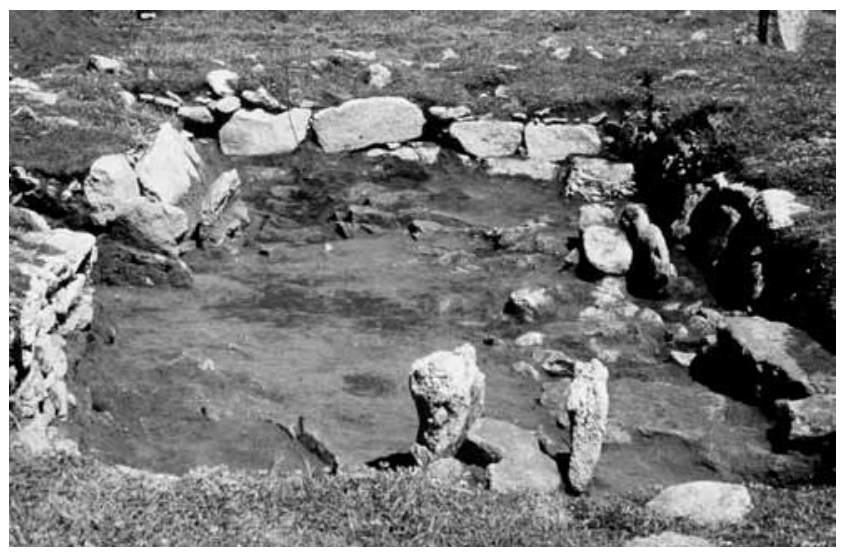

Figure 11 : La maison $\mathrm{n}^{\circ} 2$, en cours de fouille, vue de l'ouest (cliché P.-R. Giot, archives de l'UMR 6566).

Figure 11: House $n^{\circ} 2$ in course of excavation.

Le compartiment sud présente lui aussi une zone surélevée et empierrée, plus vaste et adossée au talus sud-ouest de l'enclos; à proximité, un épandage de débris de cuisine (amas étalé de coquilles de patelles et de cendres) ainsi qu'une dépression (trou à eau) furent identifiés (Giot, 1982, p. 184).

La maison $\mathrm{n}^{\circ} 3$, dans le sud de l'enclos (fig. 12), en partie dégagée lors de la campagne de 1966, montre les caractéristiques architecturales suivantes (Giot, 1967b) : la surface interne utilisable est voisine de $20 \mathrm{~m}^{2}$ mais son emprise totale dépasse $35 \mathrm{~m}^{2}$; la base de la face interne des murs est bordée de petites dalles; sa paroi nord est peu élevée et assez dégradée; une entrée semble avoir existé dans la paroi orientale, dégradée ultérieurement, tandis que la paroi sud possède un beau parement de dalles verticales et de pierres sèches disposées à plat, appuyé sur le talus de l'enclos et

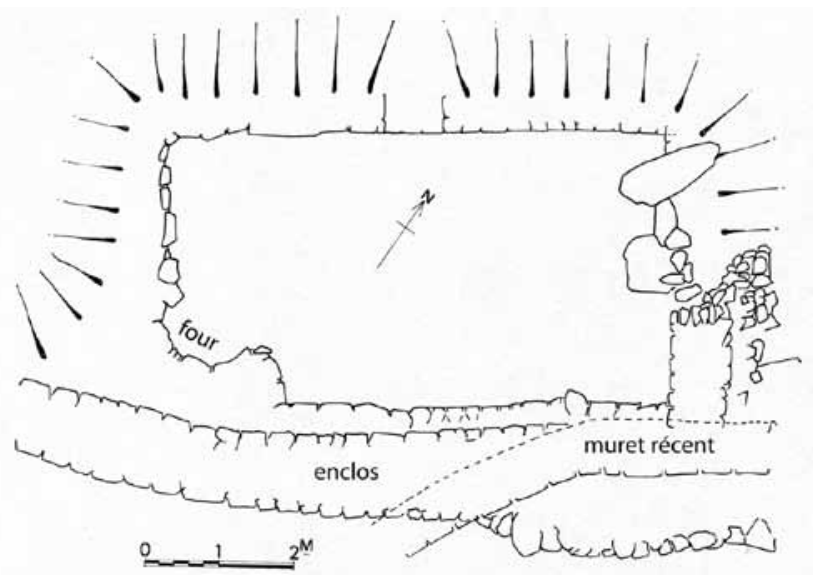

Figure 12 : Plan de la maison $n^{\circ} 3$ au sud de l'enclos (d'après Giot, 1982).

Figure 12: Plan of House $n^{\circ} 3$, in the south of the enclosure. comportant une autre demi-meule rotative. Le sol de cette construction, peu épais au-dessus du rocher, ne contenait que des tessons de l'époque de La Tène finale (Giot, 1982, p. 185). Ce bâtiment a été réutilisé et transformé à l'époque médiévale, avec notamment la construction d'un four en encorbellement dans son angle sud-ouest, qui a livré de la céramique médiévale.

Un petit amas de clayonnages provient de la partie est de l'enclos et l'on peut envisager que l'architecture de pierre ait été complétée, dans certains de ces bâtiments, par des éléments constitués de terre et de bois.

$\mathrm{Si}$ la chronologie de ces constructions a parfois donné lieu à discussion, P.-R. Giot (1987, p. 151) a lui-même reconnu que "La maison centrale de l'enclos, occupée au Moyen Âge, paraît cependant bien semblable à d'autres maisons de l'Âge du Fer de site littoraux, notamment celle dont la fouille a été entamée à l'ìle d'Iock au large de Porspoder par M.-Y. Daire en 1987. " Les parallèles sont effectivement nombreux entre les constructions présentes sur les deux sites, l'île d'Yoc'h ayant été intensivement occupée à La Tène finale (Daire, 2001); les maisons de Yoc'h et de Guennoc ont des dimensions comparables; dans tous les cas, les murs épais de 0,80 à $1 \mathrm{~m}$ construits en pierres sèches sont à double parement et blocage interne de pierrailles, avec des portes ménagées au milieu des grands côtés; le bâtiment $n^{\circ} 1$ de Guennoc présente deux entrées en vis-à-vis, comme l'une des habitations de l'île d'Yoc'h.

À l'extérieur de l'enclos, deux zones au moins ont livré des restes de constructions attribuables à l'Âge du Fer.

Entre les cairns III et IV, c'est suite au dégagement de leurs parements qu'une petite construction rectangulaire fut explorée en 1961 et 1962 (fig. 7, n 4; fig. 13); adossée par

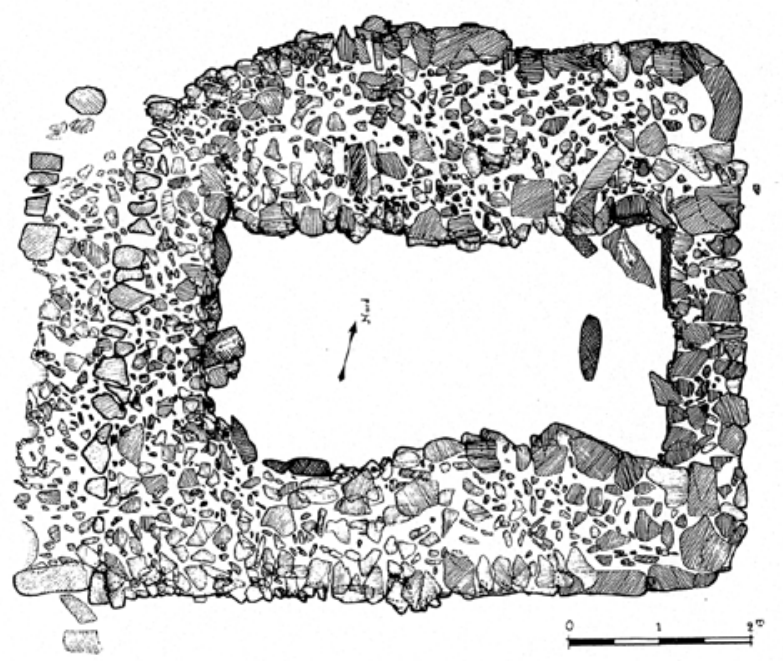

Figure 13 : Plan de la construction $n^{\circ} 4$, entre les cairns III et IV (d'après Giot, 1982).

Figure 13 Plan of Building $n^{\circ} 4$, between Cairns III and IV. 
son extrémité occidentale au muret longitudinal de l'île, elle livra, entre autres mobiliers, quelques tessons de céramiques de l'Âge du Fer. Cette construction a une emprise totale d'une cinquantaine de mètres carrés, pour un espace intérieur utile réduit à un peu moins de $15 \mathrm{~m}^{2}$. Le mur de pierre sèche longitudinal de l'île passe par-dessus le mur occidental de la construction qui, de ce fait, paraît irrégulière. Ses murs nord, ouest et sud n'ont pas tout à fait la même largeur mais étaient encore hauts de $0,60 \mathrm{~m}$ à l'époque de la fouille (Giot, 1982, p. 182). Si des dalles verticales complètent les parois du petit côté ouest, les parements des murs sont dans l'ensemble bien appareillés, l'intérieur comportant un bourrage de caillasse. L'ouverture orientale est bouchée par un petit massif de pierre ayant dû faire office de seuil à un moment de l'utilisation du bâtiment : en arrière de cette "ouverture ", quelques dalles verticales formaient une subdivision dans la construction. Au final, P.-R. Giot (1987, p. 175) évoque un possible réemploi ou transformation au Moyen Âge d'une ruine de l'Âge du Fer.

Des restes de substructions très arasées furent attribués avec plus de doute au seul Âge du Fer sur le versant ouest de l'île (fig. 3), à $40 \mathrm{~m}$ à l'ouest de l'enclos : "Situées beaucoup plus près du trait de côte actuel et couvertes par les embruns, ces trois ou quatre traces rectangulaires, faites de quelques pierrailles, avaient émergé du sol formé par des coussins d'Armeria à la suite de leur incendie. Avec la reprise de la végétation, elles ont disparu à nouveau au bout de quelques années [...]. L'intérieur de la mieux conservée, presque carrée, aurait fait environ 6 m de côté" (Giot, 1987, p. 175). Ces constructions montraient des parois de pierrailles d'environ $1 \mathrm{~m}$ de large et pourraient correspondre à un second groupe de bâtiments de l'Âge du Fer.

Discrètement mentionné par P.-R. Giot (1968), un " petit souterrain" apparait également sous la plume de J. Briard qui le localise sur le flanc sud-ouest de l'île (Briard et Onnée, 1996, p. 36), au fond d'une crique où des clichés datant de 1968 montrent l'ouverture d'une chambre à demi effondrée et recoupée par l'érosion de la falaise actuelle. Réoccupé à l'époque moderne, ce souterrain a livré un lot de céramiques de La Tène finale, dont des éléments très caractéristiques (pot à anses à œillet, céramiques à cordons et une fusaïole réalisée dans un tesson de céramique réutilisé).

\section{Une sépulture (et une vache!)}

Dans le couloir du dolmen A du cairn II, une inhumation humaine avait été aménagée, une dalle de couverture ayant été basculée volontairement en position subverticale pour y former cloison : il s'agit d'un individu " jeune ", de sexe féminin, couché sur le côté droit en chien de fusil, possédant un anneau à chaque cheville, l'un en fer, l'autre en bronze
(Giot, 1987, p. 146); à quelques éléments de l'Âge du Fer sont associées des coquilles de patelles mais aucun lot de céramique provenant de ce secteur n'a pu être isolé dans la collection. P.-R. Giot n'est guère plus explicite sur cette sépulture qu'il fait remonter à l'Âge du Fer et nous n'avons pas retrouvé le matériel issu de cette tombe.

La présence d'un squelette de vache adulte est signalée dans le couloir du dolmen B de ce même cairn, dépôt difficile à caler sur le plan chronologique mais dont certains éléments sont associés à quelques tessons de l'Âge du Fer (Giot, 1982).

\section{UN ENSEMBLE DE MOBILIERS SIGNIFICATIF}

\section{Analyse spatiale de la distribution des mobiliers de l'Âge du Fer (fig. 3)}

D’après les descriptions du cairn I, le dolmen A n'a livré que très peu d'éléments d'origine, son remplissage, bouleversé par les lapins, contenant des tessons de poteries de La Tène finale associés à des balles de fusil et des fragments d'obus (Giot, 1987, p. 140). L'absence de mobilier néolithique dans le dolmen $\mathrm{B}$ du cairn I est sans doute à mettre en relation avec les occupations ultérieures; en effet, le remplissage de la chambre a livré, sur un bon mètre d'épaisseur, de nombreuses pierres et des tessons de céramiques de l'Âge du Fer, niveau recouvert par des foyers ou zones brûlées associés à des tessons de céramiques médiévales tardives voire post médiévales. Le fond de la chambre $\mathrm{C}$ a également livré quelques tessons de l'Âge du Fer ainsi que des objets de fer très corrodés (considérés à l'époque comme "modernes") et des traces de foyers. Des céramiques de La Tène finale ont également été trouvées au pied du parement occidental du cairn I, mais il n'y en avait pas au pied du parement oriental entre les entrées des couloirs, sauf dans l'axe de ces entrées.

Le dolmen A du cairn II fut bouleversé et une partie de la couverture partiellement démantelée à l'Âge du Fer, tandis que sa chambre servit de dépotoir où furent déversés des cendres, des amas de coquilles de patelles, des ossements d'animaux et quelques tessons de poteries gauloises (Giot, 1987 , p. 146). Mais le couloir recelait des tessons de céramiques de l'Âge du Fer assez nombreux, associés à des restes organiques et à une sépulture féminine gauloise. La chambre du dolmen $\mathrm{B}$ du cairn II, lui aussi réutilisé à l'Âge du Fer, livra quelques tessons gaulois et au moins un clou en fer, tandis que le couloir recelait plusieurs fragments d'un squelette de bovidé (vache adulte). La chambre du dolmen C n'a livré que de rares tessons de l'Âge du Fer et des éclats de silex remaniés. 
Le cairn III fit l'objet de dégradations et d'occupations successives aux Âges du Bronze et du Fer, au haut Moyen Âge et à l'époque postmédiévale, mais c'est notamment à l'Âge du Fer qu'il servit de carrière pour la construction des bâtiments adjacents (cf. infra). Les tessons de céramique gauloise étaient très abondants dans les chambres et dans les couloirs des dolmens $\mathrm{A}$ et $\mathrm{A}^{\circ}$ et se doublaient, dans le cas de la chambre $\mathrm{A}^{\circ}$, d'un "amoncellement des restes de cuisine " (charbons, cendres, os de mammifères fragmentés, os de poissons et surtout coquilles de patelles). Outre la présence de céramiques gauloises au sein du dolmen $\mathrm{B}$, un foyer localisé au seuil de la chambre a fourni une date radiocarbone correspondant selon toute vraisemblance au Bronze final (GIF 164A) de même pour le foyer de la chambre du dolmen D (GIF 281). Les chambres des dolmens C et D étaient elles aussi très riches en céramiques de La Tène finale tandis que le couloir du dolmen D livrait des fragments d'amphores Dressel I. Des poteries gauloises ont également été retrouvées tout le long des parements et dans les éboulis; l'extrémité nord-ouest du cairn a d'ailleurs probablement servi de carrière à l'époque pré-romaine.

Le cairn IV, plus petit et beaucoup plus dégradé que les autres, livra des tessons de céramiques de la fin de l'Âge du Fer, accumulés devant la façade nord-est (Giot, 1987, p. 176).

Les autres points de découvertes de mobiliers de l'Âge du Fer sur l'île Guennoc ont été appréhendés à travers l'étude de la collection elle-même, par l'analyse des indications plus ou moins précises sur les étiquettes des sachets complétée par l'examen de quelques clichés de l'époque.

La répartition spatiale du mobilier céramique sur l'île (dont l'analyse est limitée par le caractère non exhaustif des explorations de terrain) montre certaines tendances, résumées dans un diagramme (fig. 14). Le secteur ayant livré les plus grandes quantités de céramiques gauloises est en premier lieu le cairn III ( $43 \%$ de l'ensemble), les poteries provenant

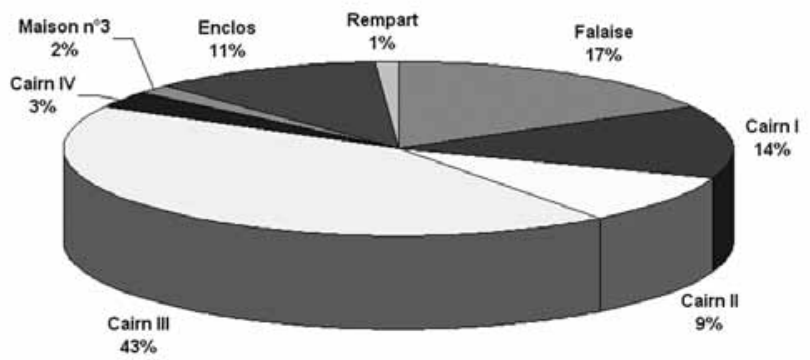

Figure 14 : Distribution des céramiques gauloises collectées sur l'île Guennoc (en poids).

Figure 14: Distributions of Gaulish ceramics collected on Guennoc island (in weights). principalement du pied des parements (fig. 15) et, pour une moindre part, des dolmens $\mathrm{A}$ et $\mathrm{A}^{\circ}$. Le cairn I a livré $14 \%$ des céramiques, principalement issues des dolmens $\mathrm{B}$ et $\mathrm{C}$; l'enclos central a fourni $11 \%$ de l'ensemble céramique. Un lot important provient des falaises de l'île, principalement dans le secteur sud-ouest et notamment à proximité du souterrain. Mais divers ramassages de surface montrent que c'est la totalité du territoire de l'île qui recèle du mobilier de l'Âge du Fer, en plus ou moins grande densité.

\section{Les céramiques}

Les recherches menées par P.-R. Giot sur l'île Guennoc, malgré leur caractère limité dans l'espace, ont livré un important ensemble de céramiques de l'Âge du Fer, soit un NR (nombre de restes) d'un peu plus de 4500 tessons représentant une masse de plus de $50 \mathrm{~kg}$; dans cet ensemble, on évalue le NMI (nombre minimum d'individus) à environ 450, ces tessons significatifs ayant fait l'objet d'une étude de détail dans le cadre d'un mémoire universitaire demeuré inédit (Daire, 1983). La publication de ce corpus nous paraît d'un apport fondamental dans l'appréhension de l'occupation humaine du site à la veille de la Conquête, tant sur le plan chronologique que sur celui des relations et contacts avec les autres communautés continentales et insulaires.

Ces céramiques montrent, selon les secteurs de fouille ou de collecte, un état de conservation différent. Alors que le poids moyen d'un tesson est de 11,2 $\mathrm{g}$ au sein de cet ensemble, les cairns ont livré des tessons de dimensions statistiquement plus grandes, avec des bases de vases ou des hauts pouvant représenter entre la moitié et le tiers de récipients complets, notamment dans le couloir du dolmen A et dans

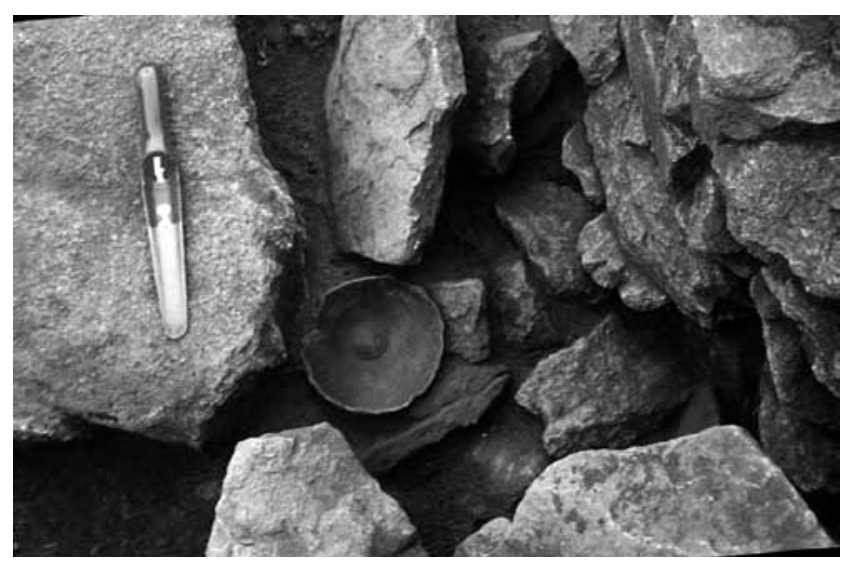

Figure 15 : Fond d'une céramique gauloise ( ${ }^{\circ} 11$, pl. 5) dans l'éboulis du parement du cairn III (cl. P.-R. Giot, archives de l'UMR 6566).

Figure 15: Base of a Gaulish pot ( $\left.n^{\circ} 11, p l .5\right)$, in the collapsed material of Cairn III. 
le dolmen $\mathrm{C}$ du cairn III ainsi qu'au pied du parement ouest de ce même cairn III. En revanche, on note une fragmentation très importante des céramiques gauloises dans l'enclos, et en particulier dans les maisons où le poids moyen d'un tesson n'est plus que de 5,6 g.

Ces différences peuvent s'expliquer, sur le plan taphonomique, par le fait que le mobilier de l'Âge du Fer s'est trouvé protégé sous des dalles mégalithiques dans les dolmens et sous les éboulis devant les parements des cairns, tandis que dans les maisons et l'enclos, il a été piétiné à l'époque préromaine mais aussi lors des occupations ultérieures (au Moyen Âge notamment).

Nous présentons en "catalogue-annexe " (pl. I à VI) les éléments les plus significatifs de cet ensemble céramique inédit, éléments classés par grandes catégories de formes (cf. infra et fig. 16), à savoir :

- planches I et II : les pots ou récipients de stockage de moyenne contenance (pots divers de type 1, pots à anses de type 2 , et bases de vases appartenant à des formes hautes de type 2bis);

- planche III : les récipients de stockage de grandes dimensions (jarres; type 1);

- planches IV et V: les jattes moyennes ou bols (type 3);

- planche VI : céramiques décorées et formes diverses (types 4 et 5) ${ }^{1}$.

\section{Aspects dimensionnels et typologiques}

Sur le plan dimensionnel, les diamètres des vases de Guennoc, s'étalent entre 10 et $30 \mathrm{~cm}$ à l'ouverture et entre 7 et $24 \mathrm{~cm}$ pour les fonds, ce qui traduit une grande diversité de gabarits, mais aussi de formes et d'usages pour ces céramiques. Ce point est cependant à nuancer par le fait que $90 \%$ des récipients sur lesquels les valeurs étaient mesurables ont un diamètre à l'ouverture inférieur à $20 \mathrm{~cm}$, la moitié d'entre eux n'excédant pas $15 \mathrm{~cm}$ et que, dans la moitié des cas, le fond mesure entre 10 et $15 \mathrm{~cm}$ de diamètre. C'est dire que, quantitativement, les céramiques petites et moyennes sont nettement majoritaires et que les grands vases de stockage, pour être présents, ne sont que très faiblement représentés.

Quelques séries de formes se dégagent de cet ensemble, que nous avons synthétisées dans un tableau typologique simplifié (fig. 16).

Au titre des récipients de stockage ou de transport (types 1 et 2) regroupant la plupart des formes hautes, une série de pots ovoïdes ou globuleux est bien documentée par des vases simplement ornés de cordons et cannelures (pl. I).

Le site a livré une série de pots à anses du type anses renfoncées à œillet (countersunk handles) (type 2; fig. 16 et

1. Le catalogue intégral des céramiques gauloises issues du site est proposé en annexe sur CD rom. pl. II), au sein de laquelle nous reconnaissons une dizaine d'individus présentant des dimensions et des caractéristiques techniques variées dans le détail. Les récipients de stockage sont de dimensions variables et l'on peut distinguer une série limitée de céramiques de taille moyenne (pl. I et II) à grande (entre 30 et $40 \mathrm{~cm}$ de diamètre à l'ouverture : pl. III) et une autre série de pots dont le diamètre à l'ouverture est voisin de $20 \mathrm{~cm}$, voire moins. Ces vases sont fréquemment ceinturés d'une ou plusieurs cannelures en creux ( $\mathrm{n}^{\circ} 9$ et 13 , pl. I). Une série de pots, auxquels s'ajoutent de plus rares jarres, présente un décor de un ou plusieurs cordons en relief $\left(\mathrm{n}^{\circ} 2\right.$ à $4,6,12$, pl. I; $\mathrm{n}^{\circ} 1$, pl. II). Leur forme, variable dans le détail, est celle d'un récipient à col plus ou moins court et lèvre éversée, et à panse ovoïde ou convexe. Les bases de ces vases (type 2 bis, fig. 16) sont tronconiques à fond plat mais les exemplaires graphités ( $\mathrm{n}^{\circ} 2$ et 9 , pl. I) et décorés, pourvus d'un élégant piédestal, appartiennent sans doute à des vases de stockage élancés et de belle facture ( $\mathrm{n}^{\circ} 11$ à 15 , pl. II).

Les formes basses et ouvertes sont ici représentées par une série bien documentée de jattes moyennes ou bols (type 3, fig. 16) dont le rapport hauteur/diamètre est voisin de 0,50 , généralement un peu supérieur. Cette série regroupe des éléments de récipients dont le diamètre à l'ouverture varie de 11 à $20 \mathrm{~cm}$; ils présentent une lèvre éversée, un col court, une panse convexe dans sa partie supérieure, fuyante dans sa partie inférieure, un fond de petite taille, proportionnellement à l'ouverture ( $\mathrm{n}^{\circ} 1,2$ et 4 , pl. IV; $\mathrm{n}^{\circ} 9$, pl. V). Ces bols possèdent soit un fond plat, soit un fond annulaire surélevé pour former une sorte de piédestal, dont un exemplaire avec ombilic bien marqué (fig. 15; nº 11, pl. V). Cette série est représentée par plusieurs vases archéologiquement complets; compte tenu des variations de dimensions, les usages de ces bols peuvent être divers. Les jattes hautes ou à haut col constituent une série peu représentée sur le pan numérique (type 4), par quelques éléments d'aspect assez « luxueux », à col surélevé se terminant par une lèvre éversée ( ${ }^{\circ} 10$ et 11 , pl. VI); il en va de même pour les formes très basses et l'on est frappé de la très faible proportion de jattes basses à profil en « $S$ ", forme pourtant classique dans les ensembles armoricains $\left(\mathrm{n}^{\circ} 3\right.$, pl. V).

Le type 5 (fig. 16) regroupe plusieurs formes plutôt basses, mais surtout présentant un profil "simple " (en terme d'analyse géométrique), avec des parois sub-verticales : il s'agit de gobelets tronconiques (représentés par des tessons mais pas par des formes complètes), ou encore des bols hémisphériques très simples que l'on voit généralement apparaître à une phase très tardive dans les ensembles armoricains $\left(\mathrm{n}^{\circ} 12,13\right.$ et 18 , pl. VI). Le fragment de récipient $\mathrm{n}^{\circ} 17$, pl. VI, (provenant du cairn III-C) occupe une place privilégiée dans cet ensemble, tout comme le baquet tripode complet présenté infra. 
Figure 16 : Répertoire typologique de la céramique gauloise de l'île Guennoc.

Figure 16: Typological chart of Gaulish ceramics from Guennoc island.

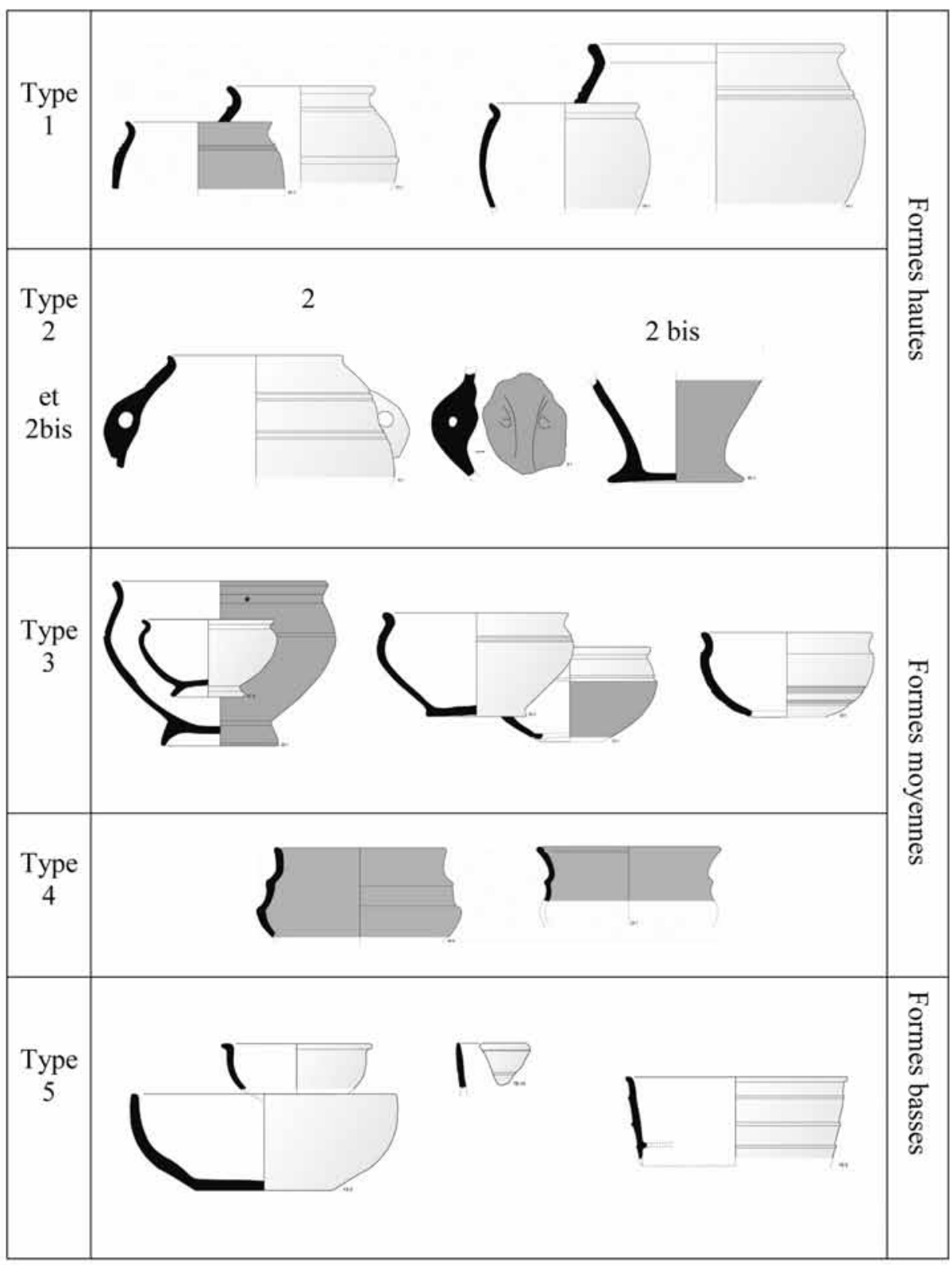

Concernant les caractères morphologiques de ces céramiques, seuls $4 \%$ des bords sont pourvus d'une cannelure labiale interne, de faible largeur, ce qui constitue un autre indice du caractère tardif de cet ensemble (Daire, 1992). Les céramiques ayant subi une enduction au graphite, totale ou partielle, sont relativement nombreuses puisqu'elles représentent $26 \%$ des fragments. Ce fort pourcentage atteste de la bonne conservation qualitative des vestiges céramiques sur le site.

\section{Aspects techniques}

Sur le plan de la réalisation de ces poteries, il a été possible de distinguer trois ensembles ou " fabriques " (au sens anglosaxon du terme).
Plusieurs céramiques sont probablement tournées au tour rapide; leurs surfaces sont généralement enduites au graphite ou engobées à l'hématite. Leur pâte contient des inclusions relativement fines, parfois même invisibles à l'œil nu, mais dans tous les cas extrêmement abondantes. Il s'agit essentiellement de quartz, de micas et de feldspath; une ou deux lames ont révélé la présence d'amphiboles (Morzadec, 1995). Ces pâtes, en général homogènes, contiennent dans certains cas de la chamotte. Les cuissons sont pour la plupart réductrices avec une post-cuisson oxydante et les températures atteintes ne furent probablement pas très élevées.

Un groupe de céramiques, modelées au colombin, montre un travail de finition de surfaces soigné et parfois des traces d'engobes. Leurs pâtes sont assez peu homogènes et pré- 
sentent beaucoup de "vides " visibles en section; les inclusions y sont toujours très abondantes mais de calibres très variés. La cuisson est réductrice et a sans doute été effectuée là encore à température assez peu élevée.

Les céramiques les plus grossières, utilitaires, montées au colombin, montrent elles aussi une pâte très peu homogène, avec beaucoup de vides, une forte densité d'inclusions (surtout du quartz et des micas) atteignant parfois un fort calibre (4 à $5 \mathrm{~mm}$ ).

Malgré le bon état de conservation général évoqué plus haut, il est parfois difficile de déterminer sur certains tessons si la céramique a subi la pose d'un engobe ou non et de distinguer formellement le type de traitement appliqué à la surface (lissage soigné ou polissage). La couleur des surfaces des tessons, tels qu'ils nous sont parvenus, est assez uniformément brune lorsqu'il n'y a pas d'enduction de graphite ou d'hématite. D'autres paraissent avoir été peints avec un engobe brun, donnant à la surface une belle couleur régulière et un lustre particulier, à moins qu'il ne s'agisse d'un lustrage particulièrement soigné.

Seuls quelques rares tessons témoignent de la pose d'un engobe rouge, probablement à l'hématite, tels deux fragments de poterie "peinte " $\left(\mathrm{n}^{\circ} 2\right.$ et $3, \mathrm{pl}$. VI), un tesson de céramique à cordon $\left(\mathrm{n}^{\circ} 10, \mathrm{pl}\right.$. V), deux hauts de pot (dont le $n^{\circ} 14$, pl. I). En relation avec cette observation, il faut noter la découverte, dans le dolmen $\mathrm{D}$ du cairn III, près de la paroi nord de la chambre, d'un bloc d'hématite rouge montrant sur une de ses faces un polissage dû à son utilisation vraisemblable pour colorer (des céramiques?); les dimensions de ce bloc sont 107 x 58 x 19 mm et sa masse est de $210 \mathrm{~g}$ (Giot, 1982).

Au sein de cet ensemble, les éléments décorés sont très peu nombreux; une dizaine de tessons montrent cependant le recours à des techniques ornementales variées.

- Deux tessons portent un décor estampé aux poinçons : le $\mathrm{n}^{\circ} 1$, pl. VI, porte une série d'une douzaine de petits points imprimés et disposés au sein d'un triangle délimité par des incisions, tandis que le tesson graphité ${ }^{\circ} 4$, pl. VI, montre des ocelles disposés par grappes de trois, organisées elles-mêmes en pendentif/triangle pointe en bas encadrant trois motifs plus complexes en grappe.

- Cinq tessons portent des décors réalisés à la pointe mousse ou au lissoir, dont trois sont des décors internes : outre les lignes parallèles du tesson $\mathrm{n}^{\circ} 7$, pl. VI, le $\mathrm{n}^{\circ} 5$ figure un bandeau horizontal portant des groupes de quatre traits parallèles disposés en chevrons sous un décor mouluré. Le $\mathrm{n}^{\circ} 6$, pl. VI est issu d'une forme basse portant un décor interne rayonnant de sinusoïde encadrée par des lignes subverticales, de même inspiration que les décors des $n^{\circ} 8$ et 9 (pl. VI).
Un groupe relativement important de céramiques présente une ornementation de cordons horizontaux ou baguettes, en relief plus ou moins marqué. Ces fragments semblent appartenir à des récipients montés au tour plus ou moins rapide et la présence d'enduction graphitique est fréquente sur ce type de céramique. Ces décors moulurés concernent divers types de récipients : des petits pots à panse convexe, d'autres jarres plus grandes et plus massives (pl. I et II), plus rarement des formes basses. Ces cordons peuvent être larges ou minces, simples ou multiples, encadrés par des cannelures en creux qui en soulignent le relief, ou au contraire à profil amorti. Un cas particulier de céramique à décor à cordon est celui des baquets (cf. infra).

Un autre ensemble numériquement important est celui des céramiques à décors de stries ou cannelures en creux, puisqu'ils représentent $25 \%$ des tessons de l'ensemble. Les formes concernées par ce type de décor sont des jarres (pl. III), dont certaines de grande taille, des jattes moyennes ou bols ( $\mathrm{pl}$. IV et $\mathrm{V}$ ) et des récipients à parois subverticales représentés par quelques tessons de gobelets. Ces cannelures sont plus ou moins fines et régulières, parfois sommairement ébauchées et traitées sans soin. Dans certains cas, ce sont de fines incisions tandis que dans d'autres elles atteignent plusieurs millimètres de largeur. La majorité des récipients comportant des décors de cannelures horizontales ont été réalisés au tour plus ou moins rapide.

Les quelques analyses pétrographiques réalisées sur des échantillons de céramiques de l'île Guennoc, qui ne sont malheureusement pas référencés en terme de typologie (Morzadec, 1995), montrent une utilisation de matériaux d'origine granito-gneissique; cette céramique peut être très fine, avec des inclusions peu nombreuses à peine visibles à l'œil nu, mais aussi grossière, avec des minéraux abondants pouvant atteindre de forts calibres. La composition de ces céramiques est trop ubiquiste pour que l'origine géographique en soit localisable; mais, de manière un peu simpliste, on a tendance à qualifier ces productions de " locales». Plus justement, on peu considérer qu'il s'agit de productions "régionales", ce qui n'empêche pas qu'elles aient participé d'un circuit de distribution plus ou moins complexe.

Un échantillon de " céramique à cordons ", probablement le baquet (cf. infra), dont le matériau serait originaire du massif de gabbro de Trégomar-Lamballe (Côtes-d'Armor), montre des échanges à longue distance relative, de l'ordre d'environ $150 \mathrm{~km}$ à vol d'oiseau entre la zone de probable production et le site d'utilisation.

\section{"Sur une remarquable céramique gauloise de l'île Guennoc"}

Nous avons déjà évoqué la présence d'une céramique particulière, à savoir un «baquet à cordons » auquel P.-R. Giot 
avait consacré un article dont nous empruntons ici le titre (Giot et Bourhis, 1964). Cette poterie ( $n^{\circ} 1$, fig. 17) est en effet remarquable à plus d'un titre : son caractère probablement exogène sur le site, sa rareté dans les ensembles régionaux et la nature des sites où ce type de forme est distribué sont autant d'éléments justifiant que l'on s'arrête sur ce cas. Ce baquet cylindrique à pieds (au nombre de 3 ou 4) et à fond ombiliqué, haut au total de $9 \mathrm{~cm}$ et large de 20 , représente une contenance d'un peu moins de 1,5l; outre un beau travail de surfaçage sur une pâte fine, ce baquet montre un décor de trois cordons horizontaux en relief très finement travaillés et ceinturant la panse. Un autre fragment $\left(\mathrm{n}^{\circ} 17, \mathrm{pl}\right.$. VI) appartient probablement à un second exemplaire un peu plus petit. Le décor rappelant ici les cerclages métalliques de baquets en bois ( $\mathrm{n}^{\circ} 3$, fig. 17), un rapprochement avec les éléments ligneux et leurs imitations céramiques de Glastonbury se confirme (Coles et Minnitt, 1995, p. 167-168; Earwood, 1993, p. 60-70). L'intermédiaire de récipients en lignite est également envisageable dans un processus de diffusion de ce type de forme de part et d'autre de la Manche (Le Nagard, 2005).

Ces baquets sont suffisamment rares pour que l'on s'arrête sur leur distribution (fig. 18), en prenant en compte des récipients morphologiquement semblables malgré cependant des variantes dans la forme des pieds (annulaires, tripodes, en piédestal...). Dans l'ouest de la France, on évoque de longue date la comparaison avec les exemplaires de la nécropole de Kerné à Quiberon, du Camp d'Artus à Huelgoat (Giot et Bourhis, 1964, p. 65-66), auxquels s'ajoutent maintenant ceux de l'habitat aristocratique de Saint-Symphorien à Paule (Ménez, 1999, p. 264, fig. 7, forme 34), du village de l'île d'Yoc'h à Landunvez (Daire, 2001) dans une variante à pied annulaire, ou encore du village gaulois de Kerhillio à Edeven (Daire, 1992), autant d'ensembles et de contextes datés de La Tène finale. Enfin, un baquet tripode à cordon découvert dans la grotte-sanctuaire des Perrats à Agris (Charente) (Ducongé, 2007) et assez semblable à l'exemplaire de Guennoc étend cette distribution vers le CentreOuest, d'autant qu'un exemplaire trouvé à Angers avait déjà fait l'objet de rapprochements stylistiques et chronologiques. On notera également la découverte d'un baquet tripode à cordons au sein de l'une des plus riches tombes de la nécropole de Bois-Guillaume "Les Boquets " (Seine Maritime), tombes ayant livré un service à boire en rapport avec un banquet funéraire, curieusement associé à de probables éléments de briquetages en argile cuite (Merleau, 2002).

La qualité de fabrication de ces baquets combinée à leur caractère exogène (démontré à Guennoc par l'analyse de la pâte) et à la particularité de leur forme, conduit à s'interroger sur la fonction de tels récipients dont, intuitivement, on devine le caractère exceptionnel : ne s'agirait-il pas d'un élément participant au service du vin, voire à des libations, comme cela a été montré pour les passoires par exemple et comme cela est suggéré par le dépôt de Bois-Guillaume? On retrouvera des céramiques apparentées sous la forme de bassins en terra nigra, à partir de l'époque augustéenne
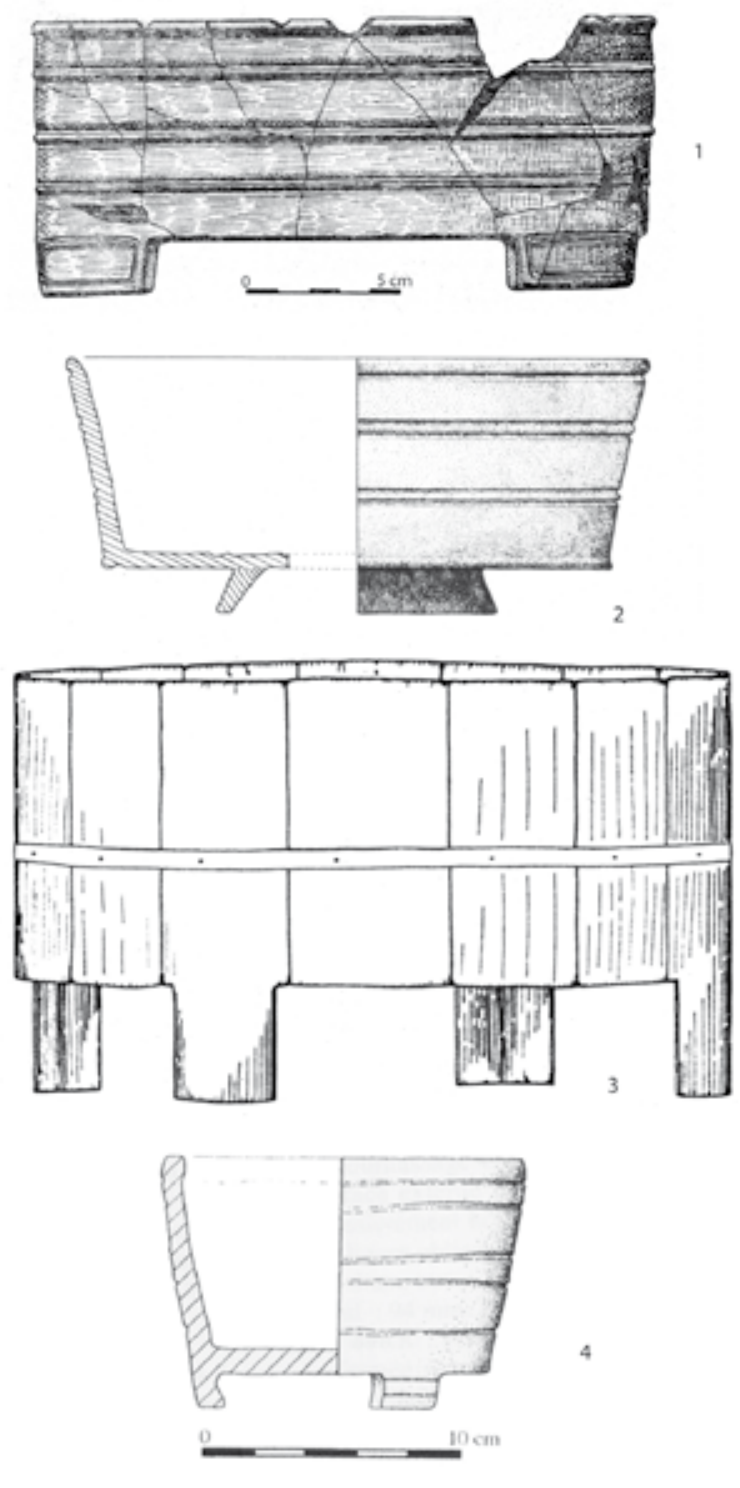

Figure 17 : Exemples de "baquets " de la fin de l'Âge du Fer (les $\mathrm{n}^{\circ} 1$ à 3 sont à la même échelle). 1 : céramique de l'île Guennoc (dessin Y. Onnée; d'après Giot et Bourhis, 1964); 2 : céramique de l'île d'Yoc'h (dessin E. Le Goff; d'après Daire, 2001); 3 : baquet en bois de Glastonbury Lake Village, Grande-Bretagne (d'après Earwood, 1993, p. 70); 4 : céramique du site de Bois-Guillaume (Seine Maritime) (d'après Merleau, 2002).

Figure 17: Examples of "tubs" from late Iron Age (1 to 3 at the same scale). 1: ceramics, Guennoc island; 2: ceramics, Yoc'h island; 3: wood, Glastonbury Lake Village (Great Britain); 4: ceramics, BoisGuillaume (Seine-Maritime). 


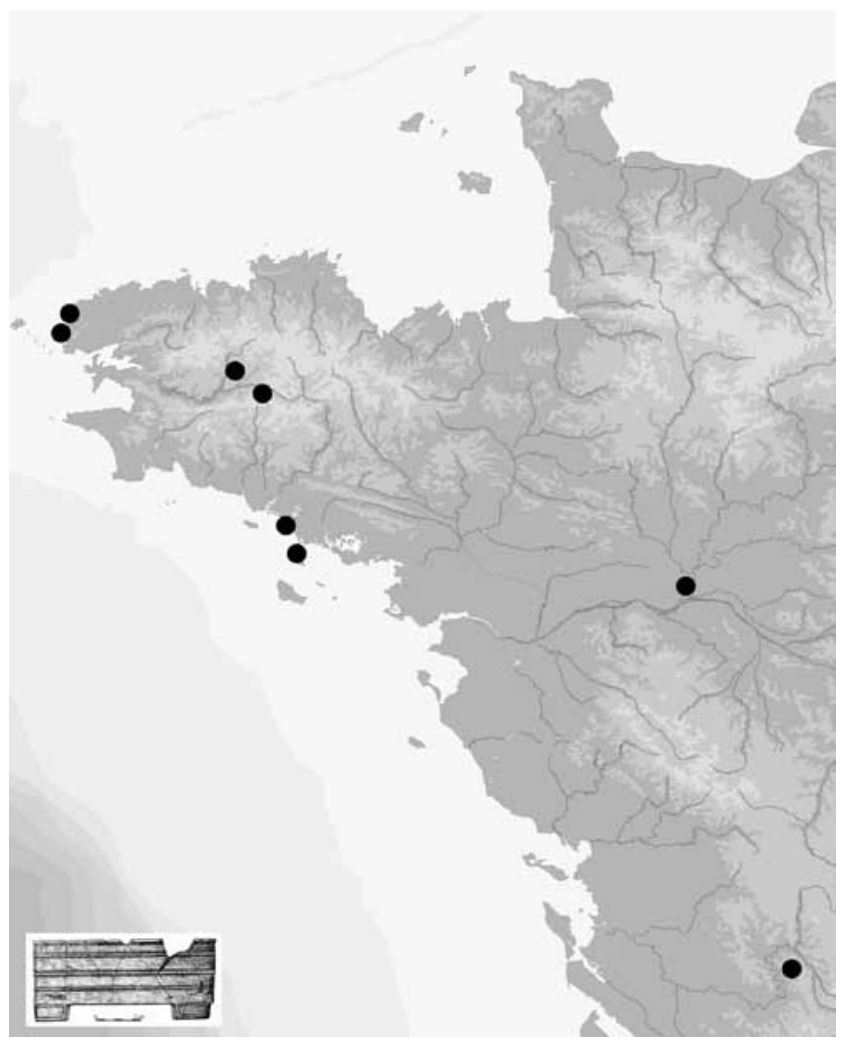

Figure 18 : Distribution des céramiques en forme de baquets à cordons (mentionnés dans le texte) dans l'Ouest et le Centre-Ouest. Figure 18: Distribution of cordonned tub-like ceramics (mentionned in text), for Western and Central-Western France.

(50/40-30 av. J.-C.) et perdurant dans les séries aquitaines de la période 30-10 av. J.-C. (Ducongé, 2007) où ce genre de forme tendra à se banaliser, mais l'analyse de cette filiation demeure relativement complexe.

\section{Les autres mobiliers de l'Âge du Fer}

Apparentées au mobilier céramique, signalons la présence de fusaïoles, dont deux éléments trouvés dans le secteur du souterrain pour l'un et en falaise pour l'autre ( $\mathrm{n}^{\circ} 21$ et 22 , pl. VI) furent réalisés dans des tessons de céramiques réutilisés, tandis que deux autres, provenant du sud-est de l'enclos et du pied du parement ouest du cairn III (non figurées), sont de véritables fusaïoles initialement façonnés comme telles.

Les amphores Dressel I (apparemment non identifiées à l'époque des fouilles) sont représentées par un lot de 178 tessons, de taille assez modeste puisqu'ils ne représentent qu'une masse de $1,620 \mathrm{~kg}$; ils proviennent de la plupart des secteurs de fouille, à savoir des falaises (environs du souterrain) pour 9 d'entre eux, de l'enclos central et des maisons $\mathrm{n}^{\circ} 2$ et 3 ainsi que de la maison $\mathrm{n}^{\circ} 4$ (67 tessons), du pied des parements du cairn III (26 tessons) et des couloirs des dolmens $\mathrm{C}$ du cairn I et $\mathrm{D}$ du cairn III (une quarantaine de fragments); quelques fragments d'amphores proviennent également du talus.

Un lot de faune (marine et terrestre) est mentionné, généralement en association avec des mobiliers et/ou structures de l'Âge du Fer :

- dans le dolmen A du cairn II, $10 \mathrm{~m}^{3}$ de coquilles de patelles et d'ossements animaux, associés à des tessons de céramiques gauloises;

- dans le dolmen $\mathrm{A}^{\circ}$ du cairn III, un gros amoncellement en tas conique de restes de cuisine (charbons de bois et cendres, os de mammiferes fragmentés, os de poissons et surtout coquilles de patelles) associés à de nombreux tessons de La Tène III;

- dans les deux cours de l'enclos central, à proximité des constructions, amas de coquilles de patelles, de cendres et autres « restes de cuisine».

Les outils lithiques que l'on peut sans conteste attribuer à l'occupation gauloise de l'île Guennoc sont représentés par trois demi-meules rotatives, provenant respectivement des maisons $n^{\circ} 2$ et 3 de l'enclos et du talus-rempart au sud est de l'île (fig. 19).

Les principaux éléments métalliques identifiés sur le site et attribués à l'Âge du Fer sont les deux (? au moins) anneaux de chevilles (et non "bracelets ») retrouvés aux jambes de la défunte inhumée dans le couloir du dolmen A du cairn II, l'un étant en bronze, l'autre en fer (objets non retrouvés); en outre, le fond de la chambre $\mathrm{C}$ du cairn I livra, en même temps que des tessons de l'Âge du Fer, des « débris fort oxydés d'objets en fer " que P.-R. Giot (1987, p. 142) hésite à attribuer sur le plan chronologique, entre l'époque préro-

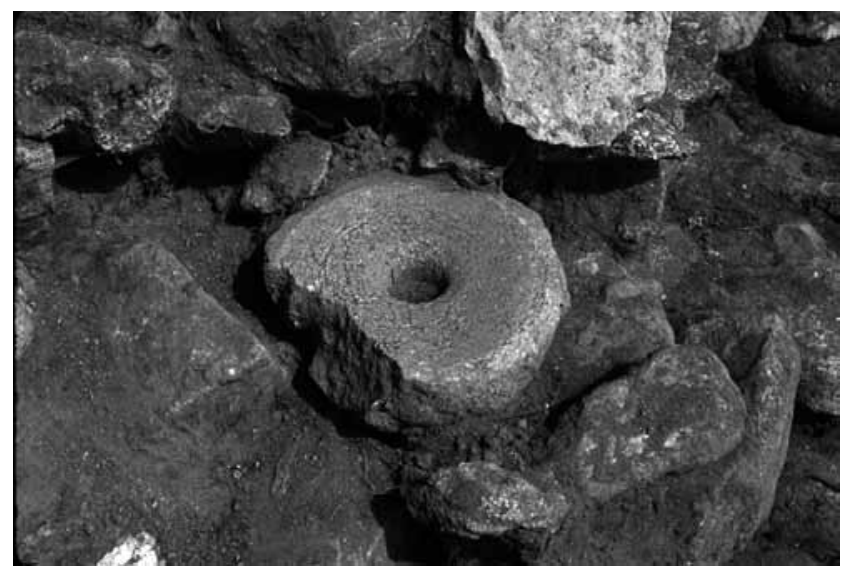

Figure 19 : Fragment de meule de l'Âge du Fer dans le talus-rempart du sud de l'île (cl. P.-R. Giot, archives de l'UMR 6566). Figure 19: Fragment of an Iron Age quern in the southern enbankment of Guenoc island. 
maine et des phases beaucoup plus récentes, puisqu'il évoque de possibles outils de goémoniers. La collection comporte un certain nombre de pièces en fer très oxydé, entières ou fragmentaires, parmi lesquelles on identifie plusieurs pièces (fig. 20) : l'emmanchement à douille d'un outil brisé $\left(n^{\circ} 1\right)$, des portions de lames plates $\left(\mathrm{n}^{\circ} 2-4\right.$ et 8$)$, de probables fragments de clous ( $\mathrm{n}^{\circ} 6,7,9,10-12,15$ et 16$)$ et des éléments de tiges de fer repliées en anneau ( $\mathrm{n}^{\circ} 5$ et 13$)$. Tout en restant prudent sur cette attribution chronologique, notons que des éléments comparables proviennent d'ensembles régionaux

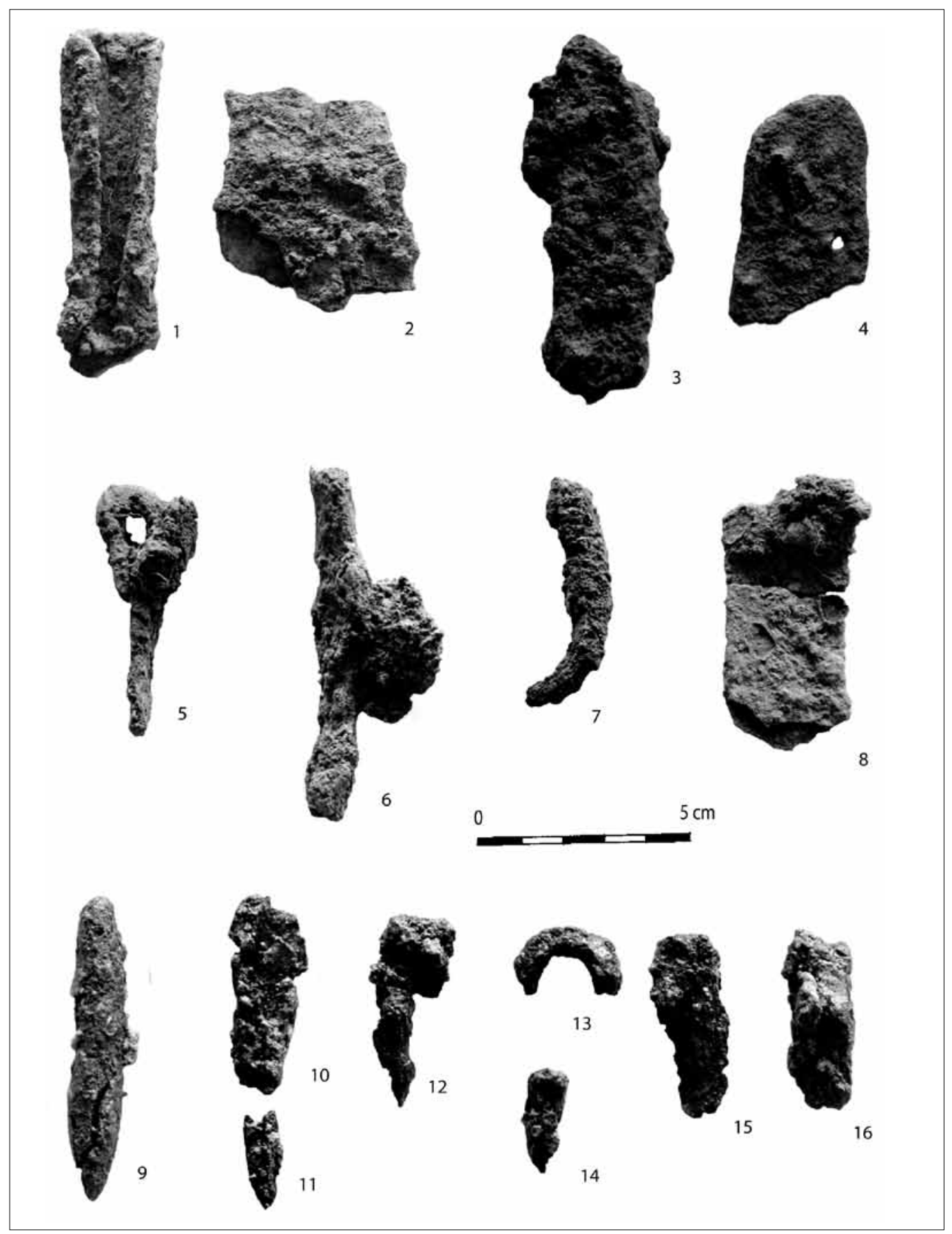

Figure 20 : Mobilier en fer (attribuable l'Âge du Fer?) de l'île Guennoc. 1 et $2:$ cairn III, dolmen D; 3 et 4 : cairn II, dolmen B; 5 à 8 : cairn III, dolmens A-A $\mathrm{A}^{\circ} ; 9$ à 16 : cairn I, dolmen B.

Figure 20: Iron artefacts (possibly Iron Age?) from Guennoc island. 1 \& 2: Cairn III; 3 \& 4: Cairn II, dolmen $B$; 5 to 8: Cairn III, dolmens $A-A^{\circ}$; 9 to 16: Cairn I, dolmen B. 
du second Âge du Fer, en particulier du site voisin de l'île d'Yoc'h à Landunvez.

\section{SyNTHÈSE ET AFFINITÉS}

\section{En résumé... des Gaulois sur l'île Guennoc!}

Si l'on synthétise les divers éléments exposés supra, l'île Guennoc révèle, à l'Âge du Fer, une occupation à la fois extensive et intensive. "Fortifié » ou clôturé sur l'une de ses faces par un talus-rempart, ce territoire de plus de cinq hectares, qui n'était pas encore une île du temps de l'indépendance gauloise, a accueilli un groupe humain de quelques familles. Celles-ci ont édifié au moins huit bâtiments de dimensions modestes (entre 30 et $40 \mathrm{~m}^{2}$ ) et d'un type classique sur le littoral de l'ouest de la Gaule à cette époque, dont certains, au sommet de l'île, étaient ceinturés par un petit enclos. Ces constructions en pierre sèche bénéficièrent d'un pillage des pierres et dalles des monuments mégalithiques antérieurs. Une structure de stockage (souterrain) complétait vraisemblablement les installations domestiques. La présence de céramiques gauloises (parfois en grande quantité) dans les dolmens peut aussi bien témoigner d'une réutilisation des structures funéraires comme dépotoirs (ou plus certainement espace de stockage) que comme habitations.

Au titre des activités de subsistance, l'élevage (une vache inhumée mal datée dans un des dolmens, mais surtout les abondants restes d'os des divers dépotoirs) était complété par la pêche et la cueillette de coquillages sur le littoral voisin, comme en attestent les quelques dépotoirs culinaires découverts dans l'enclos et certains couloirs de dolmens. Les pratiques culturales restent conjecturales mais sont probables si l'on admet l'identification protohistorique des traces de parcelles et de billons. Quelques fusaïoles témoignent d'une activité de filage, tandis que les trois (demi-) meules rotatives trouvées dans le corps du talus-rempart ainsi que dans les maisons de l'enclos attestent d'une activité de broyage, de céréales ou d'autres matières, végétales ou non.

Un argument plaide en faveur de l'intensité de l'occupation des lieux : outre l'abondance relative des céramiques et leur qualité, on note surtout l'importance du dépotoir culinaire du cairn III (patelles et autres coquillages, faune terrestre et marine), qui atteint $10 \mathrm{~m}^{3}$ et traduit un séjour prolongé d'un groupe humain conséquent.

Le dolmen A du cairn II a servi de dernière demeure à une jeune gauloise qui y fut inhumée; la présence de cette " tombe ", malheureusement fouillée de manière assez expéditive, semble avoir en partie conditionné l'occupation des lieux et donc la distribution spatiale des vestiges telle qu'elle nous apparait : la céramique domestique est beaucoup plus rare aux abords de cette tombe, c'est-à-dire dans le cairn II et autour de celui-ci, que dans l'environnement des autres cairns, ce qui s'explique si le monument est devenu un lieu « consacré » par la présence de cette tombe. Si pratiquement tous les sites de l'Âge du Fer montrent une relation entre sépultures et habitats, le lien spatial semble se resserrer au cours de la période pour aboutir à une véritable imbrication (Tanguy et al., 1990). À La Tène finale, la presqu'île de Quiberon livre plusieurs exemples d'une telle association, sur les sites de Goulvars, Port Bara, Toul Braz, Runaron et Kergroix; elle est également révélée au Braden I à Quimper (Finistère) ainsi que sur les sites un peu plus anciens du Boisanne à Plouer-sur-Rance (Côtes-d'Armor), du Talhouët à Pluvigner (Morbihan) ou de Kerangouarec à Arzano (Finistère). La nécropole de Kerné à Quiberon offre des éléments de comparaison assez précis puisque certains des squelettes y reposaient allongés sur le côté comme la défunte de Guennoc, là aussi associés à des amas de coquilles de patelles et ornés de bracelets. Un autre caractère propre aux sépultures gauloises tardives de Bretagne est le caractère souvent sommaire voire « improvisé » de certaines d'entre elles qui ne présentent plus aucune monumentalité, ce point se vérifiant à Guennoc par le caractère opportuniste de l'utilisation du couloir d'un dolmen pour y déposer un corps que l'on a simplement dissimulé au moyen d'une dalle mégalithique.

Concernant la chronologie de l'occupation de l'île à l'Âge du Fer, la céramique donne une vision assez « compacte » de cette fréquentation, avec un mobilier relativement homogène si l'on excepte la présence - classique dans de tels lots - de quelques éléments résiduels antérieurs (céramiques à décors au poinçon notamment); le profil typo-chronologique de cette série, allié à la présence d'amphores Dressel I, tend à indiquer une datation tardive de l'ensemble mobilier (fin du II et $\mathrm{I}^{\text {er }}$ siècle av. J.-C.), si l'on rappelle la faible représentation des rebords à cannelure interne - qui sont très fines - ainsi que des jattes à profils en " $S$ ", ces dernières étant remplacées par des bols hémisphériques; mais on notera tout de même que la présence de meules rotatives en réemploi dans des constructions probablement gauloises redonne une certaine épaisseur à la durée de cette fréquentation.

\section{D'île en île}

Évoquées à plusieurs reprises, les affinités sont nombreuses entre les deux sites de l'île Guennoc à Landéda et de l'île d'Yoc'h à Landunvez, distants d'un peu plus de $12 \mathrm{~km}$ à vol d'oiseau. Territoires aujourd'hui insulaires de dimensions comparables, il s'agissait à l'époque gauloise de simples promontoires ou presqu'îles peu élevées, suffisamment accessibles cependant pour que les occupants éprouvent le besoin d'édifier un talus-rempart sur la face tournée vers le 
Continent. Il s'agissait là davantage de structurer l'espace, de contrôler les accès (des animaux en particulier) que d'établir une réelle "défense ", et l'on peut difficilement appliquer le terme "d'éperon barré " à ces deux sites que notre collègue John Collis a naguère qualifiés, non sans humour, de... « îles fortes».

Dans les deux cas, les hommes ont édifié sur ces plateaux côtiers des séries de petits bâtiments en pierres sèches d'un type maintenant bien identifié sur le littoral breton (Daire, 2004), en utilisant très largement comme carrière les sépultures mégalithiques préexistantes. L'une des différences réside dans la présence, à Guennoc, d'un enclos abritant certains bâtiments; cette structuration de l'espace peut être d'avantage liée à des pratiques agricoles (nécessité de séparer cultures et animaux d'élevage) qu'à une organisation sociale du territoire.

Sur le plan quantitatif, d'après le nombre de bâtiments reconnus et l'importance du mobilier recueilli, on peut imaginer que, dans chaque cas, ce sont quelques «familles " (une trentaine de personnes au maximum de manière synchrone) qui ont pu vivre sur ces territoires alors notablement plus étendus qu'aujourd'hui (notamment en direction de l'est), en pratiquant des activités diversifiées : probablement l'élevage de caprinés comme c'est souvent le cas sur les côtes de l'ouest de la Gaule (Baudry, 2005), mais aussi la cueillette des coquillages et la pêche à pied, comme en témoignent les $10 \mathrm{~m}^{3}$ de coquilles accumulées dans le dolmen $\mathrm{A}^{\circ} \mathrm{du}$ cairn III de l'île Guennoc; c'est là une différence taphonomique importante entre les deux sites puisqu'aucun reste organique n'était conservé sur l'île d'Yoc'h. Au titre des pratiques agricoles, nous avons également évoqué les restes de billons "fossiles " tout à fait comparables sur les deux îles et qui, sur l'île d'Yoc'h, ne peuvent que remonter à l'Âge du Fer. Des traces de cultures assez semblables dans leur organisation et dans leurs dimensions ont été mises en relation avec l'occupation pré-romaine du site de Hengisbury Head (Dorset, Grande Bretagne) (Lewis, 2002) et elles montrent que les îles léonardes recèlent sans doute un potentiel encore inexploité pour l'étude des anciennes pratiques culturales. $\mathrm{Si}$ une activité saunière a été mise en évidence sur l'île d'Yoc'h, aucun vestige de briquetages n'est en revanche signalé sur Guennoc.

Nous avons donc deux groupes humains très proches dans leurs pratiques architecturales et agricoles, dans leur manière de percevoir et de structurer l'espace, bref, dans leurs modes de vie et dans leurs cultures, s'intégrant dans le contexte plus vaste des nombreux établissements, villages et hameaux côtiers ou insulaires, mais aussi des sanctuaires littoraux qui jalonnaient le littoral de l'ouest de la Gaule à l'aube de la Conquête (Bouvet et al., 2003).
À Guennoc, comme à l'île d'Yoc'h, on peut envisager un abandon de l'île à la toute fin de l'Âge du Fer (ce qui en date absolue nous met plus probablement autour du changement d'ère, voire dans le courant du $\mathrm{I}^{\mathrm{er}}$ siècle apr. J.-C.) ; la cause de cette désertion est peut-être à chercher dans les conséquences de changements climatiques et environnementaux (eh oui, déjà!) : une montée relative du niveau marin, combinée à la possible rupture d'un isthme ou d'un tombolo, auraient progressivement isolé ces territoires du Continent et ainsi compliqué l'accès et la vie quotidienne de leurs occupants.

\section{Remerciements}

Encore une fois, un grand merci à Catherine Le Gall (documentaliste, UMR 6566) et à Odile Lecocq (documentaliste, SRA Bretagne) pour leur sympathique collaboration et leur précieuse efficacité; ma reconnaissance va également vers Charles-Tanguy Le Roux, Yves Menez et Guy San Juan, relecteurs attentifs de ce manuscrit qu'ils ont enrichi de leurs utiles remarques.

\section{Bibliographie}

BATt, M. et GiOT, P.-R., 1980 - Quelques observations d'archéologie du paysage en Finistère, Bulletin de la Société archéologique du Finistère, 108, p. 17-25.

BAUdry, A., 2005 - Approvisionnement et alimentation carnée sur les sites de l'Âge du Fer en Bretagne et en Normandie, première approche. Exemple du site de "La Campagne " à Basly (Calvados), Revue archéologique de l'Ouest, 22, p. 165-179.

Bouvet, J.-P., Daire, M.-Y., Le Bihan, J.-P., Nilesse, O. et Villard, A., 2003 - Lieux et pratiques des cultes dans l'ouest de la Gaule (Bretagne et Pays-de-la-Loire), in Arcelin, P. et Brunaux, J.-L., Cultes et sanctuaires en France à l'Age du Fer, Gallia, 60, p. 75-105.

Briard, J. et Onnée, Y., 1996 - L'Âge du Bronze à l'île Guennoc (Landéda, Finistère), Bulletin de l'AMARAI, 9, p. 31-42.

Brigand, L., 2002 - Les îles du Ponant. Histoire et géographie des îles et archipels de la Manche et de l'Atlantique, Palantines, 479 p.

Coles, J. et MinnitT, S., 1995 - "Industrious and fairly civilized", the Glastonbury Lake Village, Somerset Levels Project and Somerset County Council Museums Service, 213 p.

DaIre, M.-Y., 1983 - Lîle Guennoc en Landéda. Céramiques de l'Âge du Fer (Mémoire de DEA d'Histoire ancienne), Rennes, université de Rennes 2, reprographié.

DAIRE, M.-Y., 1985 - Céramiques armoricaines de la fin de l'Âge du Fer : essai comparatif sur quelques ensembles finistériens, Bulletin de la Société archéologique du Finistère, 114, p. 77-95.

DAIRE, M.-Y., 1990 - Archéologie insulaire en Bretagne : un point de vue sur les sites de l'Âge du Fer, in La Bretagne et l'Eu- 
rope préhistorique, Mémoire en hommage à P.-R. Giot, Revue archéologique de l'Ouest, suppl. n² 2, p. 269-278.

DAIRE, M.-Y., 1992 - Les céramiques armoricaines de la fin de l'Âge du Fer, Rennes, université de Rennes 1 (Travaux du laboratoire d'Anthropologie, 39), 316 p.

DaIre, M.-Y., 2001 - Un hameau armoricain de la fin de l'Âge du Fer sur l'île d'Yoc'h, in Collis, J. (ed.), Society and environment in Iron Age Europe. (Actes du XVIII' Colloque de l'AFEAF, Winchester 1994), Sheffield, université de Sheffield, p. 159-189.

DAIRE, M.-Y., 2004 - Architecture littorale à l'Âge du Fer : ateliers artisanaux et autres constructions, Bulletin de l'AMA$R A I, 17$, p. $55-70$.

Devolr, A., 1913-1914 - Première contribution à l'inventaire des monuments mégalithiques du Finistère, Bulletin de la Société archéologique du Finistère, $41 \& 42$ (6 articles) - réédités en tiré à part $54 \mathrm{p}$.

Du Châtellier, P., 1891 - De quelques cachettes découvertes dans le Finistère, L'Anthropologie, 2, p. 17-22.

Ducongé, S., 2007 - Les poteries du second Âge du Fer dans la grotte des Perrats à Agris (Charente), in Duval, A. et Gomez De Soto, J. (dir.), Sites et mobiliers de l'Âge du Fer entre Loire et Dordogne, Chauvigny, Association des Publications Chauvinoises (Mémoire XXIX), p. 27-29.

Earwood, C., 1993 - Domestic wooden artefacts in Britain and Ireland, from Neolithic to Viking times, Exeter, University of Exeter Press, 300 p.

Giot, P.-R., 1962 - La céramique de quelques habitats littoraux du second Âge du Fer sur la côte de la Manche, Annales de Bretagne, 69, p. 19-28.

Giot, P.-R., 1964 - Chronique de préhistoire et de protohistoire finistériennes, Bulletin de la Société archéologique du Finistère, 90, p. 276-288.

Giot, P.-R., 1967a - Chronique de préhistoire et de protohistoire finistériennes, Bulletin de la Société Archéologique du Finistère, t. 93 , p. 3-25.

Giot, P.-R., 1967b - Informations archéologiques, circonscription de Bretagne et des Pays de la Loire, Gallia Préhistoire, 10-2, p. 332-364 (cf. p. 348-351).

GIOT, P.-R., 1968 - Chronique de préhistoire et de protohistoire finistériennes, Bulletin de la Société archéologique du Finistère, 94, p. 3-18 (cf. p. 6).
Giot, P.-R., 1982 - Enez Guennoc ou Geignog, un ancien microcosme celtique. Mélanges d'archéologie et d'histoire médiévale offerts à $M$. de Boüard, Paris, Société de l'Ecole des Chartes (Mémoires et Documents, 27), p. 179-190.

Giot, P.-R., 1987 - Barnenez, Carn, Guennoc. Rennes, université de Rennes 1 (Travaux du Laboratoire "Anthropologie, Préhistoire, Protohistoire et Quaternaire armoricains »), 2 vol., 212 p. et $57 \mathrm{pl}$.

Giot, P.-R., Batt, M. et Morzadec, M.-T., 1982 - Archéologie du paysage agraire armoricain, Rennes, université de Rennes 1 (Travaux du Laboratoire d'Anthropologie, Préhistoire, Protohistoire et Quaternaire armoricains), $76 \mathrm{p}$.

Giot, P.-R. et Bourhis, J.-R., 1964 - Sur une remarquable céramique gauloise de l'île Geignog, Annales de Bretagne, 71, p. 6166.

Giot, P.- R. et Morzadec, H., 1989 - Un enclos ceinturé du second âge du Fer : Kersigneau Saint-Jean à Plouhinec (Finistère). La partie occidentale, Bulletin de la Société archéologique du Finistère, 118, p. 85-113.

Giot, P.-R., Morzadec, H., Onnée, Y. et Marguerie, D., 1991 - Un enclos ceinturé du second âge du Fer : Kersigneau SaintJean à Plouhinec (Finistère). La partie orientale, Bulletin de la Société archéologique du Finistère, 120, p. 93-104.

Le Nagard, H., 2005 - Le mobilier en lignite de l'Âge du Fer dans le massif armoricain et ses marges, Les Dossiers du CeRAA, 33 , p. 55-77.

LEWIS, H., 2002 - An investigation of ancient cultivation remains at Hengistbury Head, Site 6, Christchurch, Dorset, Proceedings of the Prehistoric Society, 68, p. 83-102.

Ménez, Y., 1999 - Les sculptures gauloises de Paule (Côtes-d'Armor), Gallia, 56, p. 357-414.

Merleau, M.-L., 2002 - La mort à Bois-Guillaume : découvertes archéologiques sur la rocade nord de Rouen, déviation de la RD 43, in Six nécropoles du second Âge du Fer en Haute Normandie, Nord-Ouest Archéologie, 13, p. 41-295.

Morzadec, H., 1995 - Pétro-archéologie des céramiques armoricaines du Néolithique à la fin de l'Âge du Fer, Rennes, université de Rennes 1 (Travaux du Laboratoire d'Anthropologie de Rennes, 41), 206 p.

Tanguy, D., Briard, J., Hyvert, J., Le Bihan, J.-P. et Ménez, Y., 1990 - Sépultures et habitats en Armorique à l'Âge du Fer. Revue archéologique de l'Ouest, suppl. n³, p. 139-152. 


\section{ANNEXE I- PLANCHES TYPOLOGIQUES DES CÉRAMI- QUES GAULOISES DE L'ÎLE GUENNOC}

Les planches présentées ici regroupent les éléments les plus significatifs de cet ensemble céramique de l'Âge du Fer inédit (car non illustré par P.-R. Giot dans sa publication de 1987), éléments classés par grandes catégories de formes (cf. fig. 16), à savoir :

- planches I et II : les pots ou récipients de stockage de moyenne contenance (pots divers de type 1, pots à anses de type 2, et bases de vases appartenant à des formes hautes de type $2 \mathrm{bis}$ );

- planche III : les récipients de stockage de grandes dimensions (jarres) (type 1);

- planches IV et $\mathrm{V}$ : les jattes moyennes ou bols (type 3);

- planche VI : céramiques décorées et formes diverses (types 4 et 5).

Les commentaires ci-après complètent la lecture des planches; ils précisent le numéro d'inventaire et la provenance de l'élément céramique et donnent un rapide descriptif suivi des dimensions éventuelles (Do = diamètre à l'ouverture, Df $=$ Diamètre du fond, $\mathrm{H}$ = hauteur).

\section{Planche I}

$\mathbf{n}^{\circ} \mathbf{1}$ - (48.7, Falaises). Haut de pot à lèvre en bourrelet réalisé dans une pâte fine; $\mathrm{Do}=14,5 \mathrm{~cm}$.

$\mathbf{n}^{\circ} \mathbf{2}$ - (34.3, Falaises). Haut de pot à décor de stries horizontales multiples, Do $=16 \mathrm{~cm}$.

$\mathbf{n}^{\circ} 3$ - (14.3, Falaises). Haut de pot à décor de deux minces cordons en relief, les surfaces ont peut être été graphitées, Do $=14 \mathrm{~cm}$.

$\mathbf{n}^{\circ} \mathbf{4}-(8.1$, Cairns I-II). Haut de pot réalisé au tour rapide, orné d'un cordon en relief et lèvre à cannelure interne; Do $=16 \mathrm{~cm}$.

$\mathbf{n}^{\circ} 5$ - (8.2, Cairns I-II). Haut de pot réalisé au tour rapide, orné d'un cordon en relief; Do $=14 \mathrm{~cm}$.

$\mathbf{n}^{\circ} \mathbf{6}$ - (10.1, Cairn I, ouest de A). Haut de pot réalisé au tour rapide, orné d'un ensemble cordon en relief et cannelures en creux; Do $=16 \mathrm{~cm}$.

$\mathbf{n}^{\circ} 7$ - (13.1 Cairn I, ouest de A). Haut de pot ovoïde, Do $=11 \mathrm{~cm}$.

$\mathbf{n}^{\circ} 8$ - (10.4 Cairn I, ouest de A). Haut de pot à décor de cannelures et cordons, Do $=20 \mathrm{~cm}$.

$\mathbf{n}^{\circ} 9$ - (40.1, Cairn III, dolmen A). Haut de pot à décor de cannelures et cordons et à surface externe graphitée; Do $=14 \mathrm{~cm}$.

$\mathbf{n}^{\circ} 10$ - (56.1, Cairn I, ouest de A). Haut de pot globuleux à col court, dont la surface externe a été soigneusement polie; $\mathrm{Do}=14 \mathrm{~cm}$. $\mathbf{n}^{\circ} 11$ - (58.1, Cairn III, ouest de B). Partie supérieure d'un pot à décor dont seul le col est graphité à l'extérieur; Do $=21 \mathrm{~cm}$.

$\mathbf{n}^{\circ} 12$ - (13.2, Cairn I, ouest de A). Haut de pot à panse sphérique ceinturée de cordons horizontaux en fort relief; Do $=14 \mathrm{~cm}$.

$\mathbf{n}^{\circ} 13$ - (31.1, Cairn III, dolmen B). Haut de pot à décor de fines cannelures horizontales; $D o=13,5 \mathrm{~cm}$.

$\mathbf{n}^{\circ} 14$ - (23.6, Cairn I, ouest de A). Haut de pot à surface externe rouge, probablement enduite à l'hématite, Do $=16 \mathrm{~cm}$.

$\mathbf{n}^{\circ} 15$ - (57.1, Cairn III, ouest de A). Haut de pot à décor d'une fine cannelure peu marquée, $D o=12 \mathrm{~cm}$.

\section{Planche II}

$\mathbf{n}^{\circ} \mathbf{1}$ - (6.1, Cairn I, dolmen C) - Haut de pot à anses à œillet, ceinturé par deux cordons horizontaux encadrés de cannelures; Do $=17 \mathrm{~cm}$.

$\mathbf{n}^{\circ} \mathbf{2}$ - (4.2, Cairn IV, nord) - Fragment de panse d'un vase à anses à oillet, dont la surface extérieure porte des traces de graphitage.

$\mathbf{n}^{\circ} 3$ - (5.1, Cairn III, dolmen D). Anse à oillet appartenant à un pot dont la surface extérieure est graphitée.

$\mathbf{n}^{\circ} \mathbf{4}$ - (4.3, Cairn III, ouest de A). Anse à œillet appartenant à un pot dont la surface extérieure est graphitée.

$\mathbf{n}^{\circ} \mathbf{5}$ - (5.3, Cairn III, dolmen B). Fragment d'anse à œeillet. $\mathbf{n}^{\circ} \mathbf{6}$ - (4.4, Cairn I, ouest de A). Fragment de petite anse à œillet arrondie d'un type original.

$\mathbf{n}^{\circ} 7,8$ et 9 - (7.1, Falaises, souterrain; 4.1, Cairn III, dolmen C; 5.4, cairn III, dolmen C). Fragments d'anses à œillet.

$\mathbf{n}^{\circ} 10$ - (71.2, Cairn I, ouest). Base de pot à panse ovoïde et à dégraissant particulièrement grossier, $\mathrm{Df}=11,5 \mathrm{~cm}$.

$\mathbf{n}^{\circ} 11$ - (62.3, Cairn III, ouest de B). Base de pot ou de bol à fond surélevé, $\mathrm{Df}=8,5 \mathrm{~cm}$.

$\mathbf{n}^{\circ} 12$ - (62.1, Cairn I-II). Base de pot à fond surélevé et piédestal, dont les parois sont graphitées, $\mathrm{Df}=9,5 \mathrm{~cm}$.

$\mathbf{n}^{\circ} 13$ et 14 - (61.1, Cairn III, dolmen A et 62.2, Cairns I-II) Bases de pots à fond légèrement surélevé et piédestal; les surfaces externes sont graphitées; Df respectifs $=8,5 \mathrm{~cm}$ et $8 \mathrm{~cm}$.

$\mathbf{n}^{\circ} 15$ - (60.2, Cairn I, ouest de A). Base de pot à fond surélevé et piédestal; Do $=9 \mathrm{~cm}$.

\section{Planche III}

$\mathbf{n}^{\circ} \mathbf{1}$ et $\mathbf{2}$ - (45.2 et 43.1, Cairn III, ouest de C). Hauts de jarres ou pots à col court et relativement fermé, dont le haut de panse est ceinturé de cannelures horizontales en creux; Do respectifs $=20 \mathrm{~cm}$. 


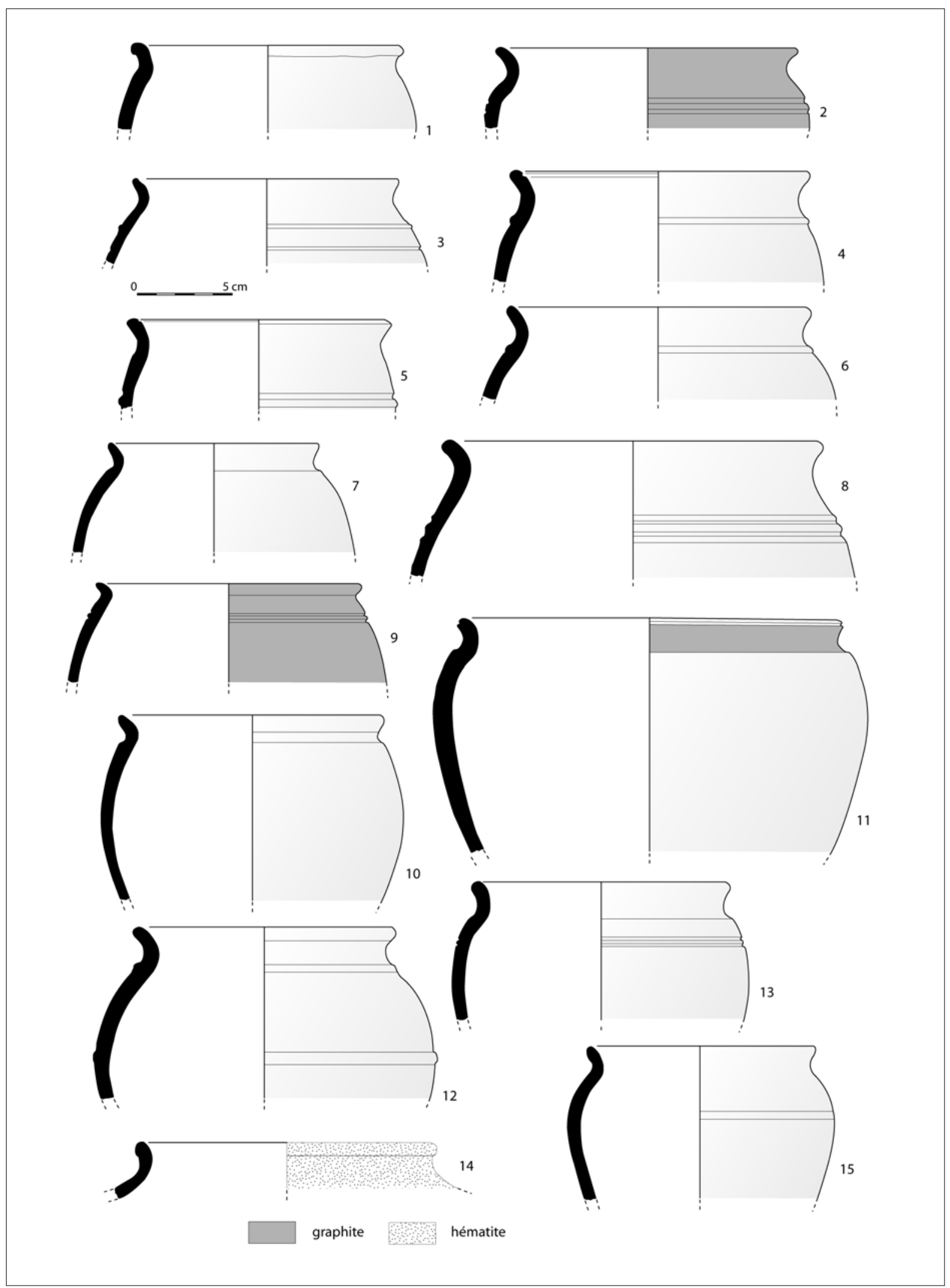

Planche I : Sélection de céramiques de l'île Guennoc - types 1 et 2 (dessin M.-Y. Daire, DAO L. Quesnel). Plate I: Sélection of ceramics from Guennoc island-types 1 \& 2. 


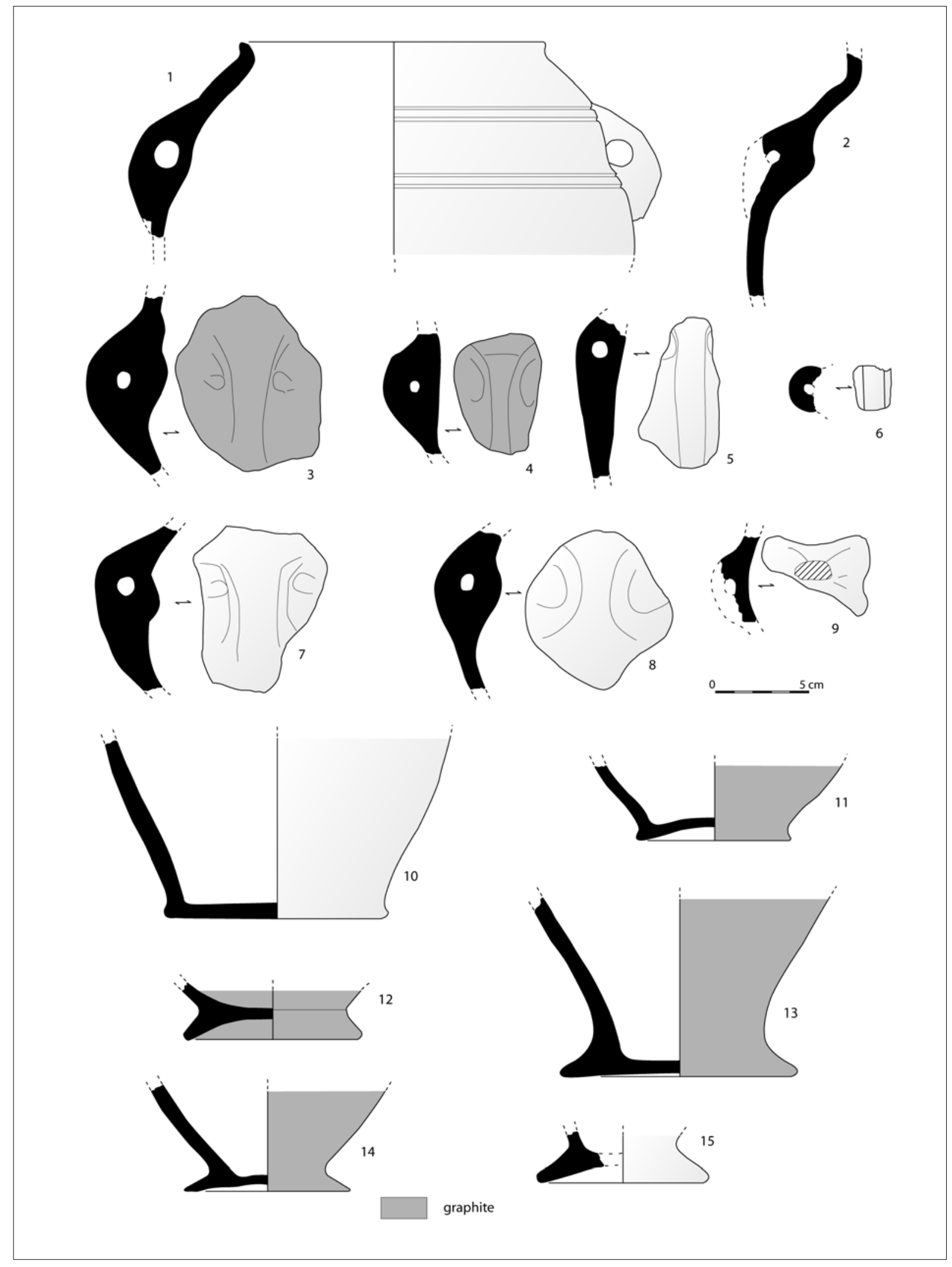

Planche II : Sélection de céramiques de l'île Guennoc : types 1 et 2, suite (dessin M.-Y. Daire, DAO L. Quesnel). Plate II: Sélection of ceramics from Guennoc island (types 1 \& 2, continued). 


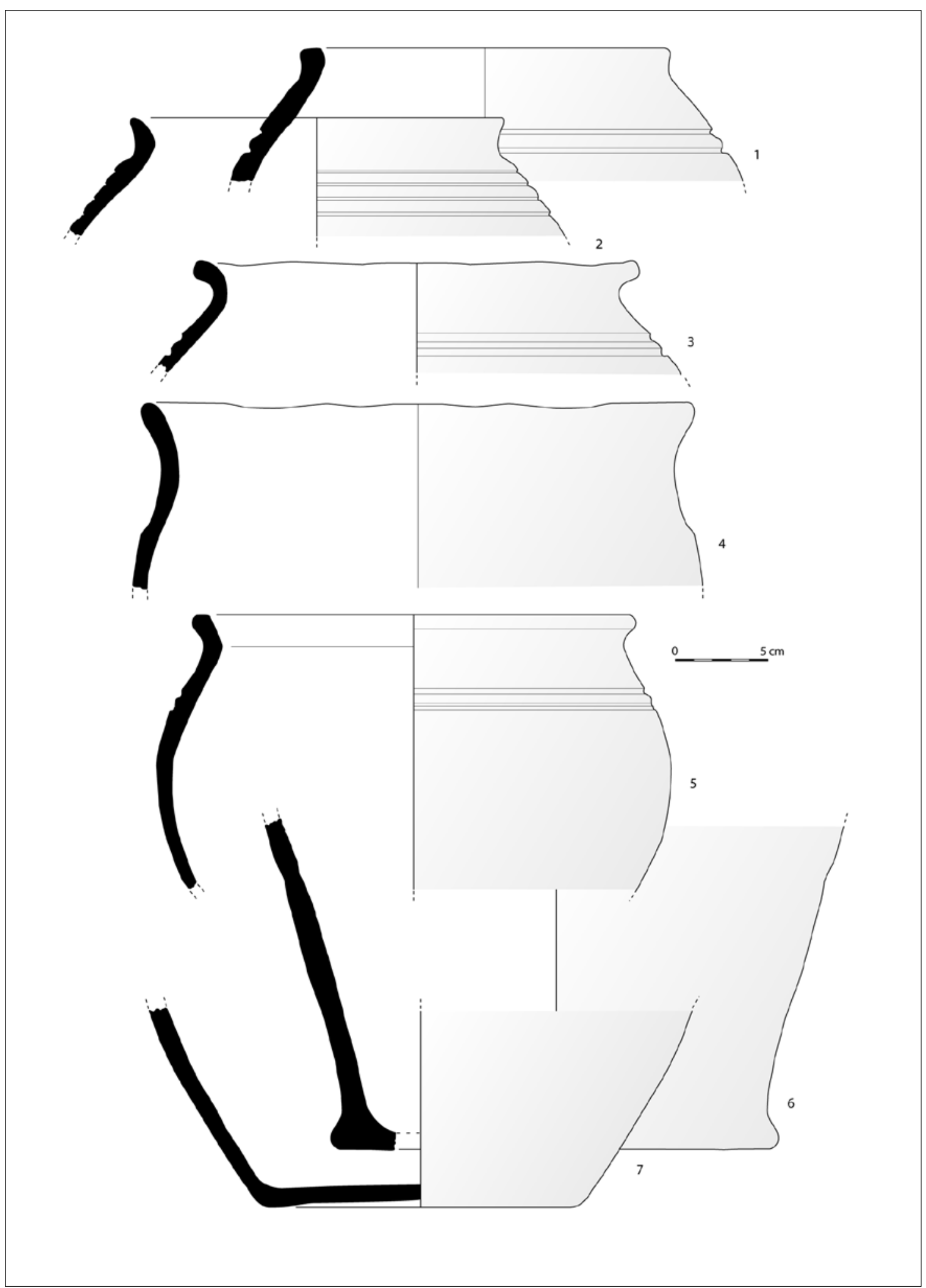

Planche III : Sélection de céramiques de l'île Guennoc, type 1 suite (dessin M.-Y. Daire, DAO L. Quesnel). Plate III: Selection of ceramics from Guennoc island (continued: type 1). 
$\mathbf{n}^{\circ} 3$ - (46.1, Falaises nord-ouest). Haut de jarre ou pot modelé, dont la panse est ceinturée de cannelures en creux; $\mathrm{Do}=24 \mathrm{~cm}$.

$\mathbf{n}^{\circ} 4$ - (59.3, Cairn I-II). Haut de jarre modelée assez grossièrement; $\mathrm{Do}=30 \mathrm{~cm}$.

$\mathbf{n}^{\circ} 5$ - (44.1, Cairn III, ouest de A). Haut de pot ou jarre à panse globuleuse, ceinturée par un cordon horizontal et une double cannelure; Do $=24 \mathrm{~cm}$.

$\mathbf{n}^{\circ} 6$ et $7-\left(72.1\right.$, Cairn III, est de $\mathrm{AA}^{\circ}$ et $\left.73.1^{\circ}\right)$. Bases de grands récipients à panses tronconiques; Do respectifs $=24 \mathrm{~cm}$ et $17 \mathrm{~cm}$.

\section{Planche IV}

$\mathbf{n}^{\circ} \mathbf{1}$ - (20.1, Falaises nord-ouest). Large bol ou jatte moyenne, à piédestal, dont la panse est ceinturée par une cannelure horizontale; la surface externe est graphitée et le col porte une perforation réalisée après cuisson. Modelée, cette céramique a été régularisée sur un tour. $\mathrm{Do}=20,5 \mathrm{~cm}$, Df $=11 \mathrm{~cm}, \mathrm{H}=15,5 \mathrm{~cm}$.

$\mathbf{n}^{\circ} \mathbf{2}-(21.3$, Cairn I, ouest de A). Petit bol à piédestal réalisé au tour rapide. $\mathrm{Do}=12,5 \mathrm{~cm}, \mathrm{Df}=7 \mathrm{~cm}, \mathrm{H}=7 \mathrm{~cm}$.

$\mathbf{n}^{\circ} 3$ - (56.2, Cairn I, ouest de A). Haut de bol à col court. Do $=16 \mathrm{~cm}$.

$\mathbf{n}^{\circ} \mathbf{4}-(22.1$, Cairn III, dolmen D). Bol à col court, dont la carène est ceinturée par une cannelure horizontale en creux. Do $=15 \mathrm{~cm}, \mathrm{Df}=7 \mathrm{~cm}, \mathrm{H}=9 \mathrm{~cm}$.

$\mathbf{n}^{\circ}$ 5, 6, 7, 9 et $10-(21.2$ et 23.1 Cairn I, ouest de A; 25.2, Cairn I-II ; 26.2, Cairn I, ouest; 21.1, Cairn I, ouest de A). Partie supérieure de jattes moyennes ou bols aux surfaces soigneusement régularisées. Do $=11 \mathrm{~cm}, 15,5 \mathrm{~cm}$, $13 \mathrm{~cm}, 12 \mathrm{~cm}, 10 \mathrm{~cm}$.

$\mathbf{n}^{\circ} \mathbf{8}$ - (25.3, Cairn I-II) Haut de bol réalisé au tour rapide dont la surface externe est enduite au graphite. Do $=13 \mathrm{~cm}$.

$\mathbf{n}^{\circ} 11$ - (30.1, Falaises). Bol au profil archéologiquement complet, réalisé grâce à un tour rapide et présentant un décor de très fines cannelures en creux dans la partie inférieure de la panse. Do $=16 \mathrm{~cm}, \mathrm{Df}=7 \mathrm{~cm}, \mathrm{H}=7,5 \mathrm{~cm}$.

\section{Planche V}

$\mathbf{n}^{\circ} \mathbf{1}$ - (24.2, Cairn III, ouest de A). Haut de large bol ou jatte dont la panse est ceinturée de deux fines cannelures horizontales en creux. Do $=21 \mathrm{~cm}$.

$\mathbf{n}^{\circ} 2$ et 4 - (36.1, Cairn III, ouest de A et 16.1, Cairns I-II). Parties supérieures de deux jattes à lèvre éversée, col court et panse globuleuse, ceinturée par des cordons en relief encadrés de cannelures en creux. Do respectifs $=14 \mathrm{~cm}$ et $16 \mathrm{~cm}$.

$\mathbf{n}^{\circ} 3$ - (19.1, Cairn III, ouest de B). Partie supérieure d'une petite jatte basse à profil en " $\mathrm{S}$ » dont la surface externe est graphitée. Do $=13,5 \mathrm{~cm}$. $\mathbf{n}^{\circ} 5$ - (26.3, Falaises ouest). Partie supérieure d'une jatte dont le profil en " $S$ " est très amorti. Do $=16 \mathrm{~cm}$.

$\mathbf{n}^{\circ} \mathbf{6}, 8$ et 10 - (34.1 Cairn I, ouest; 17.5, Cairn III, dolmen D; 34.2, Cairn I, ouest). Hauts de récipients réalisés au tour rapide dont la surface externe est graphitée et dont la panse est ceinturée de cordons encadrés de cannelures Do respectifs $=16 \mathrm{~cm}, 16 \mathrm{~cm}, 23 \mathrm{~cm}$.

$\mathbf{n}^{\circ} 7-(38.3$, Falaise ouest). Fragment de rebord de vase à lèvre à cannelure interne et décor externe d'une cannelure horizontale en creux.

$\mathbf{n}^{\circ} 9$ - (25.1, Cairn I, dolmen C). Jatte moyenne ou bol au profil archéologiquement complet dont le haut de panse est ceinturé par deux cannelures horizontales en creux. Do $=17 \mathrm{~cm}, \mathrm{Df}=9,5 \mathrm{~cm}, \mathrm{H}=10 \mathrm{~cm}$.

$\mathbf{n}^{\circ} 11$ - (60.3, Cairn III, est de $\left.\mathrm{AA}^{\circ}\right)$. Base de récipient réalisé au tour rapide, à fond surélevé, ombiliqué et à piédestal. Df $=10 \mathrm{~cm}$.

$\mathbf{n}^{\circ} 12$ - (28.1, Cairn I-II). Base de récipient de type jatte ou bol. $\mathrm{Df}=7 \mathrm{~cm}$.

\section{Planche VI}

$\mathbf{n}^{\circ} \mathbf{1}-(1.1$, Cairns I et II). Fragment de céramique portant un décor d'un triangle incisé constellé de petits points en creux.

$\mathbf{n}^{\circ} \mathbf{2}$ et 3 - (1.2 et 1.3, Cairns I et II). Fragments probables d'une même céramique dont la surface externe est de couleur rouge avec des points blancs; il pourrait s'agir d'un décor en réserve sur une enduction à l'hématite.

$\mathbf{n}^{\circ}$ 4- (2.1, Cairn III, dolmen B). Fragment de panse portant un décor estampé aux poinçons, combinant des ocelles et un motif en petite grappe stylisée. La surface externe est enduite au graphite.

$\mathbf{n}^{\circ} 5$ - (3.1, Cairn III, est de A). Fragment de vase globuleux portant un décor de cordon horizontal associé à un bandeau de chevrons réalisés au lissoir. La surface de la partie supérieure, décorée, est enduite au graphite.

$\mathbf{n}^{\circ} \mathbf{6}-(2.5$, Cairn III, ouest). Fragment inférieur de la panse d'une jatte décorée d'un cordon à l'extérieur et d'une ondulation verticale encadrée de deux traits, le tout réalisé au lissoir et appartenant probablement à un décor interne rayonnant.

$\mathbf{n}^{\circ} 7-(2.4$, Cairn IV). Fragment de céramique graphitée portant un décor de bandes obliques parallèles réalisées au lissoir.

$\mathbf{n}^{\circ} \mathbf{8}-(2.2$, Cairn IV). Base de jatte portant un décor interne rayonnant de bandes ondulées alternant avec des traits simples réalisés au lissoir.

$\mathbf{n}^{\circ} \mathbf{9}-(2.3$, Cairn IV). Base à fond surélevé à piédestal, à décor interne de stries rayonnantes réalisées au lissoir et aux surfaces graphitées. Df $=10,5 \mathrm{~cm}$. 


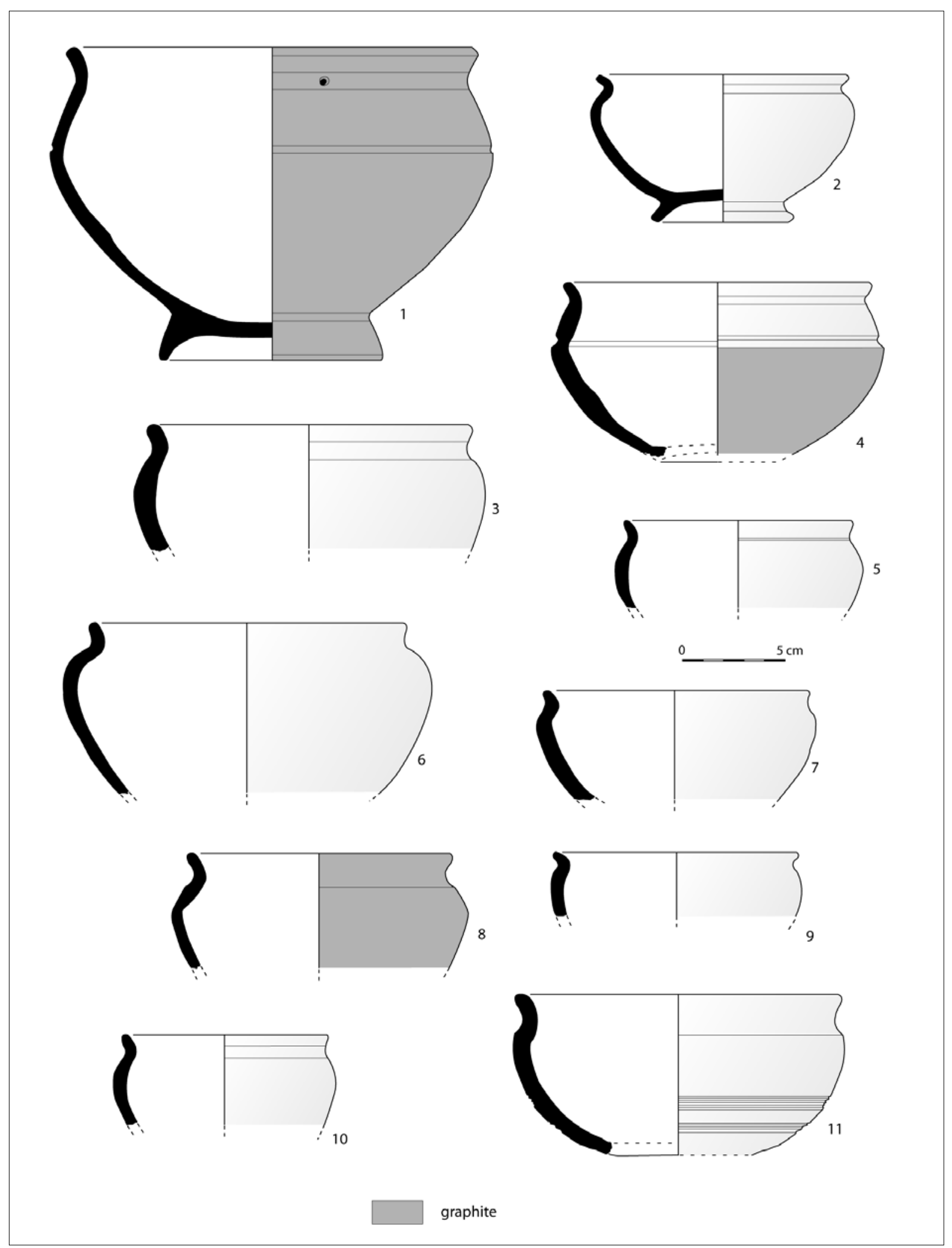

Planche IV : Sélection de céramiques de l'île Guennoc, type 3 suite (dessin M.-Y. Daire, DAO L. Quesnel). Plate IV Selection of ceramics from Guennoc island (continued: type 3). 


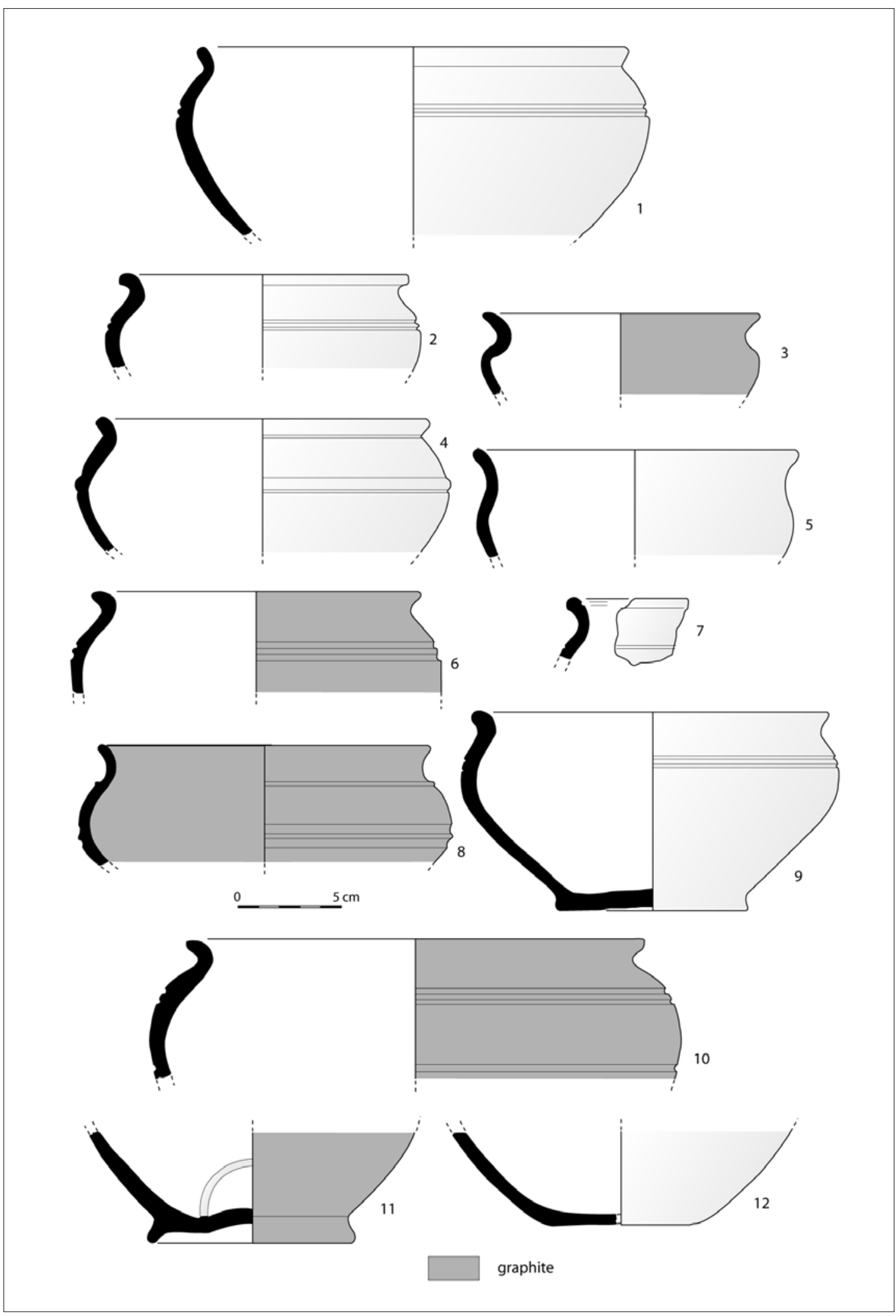

Planche V : Sélection de céramiques de l'île Guennoc : type 3, suite (dessin M.-Y. Daire, DAO L. Quesnel). Plate V: Selection of ceramics from Guennoc island (type 3, continued). 


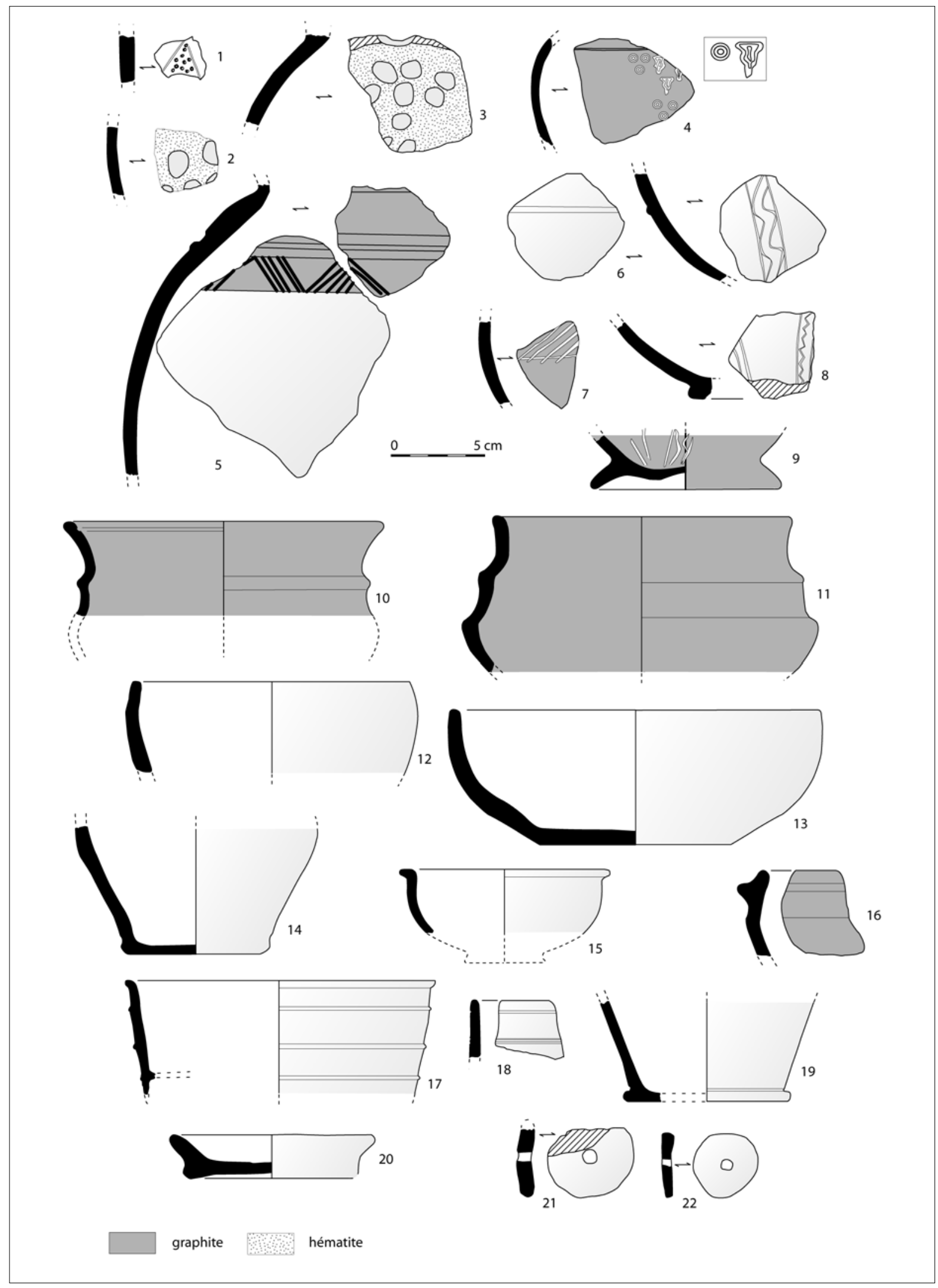

Planche VI : Sélection de céramiques de l'île Guennoc : types 4 et 5 (dessin M.-Y. Daire, DAO L. Quesnel). Plate VI: Selection of ceramics from Guennoc island: types 4 \& 5. 
$\mathbf{n}^{\circ} 10$ - (29.7, Cairn III, dolmen $\left.A^{\circ}\right)$. Haut de jatte graphitée (intérieur et extérieur) à très haut col ceinturé par un large cordon, à lèvre à cannelure interne. Do $=17 \mathrm{~cm}$.

$\mathbf{n}^{\circ} 11$ - 29.6, Cairn III, dolmen A). Haut de récipient graphité atypique au profil ondulé. Do $=16 \mathrm{~cm}$.

$\mathbf{n}^{\circ} 12$ et 13 - (75.3, Cairn III, dolmen A; 75.2, Cairn III, ouest de B). Fragments de bols modelés au profil hémisphérique. $\mathrm{Do}=15 \mathrm{~cm}$ et $20 \mathrm{~cm}$.

$\mathbf{n}^{\circ} 14$ - (75.1, Cairn III, ouest de B). Base d'un récipient modelé à profil simple et base tronconique. $\mathrm{Df}=7,5 \mathrm{~cm}$.

$\mathbf{n}^{\circ} 15$ - (26.1, Cairn III, est de C). Haut de petit bol hémisphérique réalisé au tour et à surface externe lustrée. Do $=11 \mathrm{~cm}$. $\mathbf{n}^{\circ} 16$ - (16.7, Cairn III, dolmen B). Fragment de bord à épais cordon saillant en collerette et à surface graphitée.

$\mathbf{n}^{\circ} 17$ - (18.3, Cairn III, ouest de C et D). Fragment de baquet à cordon, aux surfaces soigneusement lustrées, assez proche de l'exemplaire présenté infra. Do $=16,5 \mathrm{~cm}$.

$\mathbf{n}^{\circ} 18$ - (76.2, Cairns I-II). Fragment de bord de probable gobelet tronconique à lèvre en bourrelet.

$\mathbf{n}^{\circ} 19$ - (63.2, Cairn I, ouest). Base tronconique d'un récipient à fond plat; $\mathrm{Df}=9 \mathrm{~cm}$.

$\mathbf{n}^{\circ} 20$ - (60.1, Cairn III, ouest de A). Petite assiette soigneusement finie. $\mathrm{Do}=11 \mathrm{~cm}, \mathrm{Df}=9 \mathrm{~cm}, \mathrm{H}=2 \mathrm{~cm}$.

$\mathbf{n}^{\circ} 21$ et 22 - (5.5, Falaise ouest et 7.2, souterrain). Fusaioles réalisées dans des tessons de céramiques. 



\section{ANNEXe II}

Cette annexe complète l'article consacré à l'occupation gauloise de l'île Guennoc en présentant l'intégralité du mobilier céramique étudié en détail et dessiné, soit 450 individus représentés soit par des tessons, soit par des vases archéologiquement complets.

Cette annexe comprend :

- un tableau récapitulatif des caractéristiques de l'ensemble des tessons pris en compte dans l'étude, avec envois aux planches;

- un ensemble de 17 planches regroupant les dessins du mobilier céramique, classé par secteur de fouille ou de découverte.

Les dessins sont de M.-Y. Daire et la DAO a été réalisée par L. Quesnel.

Planche 1 - Céramiques gauloises trouvées en prospection le long des falaises de l'île.

Planche 2 - Céramiques gauloises trouvées en prospection le long des falaises de l'île.

Planche 3 - Céramiques gauloises provenant des cairns I et II.

Planche 4 - Céramiques gauloises provenant des cairns I et II.

Planche 5 - Céramiques gauloises provenant du cairn I, à l'Ouest du dolmen A.

Planche 6 - Céramiques gauloises provenant du cairn I, à l'Ouest du dolmen A.

Planche 7 - Céramiques gauloises provenant de diverses parties du cairn I.

Planche 8 - Céramiques gauloises provenant du cairn III, dolmen A.

Planche 9 - Céramiques gauloises provenant du cairn III, dolmen A.

Planche 10 - Céramiques gauloises provenant du cairn III, à l'ouest du dolmen A.

Planche 11 - Céramiques gauloises provenant du cairn III, à l'ouest du dolmen A.

Planche 12 - Céramiques gauloises provenant du cairn III, dolmen B.

Planche 13 - Céramiques gauloises provenant du cairn III, à l'ouest du dolmen B.

Planche 14 - Céramiques gauloises provenant du cairn III, à l'est des dolmens B et C.

Planche 15 - Céramiques gauloises provenant du cairn III (divers secteurs) [haut de page], et du secteur entre les cairns III et IV [bas de page].

Planche 16 - Céramiques gauloises provenant du cairn III, à l'ouest des dolmens $\mathrm{C}$ et $\mathrm{D}$ [haut de page], des sondages dans l'enclos [milieu de page] et du "souterrain " [bas de page].

Planche 17 - Céramiques gauloises provenant du cairn I, à l'ouest du dolmen A. 


\begin{tabular}{|c|c|c|c|c|c|c|c|c|c|c|c|c|c|c|}
\hline Planche & ref. mémoire & fouille & local. & nature & NB & forme & montage & $\begin{array}{c}\text { trait. } \\
\text { surface }\end{array}$ & enduction & $\begin{array}{l}\text { décor } \\
\text { interne }\end{array}$ & $\begin{array}{c}\text { décor } \\
\text { externe }\end{array}$ & $\begin{array}{c}\text { can. } \\
\text { labiale }\end{array}$ & $\begin{array}{l}\text { dia. } \\
\text { bord }\end{array}$ & $\begin{array}{l}\text { dia. } \\
\text { fond }\end{array}$ \\
\hline 1 & 11.3 & Falaises & SW & haut & 1 & pot & tour & & graphite & & cordon & & & \\
\hline 1 & 11.4 & Falaises & NW & haut & 1 & pot & & & & & cordon & & & \\
\hline 1 & 14.3 & Falaises & & haut & 1 & & & & graphite & & cordon & & 14 & \\
\hline 1 & 19.10 & Falaises & & bord & 1 & jatte & & lissage & & & & & & \\
\hline 1 & 19.11 & Falaises & & bord & 1 & jatte & & & & & & & & \\
\hline 1 & 19.12 & Falaises & & haut & 1 & jatte & & & graphite & & & & & \\
\hline 1 & 26.3 & Falaises & $w$ & haut & 1 & & & & & & & & 16 & \\
\hline 1 & 30.1 & Falaises & & entier & 1 & jatte & tour & & & & cannelures & & 16 & 7 \\
\hline 1 & 34.3 & Falaises & & haut & 1 & & & & graphite & & cannelures & & 16 & \\
\hline 1 & 34.4 & Falaises & & haut & 1 & & & & graphite & & cannelures & & & \\
\hline 1 & 34.5 & Falaises & & haut & 1 & & & & & & cannelures & & & \\
\hline 1 & 34.6 & Falaises & & haut & 1 & & & & & & cannelures & & & \\
\hline 1 & 39.6 & Falaises & SW & bord & 1 & & & & & & cannelures & & & \\
\hline 1 & 46.1 & Falaises & NW & haut & 1 & & modelé & & & & cannelures & & 24 & \\
\hline 1 & 48.7 & Falaises & & haut & 1 & & & & & & & & 14,5 & \\
\hline 1 & $49.1-2$ & Falaises & W & haut & 2 & & & & & & & & & \\
\hline 1 & 5.2 & Falaises & NW & anse & 1 & pot & & & graphite & & & & & \\
\hline 1 & 5.5 & Falaises & w & fusaĩole & 1 & & & & & & & & & \\
\hline 1 & 53.1 & Falaises & & haut & 1 & & & lissage & & & & & 21 & \\
\hline 1 & 63.1 & Falaises & & fond & 1 & & & & & & & & & 10,5 \\
\hline 1 & 63.3 & Falaises & & fond & 1 & & & & & & & & & 10 \\
\hline 1 & 70.1 & Falaises & & fond & 1 & & modelé & & & & & & & 11 \\
\hline 2 & 12.5 & Falaises & & panse & 1 & & & & graphite & & cordon & & & \\
\hline 2 & 19.7 & Falaises & sw & panse & 1 & jatte & & & $?$ & & & & & \\
\hline 2 & 19.8 & Falaises & sw & panse & 1 & jatte & & & $?$ & & & & & \\
\hline 2 & 19.9 & Falaises & sw & panse & 1 & jatte & & & & & & & & \\
\hline 2 & 26.8 & Falaises & w & haut & 1 & & & & & & cannelure & & & \\
\hline 2 & 27.1 & Falaises & & base & 1 & jatte & & & & & & & & \\
\hline 2 & 27.2 & Falaises & & base & 1 & jatte & & & & & & & & \\
\hline 2 & 28.7 & Falaises & NW & fond & 1 & & & & graphite & & & & & 11,5 \\
\hline 2 & 30.2 & Falaises & & panse & 1 & & modelé & & & & cannelures & & & \\
\hline 2 & 30.3 & Falaises & & panse & 1 & & modelé & & & & cannelures & & & \\
\hline 2 & 30.4 & Falaises & & panse & 1 & & modelé & & & & cannelures & & & \\
\hline 2 & 30.5 & Falaises & & panse & 1 & & modelé & & & & \begin{tabular}{|l|} 
cannelures \\
\end{tabular} & & & \\
\hline 2 & 30.6 & Falaises & & panse & 1 & & modelé & & & & cannelures & & & \\
\hline 2 & 30.7 & Falaises & & panse & 1 & & modelé & & & & cannelures & & & \\
\hline 2 & 33.11 & Falaises & & panse & 1 & & & & & & cannelures & & & \\
\hline 2 & 33.6 & Falaises & & panse & 1 & & & & & & cannelures & & & \\
\hline 2 & 33.7 & Falaises & & panse & 1 & & & & & & cannelures & & & \\
\hline Planche & ref. mémoire & fouille & local. & nature & NB & forme & montage & trait.surt. & enduction & $\begin{array}{l}\text { décor } \\
\text { int. }\end{array}$ & décor ext. & can. Lab. & dia. bord & dia. fond \\
\hline 2 & 33.8 & Falaises & & panse & 1 & & & & & & cannelures & & & \\
\hline 2 & 38.5 & Falaises & $w$ & panse & 1 & & & & & & cannelures & & & \\
\hline 2 & $49.3-4$ & Falaises & w & haut & 2 & & & & & & & & & \\
\hline 2 & $50.14 \cdot 16$ & Falaises & & haut & 3 & & & & & & & & & \\
\hline 2 & $53.2-6$ & Falaises & & haut & 5 & & & lissage & & & & & & \\
\hline 2 & 59.4 & Falaises & & haut & 1 & & modelé & & & & & & 20 & \\
\hline 2 & $64.1-2$ & Falaises & & fond & 2 & & & & & & & & & \\
\hline 2 & 64.3 & Falaises & & fond & 1 & & & & & & & & & 14 \\
\hline 2 & 64.4 & Falaises & & fond & 1 & & & & & & & & & 16 \\
\hline 2 & 64.5 & Falaises & & fond & 1 & & & & & & & & & 15 \\
\hline 3 & 1.1 & Caim & $1-11$ & panse & 1 & & & lissage & & & poinçonné & & & \\
\hline 3 & 1.2 et 1.3 & Cairn & $1-11$ & panse & 2 & & & & hématite & & & & & \\
\hline 3 & 15.4 & Caim & $\mid-11$ & panse & 1 & & & & & & cordon & & & \\
\hline 3 & 25.2 & Cairn & $\mid-11$ & haut & 1 & jatte & modelé & lissage & & & & & 13 & \\
\hline 3 & 25.3 & Cairn & $1-11$ & haut & 1 & jatte & tour & & graphite & & & & 13 & \\
\hline 3 & 48.1 & Caim & $1-11$ & haut & 1 & bol & & & graphite & & & & 12 & \\
\hline 3 & 48.10 & Caim & $1-11$ & bord & 1 & & & & graphite & & & & & \\
\hline 3 & 48.11 & Caim & $1-11$ & bord & 1 & & & & graphite & & & & & \\
\hline 3 & 48.12 & Caim & $\mid-\| 11$ & bord & 1 & & & & graphite & & & & & \\
\hline 3 & 48.13 & Caim & $1-11$ & bord & 1 & & & & graphite & & & & & \\
\hline 3 & 48.14 & Caim & $1-11$ & bord & 1 & & & & & & & & & \\
\hline 3 & 48.2 & Caim & $1-\|$ & bord & 1 & & & & graphite & & & & & \\
\hline 3 & 48.3 & Caim & $1-11$ & bord & 1 & & & & graphite & & & & & \\
\hline 3 & 48.4 & Caim & $1-11$ & bord & 1 & & & & graphite & & & & & \\
\hline 3 & 48.5 & Caim & $1-11$ & bord & 1 & & & & graphite & & & & & \\
\hline 3 & 48.6 & Caim & $1-11$ & bord & 1 & & & & graphite & & & & & \\
\hline 3 & $48-15$ & Caim & $\mid-\|$ & bord & 1 & & & & graphite & & & & & \\
\hline 3 & $50.1-6$ & Caim & $1-11$ & haut & 6 & & & & & & & & & \\
\hline 3 & 59.3 & Cairn & $1-11$ & haut & 1 & & modelé & & & & & & 30 & \\
\hline 3 & $76.11-13$ & Caim & $1-11$ & bord & 3 & gob. & & & & & & & & \\
\hline 3 & 76.2 & Caim & $1-11$ & haut & 1 & gob. & & & & & cannelures & & & \\
\hline 3 & 8.1 & Caim & $1-11$ & haut & 1 & pot & tour & lissage & & & cordon & fine & 16 & \\
\hline 3 & 8.2 & Cairn & $1-11$ & haut & 1 & pot & tour & lissage & & & cordon & fine & 14 & \\
\hline 3 & 8.3 & Caim & $1-11$ & lèvre & 1 & & & & & & & & & \\
\hline 4 & 12.6 & Caim & $1-\|$ & panse & 2 & & & & & & cordon & & & \\
\hline 4 & 15.1 & Caim & $1-11$ & panse & 1 & & & lissage & & & cordon & & & \\
\hline 4 & 15.13 & Caim & $1-11$ & panse & 1 & & & & graphite & & cordon & & & \\
\hline 4 & 15.2 & Caim & $\mid-\|$ & panse & 1 & & & & & & cordon & & & \\
\hline 4 & 15.3 & Cairn & $1-\|$ & panse & 1 & & & & & & cordon & & & \\
\hline
\end{tabular}




\begin{tabular}{|c|c|c|c|c|c|c|c|c|c|c|c|c|c|c|}
\hline Planche & ref. mémoire & fouille & local. & nature & NB & forme & montage & trait.surf. & enduction & $\begin{array}{l}\text { décor } \\
\text { int. }\end{array}$ & décor ext. & can. Lab. & dia. bord & dia. fond \\
\hline 4 & 15.5 & Caim & $1-\|||$ & panse & 1 & & & & graphite & & cordon & & & \\
\hline 4 & 15.6 & Caim & $1-11$ & panse & 1 & & & & graphite & & cordon & & & \\
\hline 4 & 15.7 & Caim & $1-11$ & panse & 1 & & & & graphite & & cordon & & & \\
\hline 4 & 15.8 & Caim & $1-11$ & panse & 1 & & & & graphite & & cordon & & & \\
\hline 4 & 15.9 & Caim & $1-11$ & panse & 1 & & & & graphite & & cordon & & & \\
\hline 4 & 19.17 & Caim & $|-|||$ & haut & 1 & jatte & & & graphite & & & & & \\
\hline 4 & 19.18 & Caim & $1-11$ & haut & 1 & jatte & & & graphite & & & & & \\
\hline 4 & 19.19 & Caim & $1-11$ & panse & 1 & jatte & & & graphite & & & & & \\
\hline 4 & 19.2 & Caim & $1-11$ & bord & 1 & jatte & & & graphite & & & & & \\
\hline 4 & 19.21 & Caim & $1-11$ & panse & 1 & jatte & & & graphite & & & & & \\
\hline 4 & 19.22 & Caim & $1-\| 11$ & panse & 1 & jatte & & & & & & & & \\
\hline 4 & 28.1 & Caim & $1-11$ & base & 1 & jatte & & & & & & & & 7 \\
\hline 4 & 28.2 & Caim & $1-11$ & base & 1 & jatte & & & graphite & & & & & \\
\hline 4 & 28.3 & Caim & $1-11$ & base & 1 & jatte & & & graphite & & & & & \\
\hline 4 & 28.4 & Caim & $1-11$ & base & 1 & jatte & & & graphite & & & & & \\
\hline 4 & 28.5 & Caim & $1-11$ & fond & 1 & & & & graphite & & & & & 7 \\
\hline 4 & 35.1 & Caim & $1-11$ & panse & 1 & & & & & & cannelures & & & \\
\hline 4 & 35.2 & Caim & $1-11$ & panse & 1 & & & & & & cannelures & & & \\
\hline 4 & 35.3 & Caim & $1-11$ & panse & 1 & & & & & & cannelures & & & \\
\hline 4 & 35.7 & Caim & $1-11$ & panse & 1 & & modelé & & & & & & & \\
\hline 4 & 35.8 & Caim & $1-11$ & panse & 1 & & & & & & cannelures & & & \\
\hline 4 & 62.1 & Caim & $1-11$ & fond & 1 & pied. & & & graphite & & & & & 9,5 \\
\hline 4 & 62.2 & Caim & $1-\| 11$ & fond & 1 & & modelé & & & & & \multicolumn{2}{|c|}{ sommitale } & 9 \\
\hline 4 & 70.4 & Caim & $|-|||$ & fond & 1 & & modelé & & & & & & & \\
\hline 4 & 70.5 & Caim & $1-11$ & fond & 1 & & Modelé & & & & & & & 16 \\
\hline 4 & 70.6 & Caim & $1-|| \mid$ & fond & 1 & & Modelé & & & & & & & 9 \\
\hline 4 & 73.1 & Caim & $1-11$ & fond & 1 & & modelé & & & & & & & 17 \\
\hline 4 & 74.1 & Caim & $1-11$ & fond & 1 & & modelé & & & & & & & 10 \\
\hline 4 & 74.2 & Caim & $|-|||$ & fond & 1 & & modelé & & & & & & & 11 \\
\hline 5 & 10.2 & Caim & IWA & haut & 1 & pot & & & hématite & & & & & \\
\hline 5 & 13.1 & Caim & IWA & haut & 1 & pot & & & & & cordon & & 11 & \\
\hline 5 & 13.2 & Caim & IWA & haut & 1 & pot & & & & & cordon & & 14 & \\
\hline 5 & 21.1 & Caim & IWA & haut & 1 & jatte & & lustrage & & & & & 10 & \\
\hline 5 & 21.2 & Caim & IWA & haut & 1 & jatte & & Iustrage & & & cannelure & & 11 & \\
\hline 5 & 21.3 & Caim & IWA & entier & 1 & jatte & tour & & & & & & 12,5 & 7 \\
\hline 5 & 23.1 & Caim & IWA & entier & 1 & jatte & & & & & & & 15,5 & \\
\hline 5 & 23.6 & Caim & IWA & haut & 1 & & & & hématite & & & & 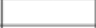 & \\
\hline 5 & 51.1 & Caim & IWA & haut & 1 & & & & & & & & 15 & \\
\hline 5 & 51.2 & Caim & IWA & haut & 1 & & & & & & cannelures & & 20 & \\
\hline Planche & ref. mémoire & touille & local. & nature & NB & forme & montage & trait.surf. & enduction & $\begin{array}{l}\text { décor } \\
\text { int. }\end{array}$ & décor ext. & can. Lab. & dia. bord & dia. fond \\
\hline 5 & 56.1 & Cairn & IWA & haut & 1 & & & polis. & & & & & 14 & \\
\hline 5 & 56.2 & Cairn & IWA & haut & 1 & & & & & & & & 16 & \\
\hline 6 & 10.1 & Cairn & IWA & haut & 1 & pot & tour & & & & cordon & & 16 & \\
\hline 6 & 10.3 & Caim & IWA & haut & 1 & pot & & & & & cordon & & & \\
\hline 6 & 10.4 & Caim & IWA & haut & 1 & pot & & & & & cannelures & & 20 & \\
\hline 6 & 13.3 & Caim & IWA & panse & 1 & & & lissage & & & cordon & & & \\
\hline 6 & 13.4 & Cairn & IWA & panse & 1 & & & & & & cordon & & & \\
\hline 6 & 13.5 & Caim & IWA & panse & 1 & & & & & & cordon & & & \\
\hline 6 & 23.2 & Caim & IWA & col & 1 & & & & & & & & & \\
\hline 6 & 23.4 & Caim & IWA & haut & 1 & & & & graphite & & & & & \\
\hline 6 & 24.3 & Caim & IWA & panse & 1 & & & & & & cannelure & & & \\
\hline 6 & 32.3 & Caim & IWA & panse & 1 & & & & hématite? & & & & & \\
\hline 6 & 4.1 & Cairn & IWA & anse & 1 & pot & & & & & & & & \\
\hline 6 & 4.4 & Cairn & IWA & anse & 1 & pot & & & & & & & & \\
\hline 6 & 60.2 & Caim & IWA & fond & 1 & pied. & & lissage & & & & & & 9 \\
\hline 6 & 66.1 & Caim & IWA & fond & 1 & & & & & & cannelures & & & 10 \\
\hline 6 & 71.1 & Caim & IWA & fond & 1 & & modelé & & & & & & & 11,5 \\
\hline 6 & 71.2 & Caim & IW & fond & 1 & & & & & & & & & 11,5 \\
\hline 7 & 11.5 & Caim & IW & haut & 1 & pot & \multicolumn{2}{|l|}{ colombin } & & & cordon & & & \\
\hline 7 & 11.7 & Caim & IW & haut & 1 & pot & & & & & cordon & & & \\
\hline 7 & 16.1 & Caim & IB & haut & 1 & & tour & & & & cordon & & 16 & \\
\hline 7 & 16.2 & Caim & IW & panse & 1 & & tour & & & & cordon & & & \\
\hline 7 & 24.1 & Caim & IW & haut & 1 & jatte & & & & & cannelure & & 20 & \\
\hline 7 & 26.2 & Caim & IW & haut & 1 & jatte & & & & & & & 12 & \\
\hline 7 & 26.6 & Caim & IB & haut & 1 & jatte & & & & & & & & \\
\hline 7 & 34.1 & Caim & IW & haut & 1 & & & & graphite & & cannelures & & 16 & \\
\hline 7 & 34.2 & Caim & IW & haut & 1 & & & & graphite & & cannelures & & 23 & \\
\hline 7 & 40.3 & Caim & IB & haut & 1 & & & & & & cannelures & & 16 & \\
\hline 7 & 46.2 & Caim & $1-11$ & panse & 1 & & & & & & cannelures & & & \\
\hline 7 & $48-16$ & Caim & $1-11$ & bord & 1 & & & & graphite & & & & 15 & \\
\hline 7 & 55.1 & Caim & IB & haut & 1 & & & & & & & fine & & \\
\hline 7 & 6.1 & Caim & IC & haut & 1 & pot & & & & & cordons & & 17 & \\
\hline 7 & 63.2 & Caim & IW & fond & 1 & & & & & & & & & 9 \\
\hline 8 & 17.2 & Caim & III A & haut & 1 & & tour & lustrage & graphite & & cordon & & & \\
\hline 8 & 17.4 & Caim & III A & panse & 1 & & & & $?$ & & cordon & & & \\
\hline 8 & 19.15 & Caim & III A & bord & 1 & & & & & & & fine & & \\
\hline 8 & 27.3 & Caim & III $A^{\circ}$ & base & 1 & jatte & & & & & & & & 11 \\
\hline 8 & 28.6 & Caim & III A & fond & 1 & & tour & & & & cannelure & & & 12.5 \\
\hline 8 & 29.1 & Caim & III A & panse & 1 & jatte & & & & & & & & \\
\hline
\end{tabular}




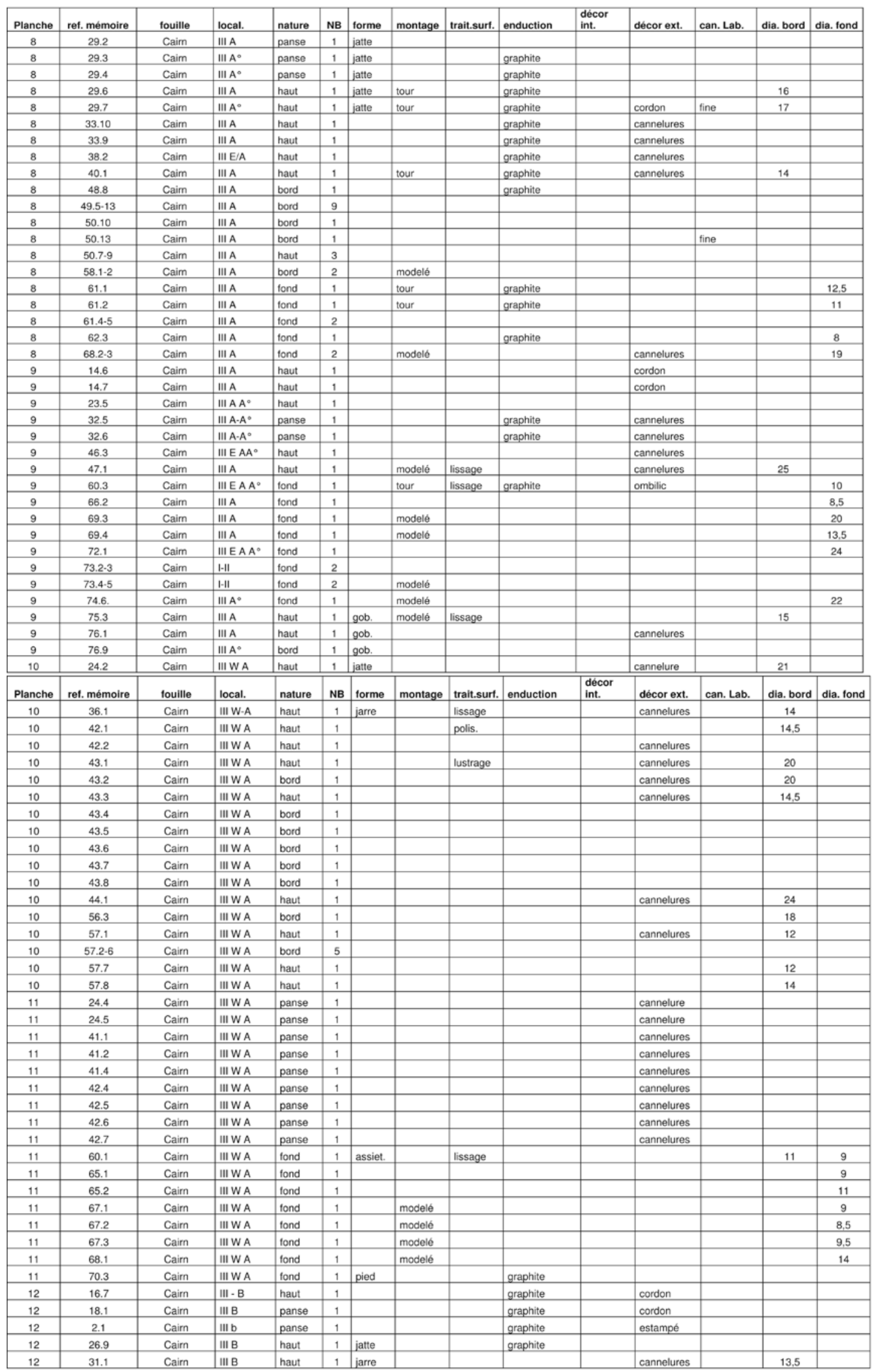




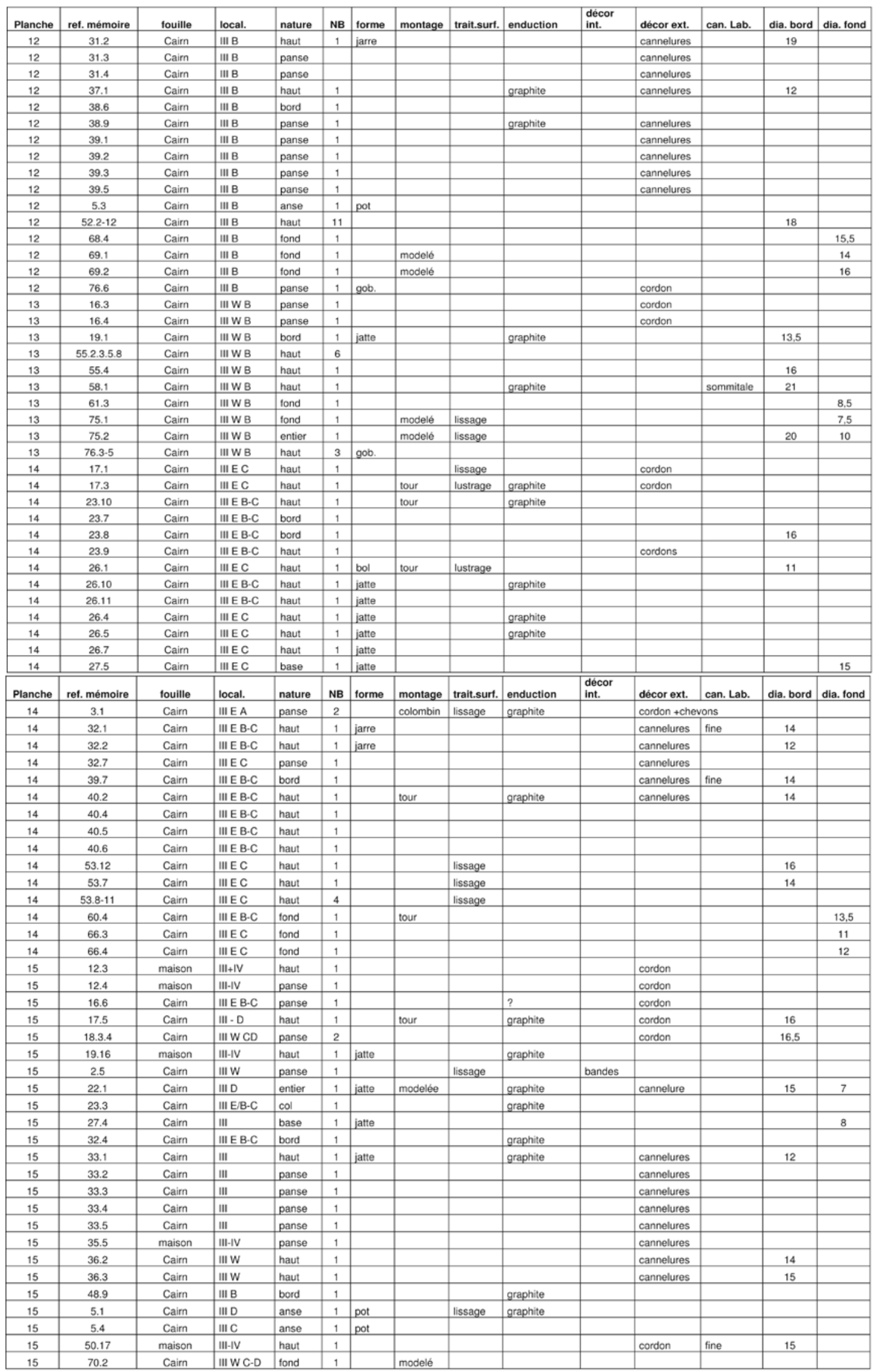




\begin{tabular}{|c|c|c|c|c|c|c|c|c|c|c|c|c|c|c|}
\hline Planche & ref. mémoire & fouille & local. & nature & NB & forme & montage & trait.surf. & enduction & $\begin{array}{l}\text { décor } \\
\text { int. }\end{array}$ & décor ext. & can. Lab. & dia. bord & dia. fond \\
\hline 15 & 76.8 & Cain & III C & panse & 1 & & & & & & cannelures & & & \\
\hline 16 & 11.1 & Enclos & SE & panse & 1 & pot & & & engobe? & & cordon & & & \\
\hline 16 & 11.2 & Enclos & $\mathrm{SE}$ & haut & 1 & pot & & & graphite & & cordon & & & \\
\hline 16 & 11.6 & Enclos & SE & base & 1 & pot & & & graphite & & cordon & & & \\
\hline 16 & 12.1 & Falaises & souterrain & haut & 1 & pot & & & graphite & & cordon & & & \\
\hline 16 & 12.2 & Falaises & souterrain & haut & 1 & pot & colombin & & & & cordon & & & \\
\hline 16 & 19.13 & Enclos & SE & haut & 1 & jatte & & & graphite & & & & & \\
\hline 16 & 19.6 & Caim & IIIWC & panse & 1 & jatte & & & $?$ & & & & & \\
\hline 16 & 35.6 & Caim & III WC & panse & 1 & & & & & & & & & \\
\hline 16 & 38.7 & Enclos & SE & bord & 1 & & & & & & & & & \\
\hline 16 & 45.1 & Caim & III WC & haut & 1 & & & & & & cannelures & & 18 & \\
\hline 16 & 45.2 & Caim & III WC & haut & 1 & & & & & & cannelures & & 20 & \\
\hline 16 & 45.3 & Cairn & III WC & panse & 1 & & & & & & cannelures & & & \\
\hline 16 & 54.1 & Caim & III WC & haut & 1 & & & & graphite & & & & 11 & \\
\hline 16 & 54.2 & Caim & III WC & haut & 1 & & & & & & & & 14 & \\
\hline 16 & 54.3 & Cain & IIWC & haut & 1 & & & lustrage & & & & & 16 & \\
\hline 16 & 54.4 & Caim & III WC & haut & 1 & & & & & & cannelures & fine & 16 & \\
\hline 16 & 54.5 & Caim & III W C & fond & 1 & & & & & & cannelures & & & 10 \\
\hline 16 & 55.9 & Falaises & souterrain & haut & 1 & & & & & & & & & \\
\hline 16 & 7.1 & Falaises & souterrain & anse & 1 & & & lissage & & & & & & \\
\hline 16 & 7.2 & Falaises & souterrain & fusaiole & 1 & & & & & & & & & \\
\hline 16 & 70.7 & Falaises & souterrain & fond & 1 & pied & & & graphite & & & & & 11 \\
\hline 16 & 76.10 & Cain & III WC & bord & 1 & gob. & & & & & cannelures & & & \\
\hline 17 & 14.1 & Caim & IV & haut & 1 & & & & & & cordon & & & \\
\hline 17 & 14.2 & Caim & IV & haut & 1 & & & & & & cordon & & & \\
\hline 17 & 14.4 & Caim & IV Parmt & haut & 1 & & & & & & cordon & & & \\
\hline 17 & 14.5 & Caim & IV Parmt & haut & 1 & & & & & & cordon & & & \\
\hline 17 & 2.2 & Cain & IV & base & 1 & & & & engobe & bandes & & & & \\
\hline 17 & 2.3 & Caim & IV & base & 1 & & & & graphite & bandes & & & & 10,5 \\
\hline 17 & 2.4 & Caim & IV & panse & 1 & & & & graphite & & \multicolumn{2}{|c|}{ bandes lissées } & & \\
\hline 17 & 36.4 & Caim & IV Parmt & bord & 1 & & & & & & & & 12.5 & \\
\hline 17 & 37.2 & Caim & IV & haut & 1 & & & & & & & & 16 & \\
\hline 17 & 37.3 & Caim & IV & haut & 1 & & & & & & \begin{tabular}{|l} 
cannelures \\
\end{tabular} & & 20 & \\
\hline 17 & 37.4 & Caim & IV Parmt & haut & 1 & & & & & & \begin{tabular}{|l|} 
cannelures \\
\end{tabular} & & 10 & \\
\hline 17 & 38.1 & Caim & IV nord & haut & 1 & & & & & & \begin{tabular}{|c|} 
cannelures \\
\end{tabular} & & 20 & \\
\hline 17 & 38.4 & Caim & IV nord & haut & 1 & & modelé & & & & cannelures & & & \\
\hline 17 & 38.8 & Caim & IV & bord & 1 & & & & & & & & & \\
\hline 17 & 4.2 & Caim & IV N & haut & 1 & pot & & & graphite & & & & & \\
\hline 17 & 52.1 & Cain & IV W & haut & 1 & & & & & & & & 14 & \\
\hline Planche & ref. mémoire & fouille & local. & nature & NB & forme & montage & trait.surf. & enduction & $\begin{array}{l}\text { décor } \\
\text { int. }\end{array}$ & décor ext. & can. Lab. & dia. bord & dia. fond \\
\hline \multirow[t]{32}{*}{17} & 68.5 & Caim & IV & fond & 1 & & modelé & & & & & & & 10 \\
\hline & 15.10 & Caim & I-1I & panse & 1 & & & & graphite & & cordon & & & \\
\hline & 15.11 & Caim & $1-11$ & panse & 1 & & & & graphite & & cordon & & & \\
\hline & 15.12 & Caim & $1-\| 11$ & panse & 1 & & & & graphite & & cordon & & & \\
\hline & 16.5 & Caim & IV Parmt & haut & 1 & & & & $?$ & & cordon & externe & & \\
\hline & 17.6 & Caim & III W/CD & haut & 1 & & tour & & & & cordon & & 20 & \\
\hline & 18.2 & Caim & III WA & panse & 1 & & & & & & cordon & & & \\
\hline & 19.14 & Falaises & NW & bord & 1 & & & & & & & & & \\
\hline & 19.20 & Caim & $1-11$ & panse & 1 & jatte & & & graphite & & & & & \\
\hline & 19.3 & Caim & III W B & bord & 1 & jatte & & & lustrage & & & & & \\
\hline & 19.4 & Caim & III W B & bord & 1 & jatte & & & Iustrage & & & & & \\
\hline & 19.5 & Caim & III W B & bord & 1 & jatte & & & graphite & & & & & \\
\hline & 20.1 & Falaises & NW & entier & 1 & jatte & modelé & & graphite & & cannelure & & 20,5 & 11 \\
\hline & 22.2 & Caim & IIIA & panse & 1 & jatte & & & graphite & & cannelure & fine & & \\
\hline & 25.1 & Caim & IC & entier & 1 & jatte & modelé & & & & cannelure & & 17 & 9,5 \\
\hline & 29.5 & Caim & III W B & bord & 1 & jatte & & & & & & & & \\
\hline & 30.8 & Falaises & & panse & 1 & & modelé & & & & cannelures & & & \\
\hline & 35.4 & Caim & $1-11$ & panse & 1 & & & & & & cannelures & & & \\
\hline & 38.3 & Falaise & w & haut & 1 & & & & & & cannelures & fine & & \\
\hline & 39.4 & Caim & III B & bord & 1 & & & & & & cannelures & & & \\
\hline & 4.3 & Caim & III W A & anse & 1 & pot & & & graphite & & & & & \\
\hline & 41.3 & Caim & III WA & panse & 1 & & & polis. & & & & & & \\
\hline & 41.5 & Caim & IIIWA & fond & 1 & & & & & & & & 20 & \\
\hline & 42.3 & Caim & III W A & panse & 1 & & & & & & cannelures & & & \\
\hline & 50.11 & Caim & III W/CD & bord & 1 & & & & & & & & & \\
\hline & 50.12 & Caim & III WA & bord & 1 & & & & graphite & & & & & \\
\hline & 51.3 & Caim & IIIA & base & 1 & & & & & & & & & 14.5 \\
\hline & 62.4 & Caim & III A & fond & 1 & & & & graphite & & & & & 11 \\
\hline & 65.3 & Caim & III WA & fond & 1 & & & & & & & & & \\
\hline & 74.3.4.5. & Caim & III A & fond & 3 & & modelé & & graphite & & & & & \\
\hline & 76.7 & Caim & IIIEC & panse & 1 & & & & & & & & & \\
\hline & 9.1 & Caim & III WA & haut & 1 & pot & & lustrage & & & cordon & & 12 & \\
\hline
\end{tabular}



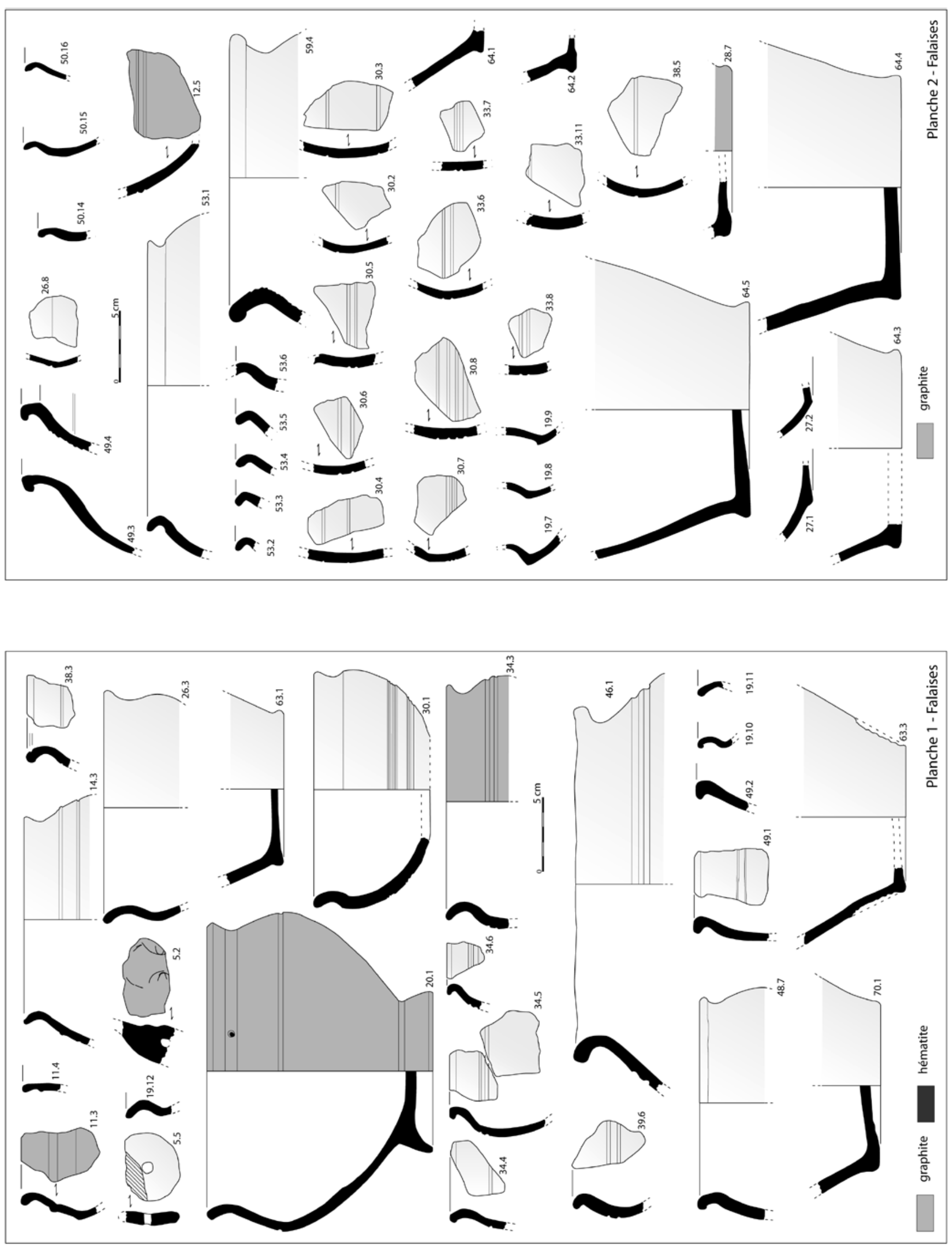

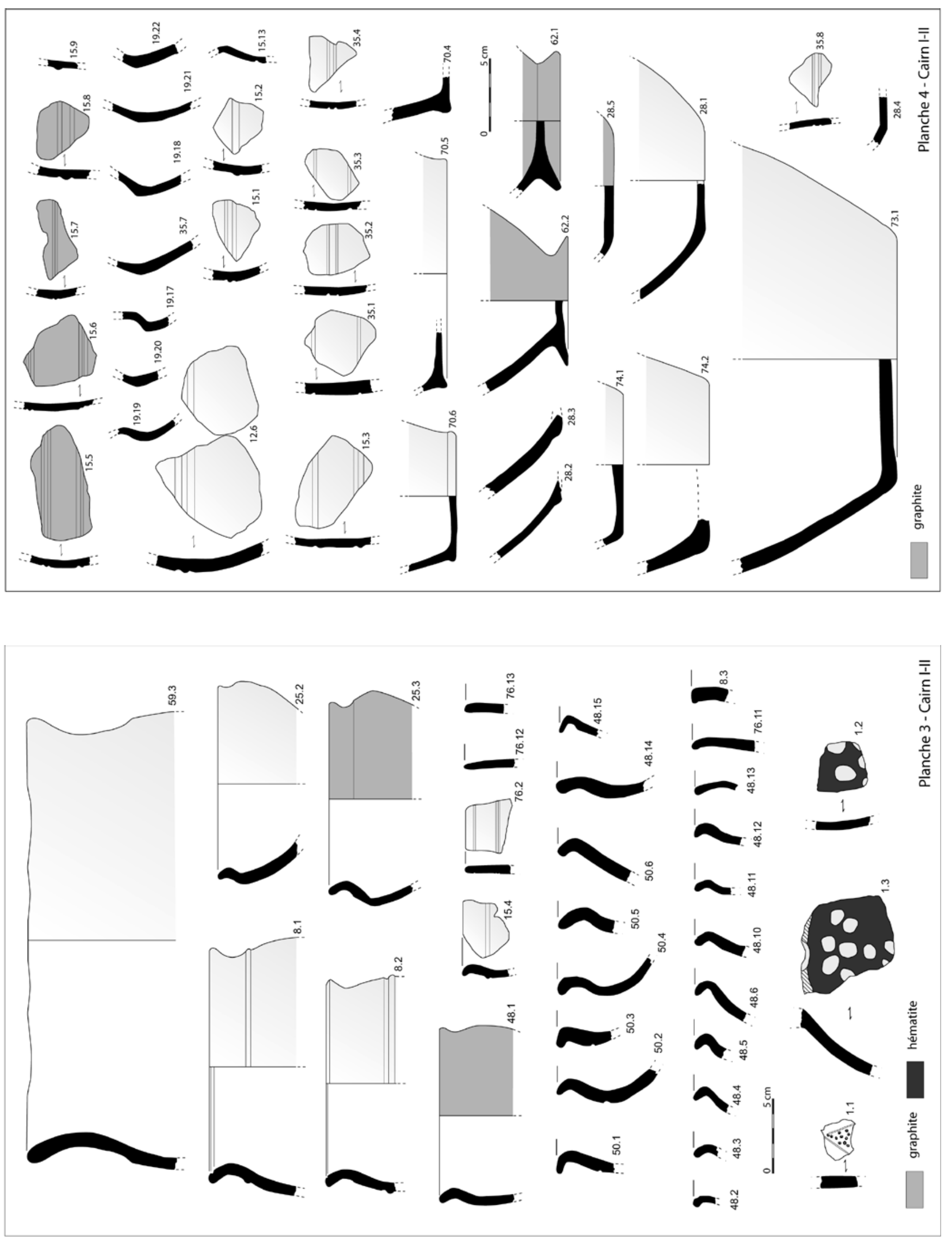

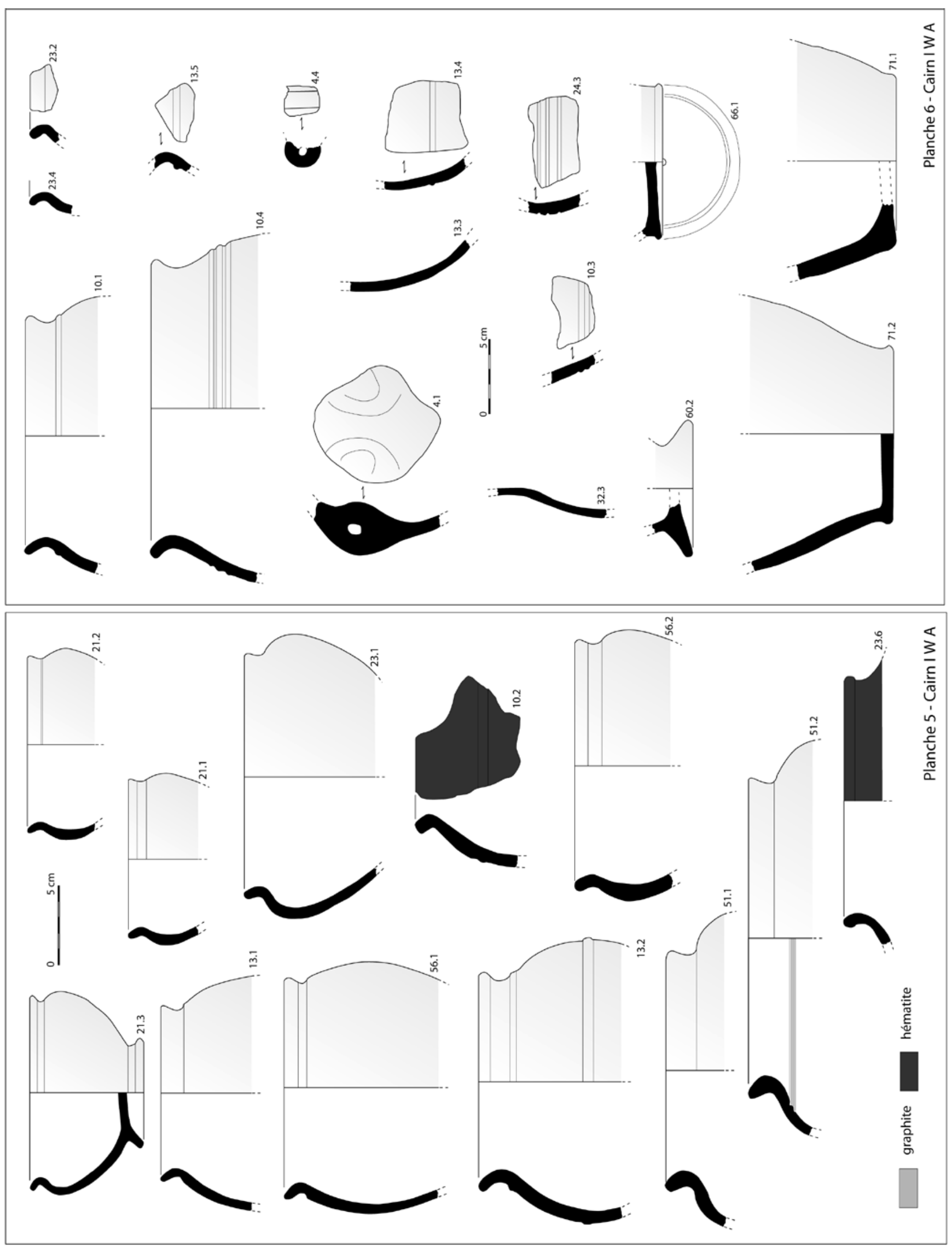

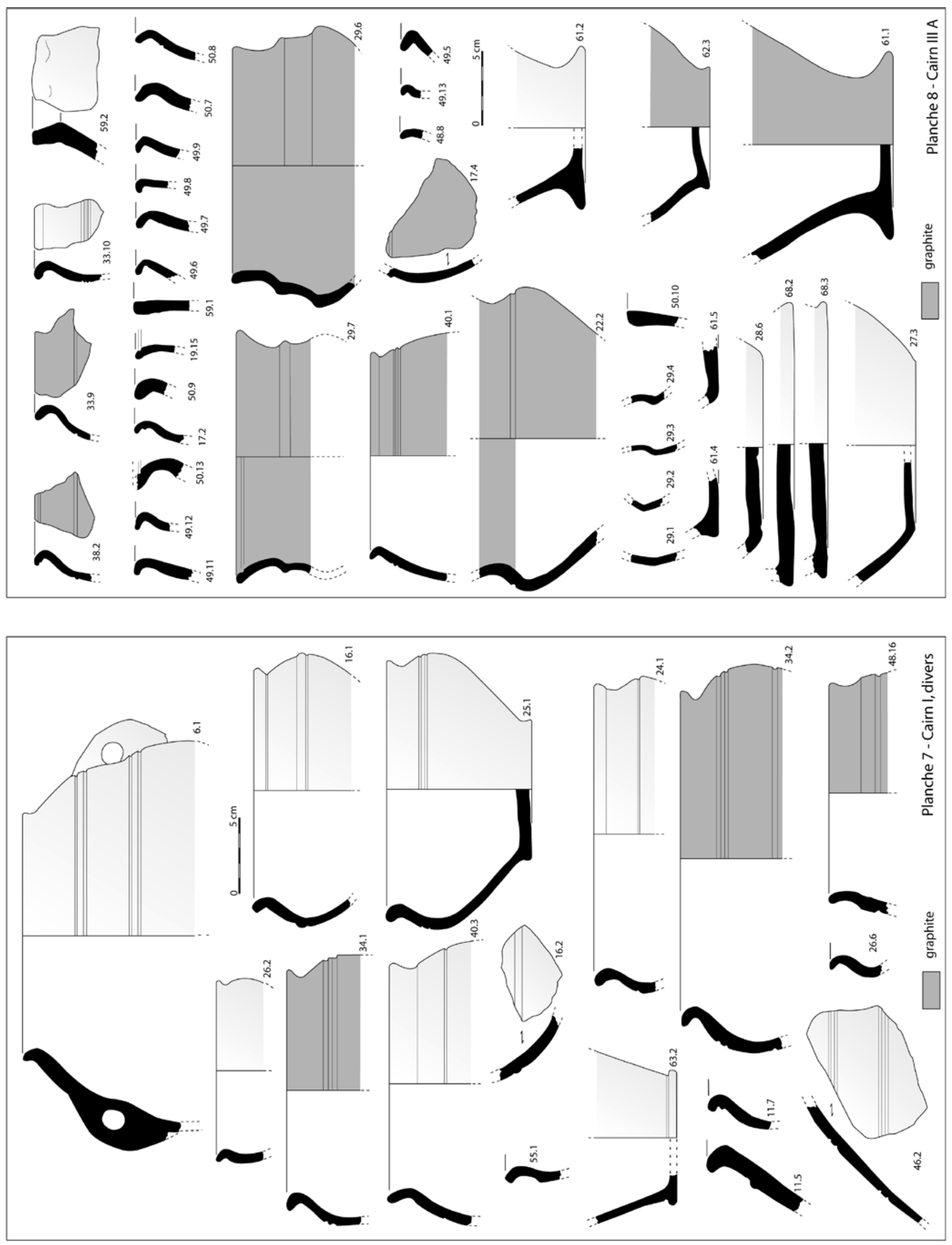

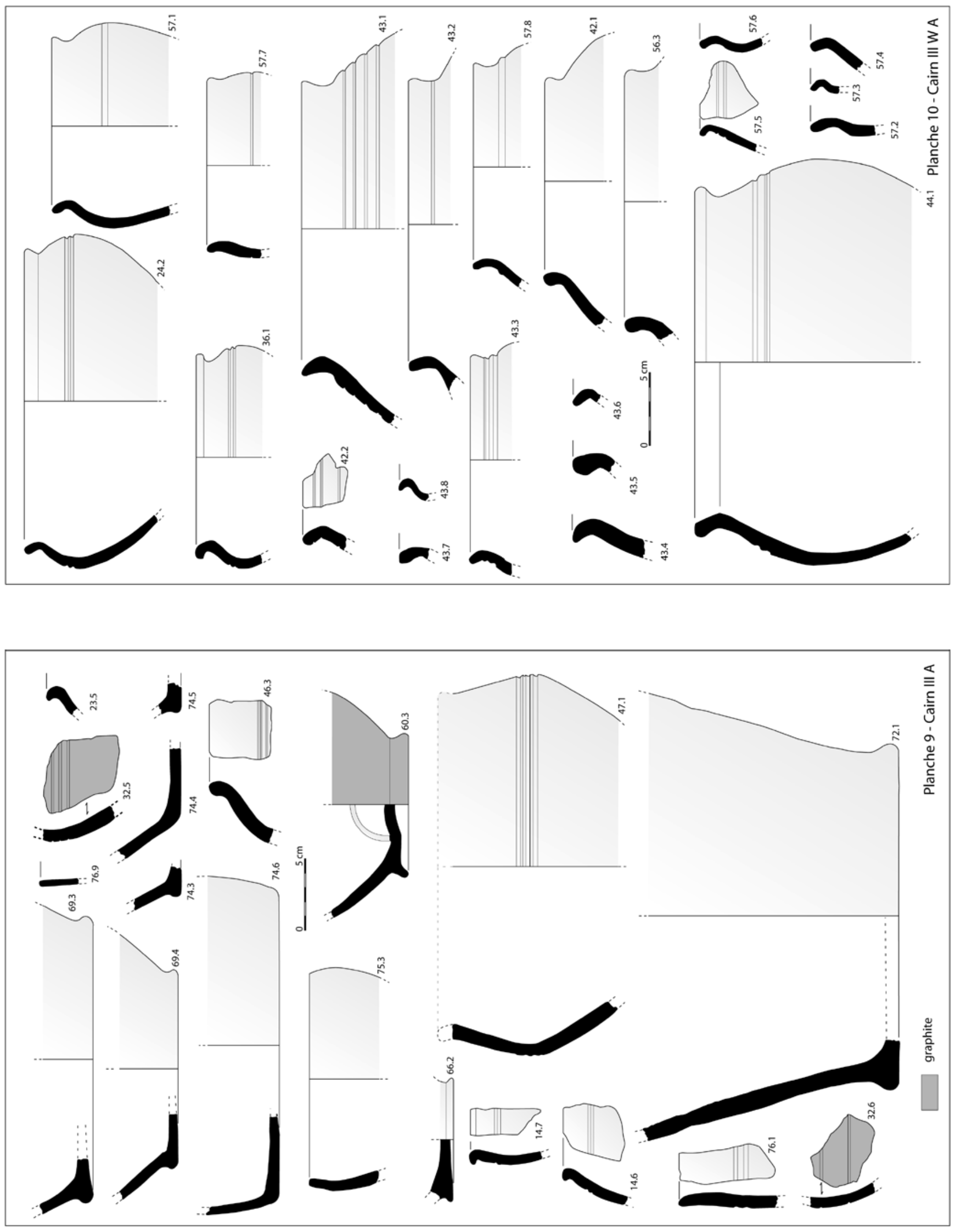

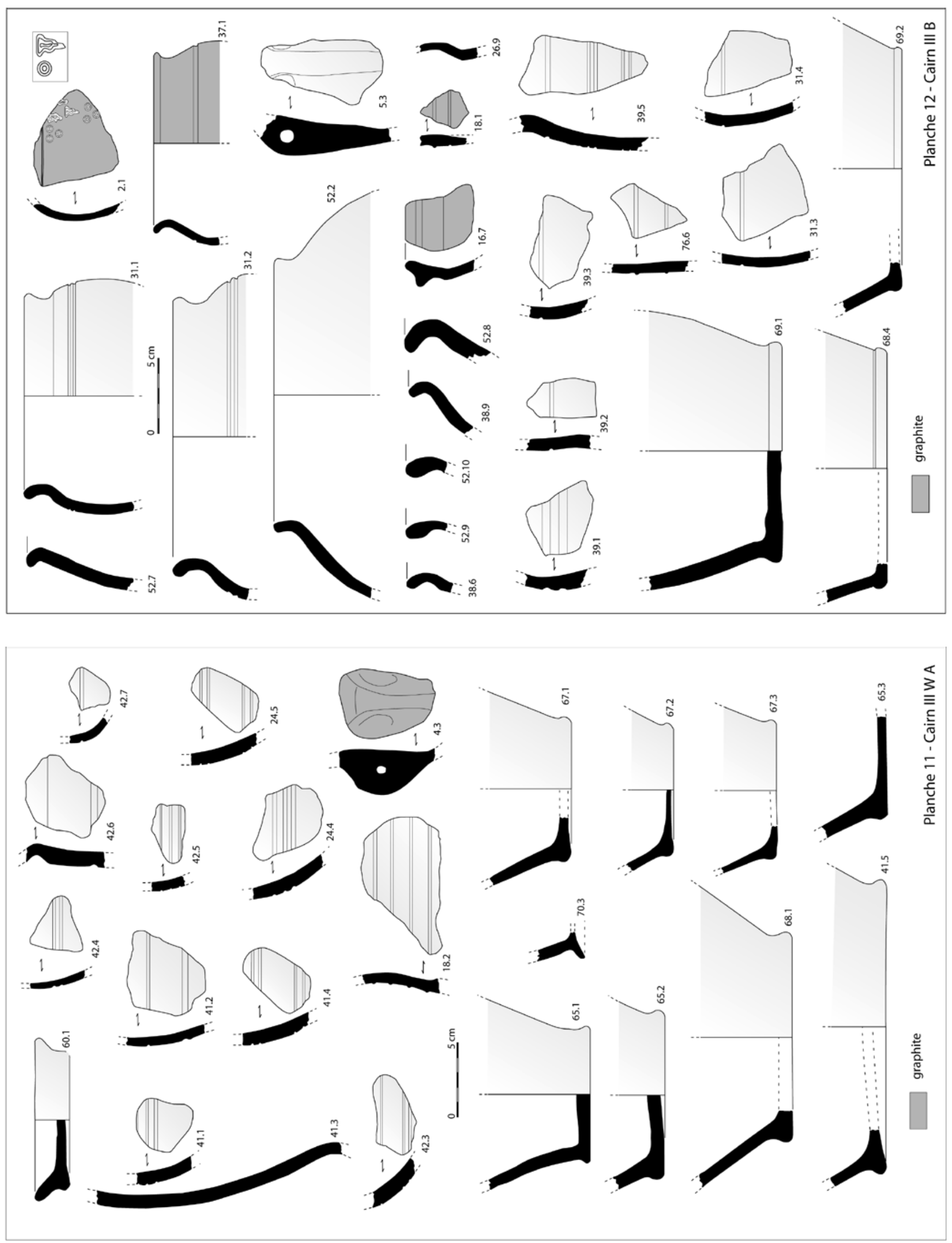

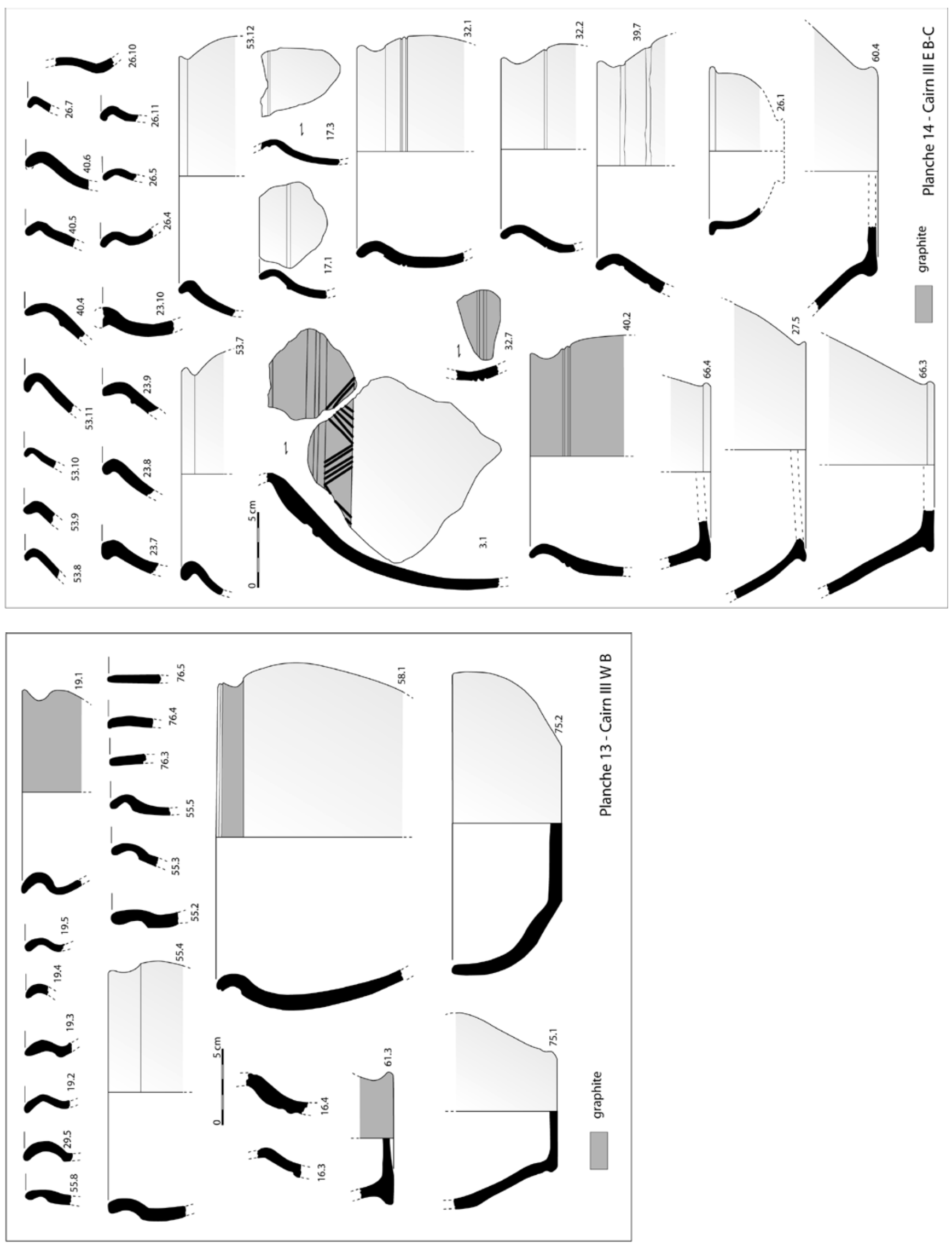


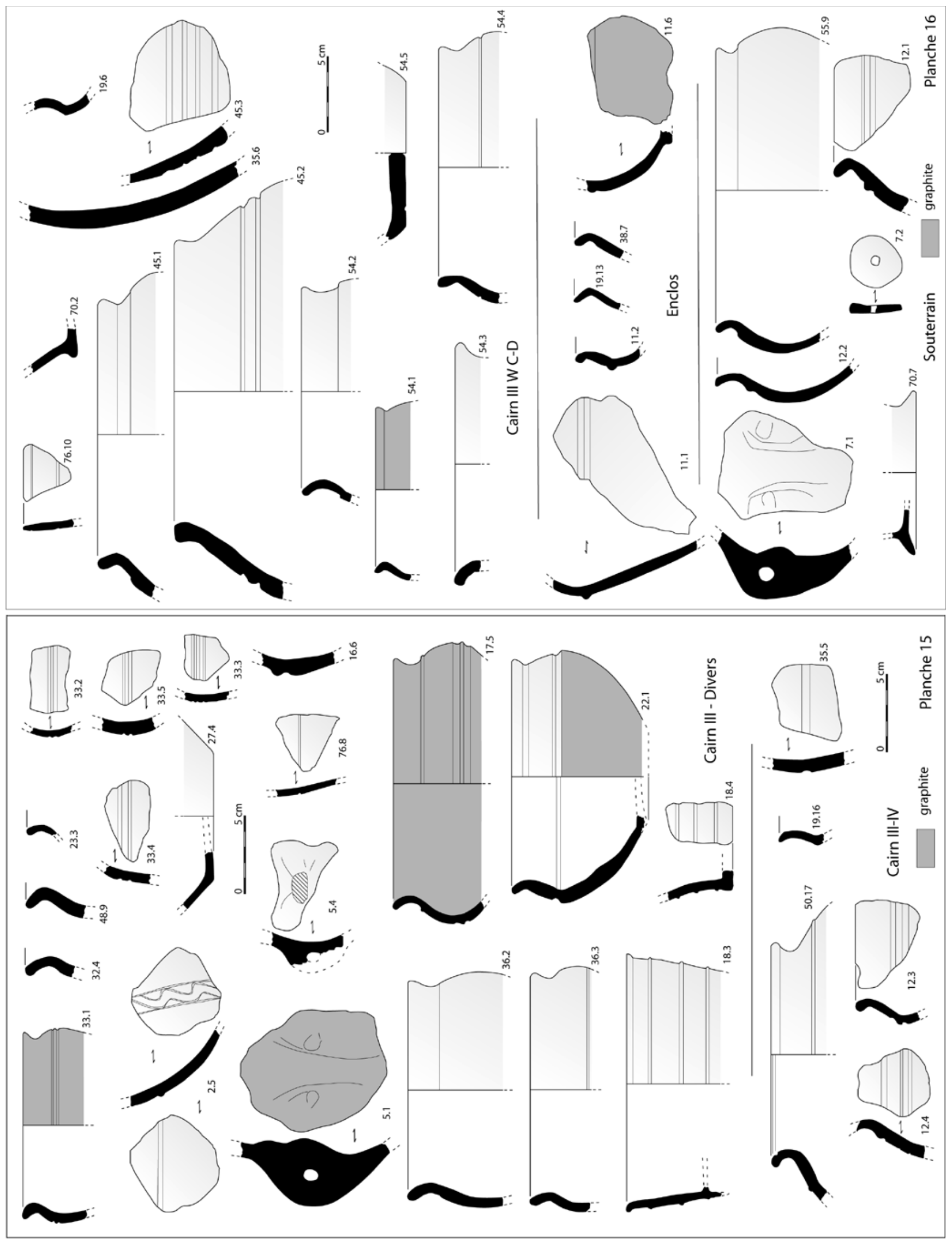




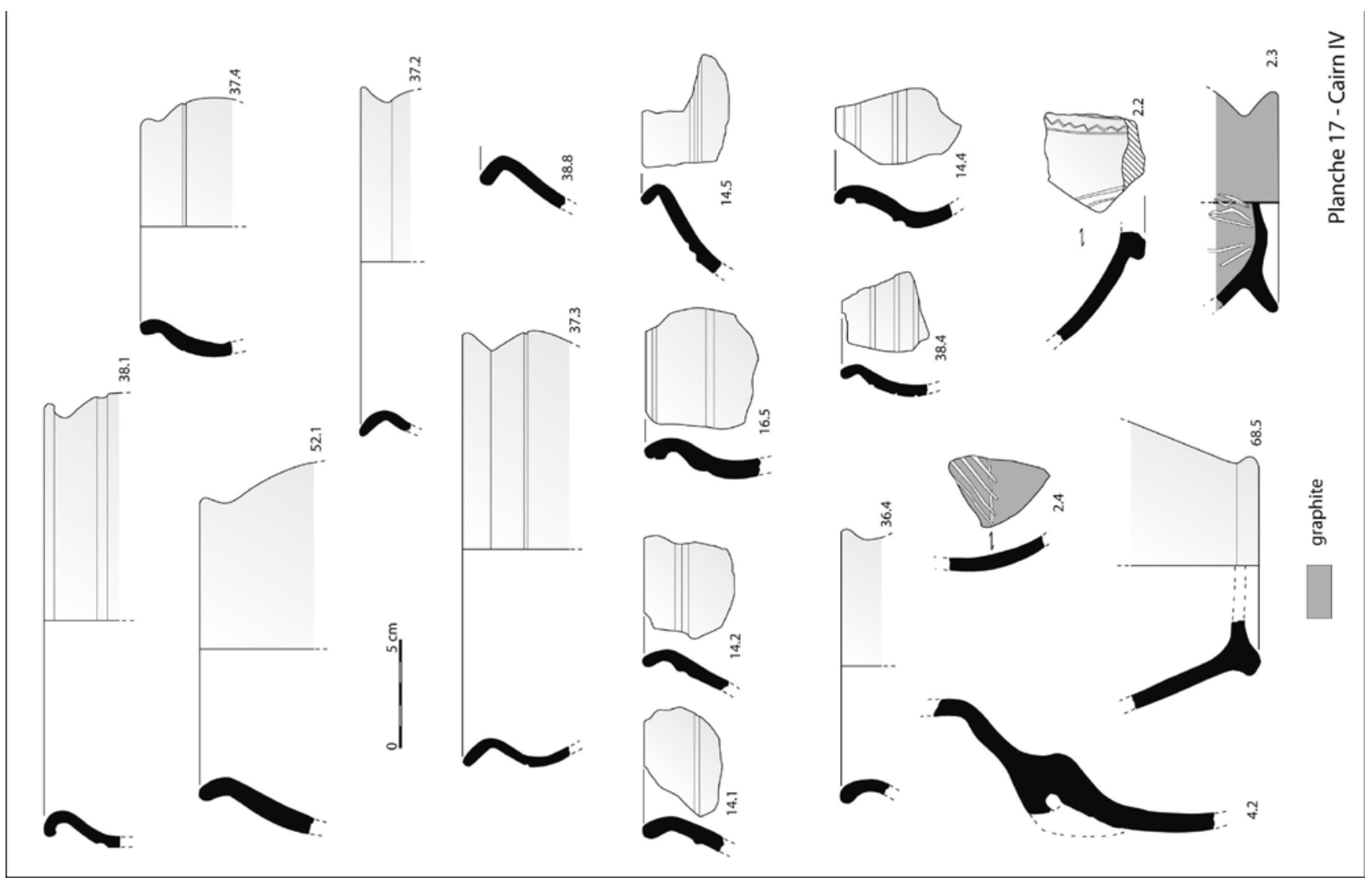


